\title{
THE FERTILITY-SEX RATIO TRADE-OFF: UNINTENDED CONSEQUENCES OF FINANCIAL INCENTIVES*
}

\author{
S Anukriti ${ }^{\dagger}$
}

July 2013

\begin{abstract}
Lower fertility can translate into a more male-biased sex ratio if son preference is persistent and technology for sex-selection is easily accessible. This paper investigates whether financial incentives can overcome this trade-off in the context of an Indian scheme, Devirupak, that seeks to decrease both fertility and the sex ratio at birth. First, I construct a model where the effects of incentives are determined by the strength of son preference, the cost of children, and the cost of sex-selection, relative to the size of incentives. Second, I create a woman-year panel dataset from retrospective birth histories and use variation in the composition of pre-existing children as well as the state and the year of program implementation to estimate its causal effect. Devirupak successfully lowers the number of children by 0.9 percent, but mainly through a 1.9 percent decrease in the number of daughters. Faced with a choice between a son and only daughters, couples choose a son despite lower monetary benefits, and thus the sex ratio at birth unintentionally increases. A subsidy worth 10 months of average household consumption expenditure is insufficient to induce parents to give up sons entirely. Instead, Devirupak increases the proportion of one-boy couples by 5 percent. Only the most financially disadvantaged groups exhibit an increase in the proportion of one-girl couples.
\end{abstract}

JEL: D1, J13, J16, I15

*I am grateful to Pierre-André Chiappori, Cristian Pop-Eleches, and Bernard Salanié for their invaluable guidance and support. I also thank Achyuta Adhvaryu, Douglas Almond, Prashant Bharadwaj, David Blakeslee, Ritam Chaurey, Lena Edlund, Rema Hanna, Supreet Kaur, Todd J. Kumler, Ilyana Kuziemko, Leigh Linden, Costas Meghir, Dilip Mookherjee, Michael Mueller-Smith, David Munroe, Suresh Naidu, Petra Persson, Evan Plous, Mark Rosenzweig, Maya Rossin-Slater, Sébastien Turban, Duncan Thomas, Anna Tompsett, Lesley J. Turner, Eric Verhoogen, and participants at the NEUDC, the Workshop on Households and Risk at Georgia State University, the University of Chicago SSSI, Simon Fraser University, Ohio State University, Boston College, Stanford School of Medicine, UC - Santa Cruz, Barnard College, Williams College, IFPRI, Heinz College, IIES-Stockholm, and the Applied Micro Workshop at Columbia University for helpful comments. All errors are my own.

${ }^{\dagger}$ Department of Economics, Boston College, 140 Commonwealth Avenue, Chestnut Hill, MA 02467. Email: anukriti@bc.edu. Telephone: (814) 308-2897. 


\section{Introduction}

This paper examines whether financial incentives can simultaneously decrease fertility and the male to female sex ratio at birth in societies where sons are preferred. In the past few decades, the sex ratio at birth has increasingly become more male-biased in India and other Asian countries. In comparison to the biologically normal range of 1.03 - 1.06, the sex ratio at birth in 2006-08 was 1.11 for India as a whole, and as high as 1.18 and 1.20 in states like Haryana and Punjab, respectively. ${ }^{1}$ Declining fertility, a strong preference for sons, and easy access to cheap technology for sex-selection are widely believed to be some of the key factors underlying this trend. ${ }^{2}$ Bhalotra and Cochrane (2010) estimate that approximately 480,000 sex-selective abortions took place per year in India during 1995-2005. ${ }^{3}$

The growing number of "missing girls" has led to the introduction of several government programs that aim to reduce the sex ratio at birth by providing monetary incentives to parents who have daughters. ${ }^{4}$ The eligibility criteria of these policies differ significantly in terms of the restrictions imposed on the number of sons. While some provide benefits to parents who have only daughters and no sons (e.g. Balri Rakshak Yojana), others impose no limits on the number of sons, as long as parents have the requisite number of daughters (e.g. Ladli). If the incentives are large enough to make daughters more desirable than sons, then parents may substitute girls for boys and the sex ratio may decrease without increasing fertility. However, if son preference is mainly a cultural phenomenon that persists over time, ${ }^{5}$ then a program that benefits daughters-only parents might be ineffective in persuading families to make this substitution. An alternate policy that incentivizes parents to have daughters without restrictions on the number of sons may increase female births, but at the cost of higher fertility, which may be an undesirable outcome for policymakers in highly populated countries. Thus, it is difficult to design incentives that simultaneously decrease fertility and the sex ratio at birth when son preference is strong.

I examine a conditional cash transfer scheme, Devirupak, introduced by the north Indian state of Haryana and show that even reasonably large financial incentives may be ineffective in reducing sex ratios if lower fertility is also targeted, thus highlighting the fertility-sex ratio trade-off. I do not find evidence for an increase in the quantity demanded of daughters in response to a substantial decrease

\footnotetext{
${ }^{1}$ Source: Sample Registration System. China's sex ratio at birth was 1.18 in 2010 according to the Census data.

${ }^{2}$ Bhalotra and Cochrane (2010), Chung (2007), Das Gupta (1987), Ebenstein (2010), Li et al. (2011), Lin et al. (2010), Li and Zheng (2009), Park and Cho (1995), Zeng et al. (1993), and references therein.

${ }^{3}$ This number is about one-fourth of the number of female births in the United States in 2002.

${ }^{4}$ For example, the Care for Girls Campaign in China; Apni Beti, Apna Dhan and Ladli in India.

${ }^{5}$ Abrevaya (2009), Almond and Edlund (2008), Almond et al. (2011), and Dubuc and Coleman (2007) find evidence for persistence in son preference among Asian immigrants to the United States, Canada, England, and Wales.
} 
in their relative price. Moreover, I show that the sex ratio unintentionally increases when parents whose only child is a boy are also rewarded in an attempt to reduce fertility despite larger benefits for parents whose only child is a girl.

Like other states in north and north-west India, Haryana has historically been a high son preference state and its sex ratio at birth has become increasingly more male-biased in recent decades. The average marital fertility in Haryana, ${ }^{6}$ though decreasing, also remains significantly above the replacement level. In light of these trends, Devirupak seeks to promote a one-child norm ${ }^{7}$ and to decrease the sex ratio at birth. It provides monthly benefits, for a period of 20 years, to couples who become sterilized after having one child (of either sex) or two girls (and no boy). The magnitude of these incentives is substantial - the monthly benefit for couples whose only child is a girl is approximately half of Haryana's per capita monthly consumption expenditure (IHDS 2005). The total benefit received over 20 years by these parents is also sufficient to cover the average dowry expense. The incentive offered to parents of one girl is larger than the amount that parents of one boy or two girls receive. Couples who are childless, have a boy and a girl, or have more than two children receive nothing. Given its twin objectives, Devirupak provides a unique opportunity to study how fertility and sex ratios jointly change in response to financial incentives in a high son preference region.

I construct a simple conceptual framework where couples vary in the degree of son preference and the cost of children, and decisions about child-bearing and sex-selection are jointly made. This model provides insights about the differential effects of financial incentive schemes like Devirupak on couples with distinct socio-economic characteristics. At each decision node a couple chooses between not giving birth and pregnancy with and without sex-selection. Technology for sex-determination is not costless but widely available. The equilibrium number and sex composition of children then depend on the degree of son preference and the cost of children relative to the cost of sex-selection. I show that the likelihood of sex-selection increases with the cost of children and the degree of son preference.

To derive testable predictions about the effects of incentives, I first solve for optimal strategies in the absence of incentives. Since different strategies result in distinct outcomes, by observing a couple's child composition at the start of the scheme I can deduce the strategy they were following in the absence of Devirupak. Then I introduce incentives in the model and derive specific predictions about whether and which couples deviate from their optimal strategy and the resulting effects on their fertility and the proportion of sons. This theoretical framework is quite general and can be easily

\footnotetext{
${ }^{6}$ In 2009, Haryana's average marital fertility was 4.4 births per woman (Source: Sample Registration System).

${ }^{7}$ India's population policy has historically promoted a two-child norm using media campaigns with popular slogans like "Hum Do, Hamare Do" (literal translation "We Two, Our Two") and more recently, through state-level laws that disbar individuals with more than two children from contesting local and state legislature elections (Buch (2006)).
} 
modified to assess the impact of schemes with alternate incentive structures.

My model predicts that couples who have one child at the start of Devirupak in Haryana are less likely to have a second child. However, if there is a second birth, it is more likely to be a boy relative to second births in the absence of incentives. There are two reasons why couples who choose to forgo the one-child incentives are more likely than earlier to sex-select their second pregnancies. First, there is selection into second pregnancy by couples with relatively stronger son preference. Second, the one-child incentives make sex-selection for the second pregnancy less "costly". As a result, fertility decreases but the sex ratio of second births increases for couples who began child-bearing before the scheme. However, the effect on the sex ratio of first births is ambiguous and depends on the distribution of son preference and the costs of children and sex-selection in Haryana. For certain distributions it is possible that couples are more likely to select the sex of their first child and, if their first child was born before Devirupak, more likely to stop child-bearing if the first-born is a boy (than if it is a girl), thereby increasing the proportion of one-boy couples in Haryana.

To test these theoretical predictions, I construct a large woman-year panel dataset by combining complete retrospective birth histories from the National Family Health Surveys and the District-Level Household Survey of India. I compare women in Haryana to their counterparts in a group of similar neighboring states and employ the variation in incentives by the year of program implementation and the composition of older children to estimate the causal effect of Devirupak in a double and triple differences-in-differences framework.

My main findings are as follows. First, Devirupak reduces fertility. The number of living children decreases by 0.9 percent. However, this decrease is primarily driven by a 1.9 percent decline in the number of living girls. Second, the proportion of couples with one daughter and no sons does not increase despite one-girl being the most remunerative child composition in terms of the scheme's benefits. However, the proportion of couples that has only one son increases significantly by 4.9 percent. Thus, faced with a choice between one son and one or two daughters, couples in Haryana choose to have only one son, even at the cost of receiving smaller benefits. Third, the sex ratio of first births increases significantly. This finding is important in light of the fact that previous literature finds no evidence of sex-selection for first births in India. Since Devirupak only offers benefits to couples with either one child or two girls, it induces couples to make decisions about sex-selection at first parity. Fourth, consistent with the theoretical predictions, I find that second births to couples who have one child when Devirupak is implemented are more likely to be a boy. This increases the sex ratio of second births as well. Fifth, there is an increase in the gap between marriage and first birth and the gap between first two births. To the extent that sex-selection takes time, this delay in births supports my finding that Devirupak causes greater sex-selection for the first two births. Lastly, the number of 
fertile years decreases and the probability of sterilization increases.

I also examine heterogeneity in Devirupak's effects and find that the increase in the one-boy outcome is driven by women who are less than 26 years old, who have 1-5 years of schooling, who work outside the home, and who belong to households that are relatively wealthy or own agricultural land. On the other hand, women who are approaching the end of their fertile years or who belong to poor, low-caste, or landless households are more likely to have only one girl. However, this latter effect is not sufficiently large to decrease the overall sex ratio in Haryana.

Moral arguments can be made both in favor of parents' right to choose the sex of their offspring as well as against selective abortion of girls (Kumar (1983)). Abstracting from these ethical dilemmas, there are several reasons why a significantly male-biased sex ratio at birth is undesirable. The resulting scarcity of women on the marriage market can substantially increase the number of unmarried and childless men, ${ }^{8}$ who may face destitution in old age since children through marriage are the most important source of support for the elderly in countries like India that lack institutional social security (Das Gupta et al. (2010)). Rising sex ratios can lead to higher prevalence of sexually-transmitted diseases (Ebenstein and Sharygin (2009)) and more crime (Edlund et al. (2007), Drèze and Khera (2000))..$^{9}$ Sex-selection may also result in girls being consistently born to lower-status parents, thereby relegating women to lower social strata (Edlund (1999)). On the other hand, sex-selective abortions might be preferable to infanticide or postnatal discrimination (Goodkind (1996)). Lin et al. (2010) show that the ability to practice prenatal sex-selection reduces discrimination against girls who are born. ${ }^{10}$ A shortage of women on the marriage market may also increase their bargaining power. ${ }^{11}$

Despite a growing literature on the consequences of skewed sex ratios, there is limited evidence on whether sex ratios will balance on their own in the future and whether proactive public policy can be effective in reducing these imbalances. ${ }^{12}$ Moreover, the experience of China's One-Child Policy has shown that programs aimed at reducing fertility may lead to undesirable increases in the sex ratios. In other countries where population policies are not coercive or restrictive, such as India, we may observe a similar trade-off between fertility and the sex ratio at birth as desired fertility decreases while son preference remains strong. Thus, an understanding of the factors that underlie decisions about the

\footnotetext{
${ }^{8}$ Bhaskar (2011) estimates that one in five boys born in recent cohorts in China will be unable to find female partners.

${ }^{9}$ Kaur (2010) and others link the recent resurgence of caste-based village councils, khap panchayats, in north India and the imposition of extreme social restrictions on women and intra-subcaste marriages by them to the shortage of brides.

${ }^{10}$ In a similar vein, Pop-Eleches (2006) shows that a ban on abortions in Romania led to inferior socio-economic outcomes during adulthood for "unwanted" children.

${ }^{11}$ See Chiappori et al. (2002) and related papers for the large literature on household bargaining in developed countries. Stopnitzky (2012) shows that a relative scarcity of women in Haryana has increased their bargaining power on the marriage market and they are able to secure improved sanitation facilities at home as a result.

${ }^{12}$ Bhaskar (2011), Chung and Gupta (2007), Das Gupta et al. (2003), Edlund and Lee (2009).
} 
quantity of children and sex-selection as well as the efficacy of incentives in resolving the fertility-sex ratio conflict is of tremendous practical importance.

The literature on the effects of financial incentives on fertility ${ }^{13}$ and sex ratios in high son preference countries is extremely limited. Li et al. (2011) and Ebenstein (2010) analyze the impact of fines imposed by China's One-Child Policy on fertility. Bedi and Srinivasan (2009) and Sinha and Yoong (2009) evaluate incentive schemes targeted at reducing the sex ratio in India. However, none of the policies evaluated by these papers target both fertility and sex-selection. To my knowledge, this paper is the first to model and estimate the causal effect of an actual financial incentives scheme aimed at jointly reducing fertility and sex ratios in a high son preference region. The paper most closely related to mine is Ebenstein (2011) which uses simulations to show that a potential subsidy worth 9 months of income for daughters-only parents may reduce the sex ratio from 1.14 to 1.10 and lower fertility from 1.81 to 1.77 births in China. Unlike these forecasts, I find that a subsidy worth 10 months of average household consumption expenditure ${ }^{14}$ is insufficient to induce parents in Haryana to have only one daughter and no sons.

Devirupak is one of the first schemes of its kind. In recent years, other Indian states with skewed sex ratios have initiated similar programs, most notably Punjab's Balri Rakshak Yojana (2009). Given the paucity of empirical and theoretical evidence on how to optimally design these incentive schemes, a wide variety of programs have been implemented. The findings of this paper emphasize that the structure of these programs must be carefully designed to avoid unintended consequences since key parameters such as the degree of son preference and the cost of children are largely unobservable.

Section 2 describes Devirupak in more detail. Section 3 presents a simple model that generates testable predictions and provides an intuitive understanding of the underlying mechanisms. Sections 4 and 5 describe the data and the empirical strategy. Section 6 presents the estimation results and Section 7 concludes the paper.

\footnotetext{
${ }^{13}$ There is a larger strand of literature that studies the relationship between fertility and financial incentives in the context of pro-natal policies in developed countries, e.g. Cohen et al. (2012), Laroque and Salanié (2012), and Milligan (2005).

${ }^{14} \mathrm{I}$ arrive at this number in the following manner. The differential monthly subsidy provided by Devirupak to parents of one daughter is Rs. 300. At the rate of 3\% per annum, the 20-year present discounted value of this subsidy is Rs. 53,560 . The annual household expenditure in Haryana is approximately Rs. 64,800 assuming that the average monthly per capita consumption expenditure is Rs. 1,080 (IHDS 2005) and the average household size is five (2001 Census of India). Thus, the subsidy represents about 10 months of household consumption expenditure.
} 


\section{Context}

\subsection{Details of Devirupak}

The Government of Haryana announced and implemented Devirupak on September 25, $2002 .{ }^{15}$ Under this scheme, eligible couples who adopt a terminal method of family planning ${ }^{16}$ receive monthly payments for a period of 20 years. The incentive amount varies with the number and the sex composition of their children at the time of sterilization (Table I). Couples who choose sterilization after their first child receive a monthly benefit of Rs. 500 (\$10) if they have a daughter and Rs. $200(\$ 4)$ if they have a son. Devirupak also provides Rs. $200(\$ 4)$ per month to parents of two children, but only if both are daughters. Couples with any other composition of children (including no children) are not eligible to receive any benefits. The local Civil Surgeon's Office credits these payments into a beneficiary couple's joint-account on a monthly basis.

Prospective beneficiaries have to register themselves with the local village panchayat or the municipal committee. To be eligible, the husband and the wife should be less than 45 and 40 years old, respectively, on the date of sterilization. Further, neither of them should be an income tax payer. Registered couples are permitted to wait until their youngest child is 5 years old before undergoing sterilization, but they start receiving the benefits only after the surgical procedure has taken place. If their last-born child dies and a beneficiary couple undergoes re-canalization, ${ }^{17}$ they are no longer entitled to future benefits, although past benefits do not have to be refunded. The rules mentioned thus far have been in place since November 24, 2003 - the eligibility criteria were more complicated before then. The original set of rules are described in Appendix A. ${ }^{18}$

There are several reasons why Devirupak provides a more suitable context than other similar Indian policies for examining the causal effect of financial incentives on both fertility and sex ratios. Firstly, it generates differential incentives for marginal births, sex-selection, and sterilization, that vary by the number as well as the sex composition of older children. One-child couples are entitled to larger benefits per child than those who have two or more children. This feature is aimed at promoting a one-child norm. However, since childless couples receive nothing, unintentionally, Devirupak also incentivizes parents to have at least one child, which is contrary to the scheme's stated objective of

\footnotetext{
${ }^{15}$ Website: http: //haryanahealth.nic. in/menudesc. aspx?page=112

${ }^{16}$ Vasectomy or tubectomy (also known as male or female sterilization, respectively).

${ }^{17}$ Although sterilization is considered a permanent method of contraception, it is possible to reverse it surgically.

${ }^{18}$ I examine the differential effect of both sets of rules in Section 6.7.
} 
decreasing fertility. ${ }^{19}$ For a given number of children, the incentive is larger for a subsequent girl than a subsequent boy (but only for a maximum of two children) in order to decrease the relative cost or increase the relative value of daughters. Secondly, other schemes that reward parents for giving birth to a daughter, such as Ladli in Delhi, make the benefits available only after the daughter has turned 18, and in many cases, the beneficiary is the daughter rather than the parents. In contrast, Devirupak directly incentivizes the parents, who start receiving the benefits as soon as they become sterilized. If parents are myopic and discount the future, an immediate and steady stream of benefits is more likely to be persuasive than a lump-sum payment almost two decades later. Lastly, Devirupak's incentive amounts are substantially larger than those being offered by other programs, e.g. through subsidized school education or lump-sum benefits at the time of a daughter's marriage.

\subsection{Sterilization}

Female sterilization is the most prevalent modern method of contraception in India - 34 percent of all currently-married women in the 15-44 age group are sterilized. ${ }^{20}$ In contrast, only 1 percent of these women report that their husband is sterilized. The corresponding numbers for Haryana are 38 percent for women and 1 percent for men. The surgery required for sterilization is performed for free at public health facilities and at a subsidized rate at private health centers across India. Most sterilized couples (84 percent) undergo the procedure at government facilities. ${ }^{21}$ It must be noted that in all states, sterilization adopters are entitled to receive a one-time incentive payment as compensation for the income lost during the surgery. In fact, India was the first country to introduce financial rewards for sterilization in 1952, as part of its family planning policy. However, these one-time incentives (with a maximum of $\$ 22)$ are substantially smaller than the benefits offered by Devirupak $(\$ 48-\$ 120$ per year for 20 years). In addition, unlike Devirupak, the temporal variation in these national incentives is common across all states and does not vary with the number and the sex composition of children. ${ }^{22}$

\footnotetext{
${ }^{19}$ Since only a small fraction of currently-married women at the end of their fertile years report being childless, this latter effect is unlikely to be an important margin of influence on the overall fertility rate. According to DLHS-2 (2002-04), about 1 percent of currently-married women in the 40-44 age group in Haryana have never given birth. Since this includes at least some women who are childless due to infertility, the fraction of women who remain childless voluntarily is even lower.

${ }^{20}$ The data source for all statistics on contraception in this section is the DLHS-3 (2007-08).

${ }^{21}$ Around 12 percent of sterilization users report facing any kind of health problem.

${ }^{22}$ It is possible that the real value of these national incentives varies across states (Bharadwaj (2008)). However, this alone is not problematic since my empirical strategy also uses variation in the number and the sex composition of older children.
} 


\section{Conceptual Framework}

This section presents a simple model in which the optimal number and the sex composition of children are determined by parents' son preference, the cost of children, and the cost of sex-selection. ${ }^{23}$ I start by examining the equilibrium in the absence of both technology for sex-determination (PSDT) and financial incentives, and then introduce them gradually in the model.

When Devirupak was announced, couples in Haryana had different family structures. Those who had no children, one child, or two daughters were "treated" by the scheme, whereas the rest were not. However, we cannot simply compare the future outcomes of couples with dissimilar child compositions in 2002 and attribute the differences to variation in Devirupak's incentives. For example, one-boy families may be more or less likely to sex-select at higher parities than daughters-only families even in the absence of incentives. Moreover, characteristics such as son preference that determine the child composition in 2002 are also likely to influence the effectiveness of incentives in altering child-bearing behavior. Thus, the child composition at the start of Devirupak, although pre-determined, is certainly not exogenous in this context.

To take this endogeneity into account, I first analyze the decision-making process in the absence of incentives to derive the optimal strategies for different "types" of couples, where type reflects a couple's degree of son preference and their cost of children. Since different strategies result in distinct outcomes, by observing a couple's child composition at the start of Devirupak, I can deduce the strategy they were following, and thus learn about their type. Thereafter, I examine how the introduction of incentives alters the optimal strategy for different types of couples. Essentially, I compare the equilibrium outcomes for the same type of couples with and without incentives. This ensures that my theoretical predictions can be placed in a causal empirical framework later on.

\subsection{Model Set-up}

Consider a unitary ${ }^{24}$ household comprising a couple and their children. A couple's utility is additively separable in the number of sons, $b$, the number of daughters, $g$, and consumption, $\mathcal{C}$, and written as:

$$
U(b, g, \mathcal{C})=\delta b+g+V(\mathcal{C})
$$

\footnotetext{
${ }^{23}$ All proofs are in Appendix B.

${ }^{24}$ It is reasonable to abstract from intra-household bargaining issues since the husband and the wife are joint beneficiaries in the context of Devirupak.
} 
Son preference is reflected in the parameter $\delta$. I assume that $\delta \geqslant 1$. Couples maximize utility subject to their budget constraint:

$$
\mathcal{C}+(b+g) c+c_{s} s \leqslant Y+S(b, g)
$$

where $s$ is the number of pregnancies for which sex-selection takes place and $c_{s}>0$ is the fixed cost per instance of sex-selection. ${ }^{25}$ The gender-invariant cost of a child is $c>0$, which includes the cost of child-rearing as well as the opportunity cost of having children. A couple's exogenous income is $Y$ and $S(b, g)$ is the present discounted value of sterilization payments received from Devirupak, as a function of $b$ and $g$. The price of consumption is normalized to one. There are no spontaneous abortions or still-births. Moreover, all couples have costless access to contraception and all pregnancies are planned.

For simplicity, I assume that the utility function is linear in consumption. Specifically, $V(\mathcal{C})=\mathcal{C}$, i.e. the marginal utility derived from children is independent of income and we can essentially ignore $Y$. However, this does not imply that differences in socio-economic characteristics across couples are irrelevant in this model. Instead, these characteristics affect equilibrium outcomes through the cost of children, $c$, and the intensity of son preference, $\delta$, which are the two dimensions along which couples are allowed to differ. ${ }^{26}$ Substituting the budget constraint in the utility function and ignoring $Y$ yields:

$$
U(b, g, s)=\delta b+g-(b+g) c-c_{s} s+S(b, g)
$$

In the absence of sex-selection, half of all pregnancies result in a male birth. If a woman opts for an ultrasound test, then she always aborts if the fetus is female. In the absence of incentives, it is clearly sub-optimal to not do so if an ultrasound test is costly. However, when incentives for a girl are higher relative to a boy, it is possible that some couples might find it optimal to abort a boy in order to receive more money. Since there is no evidence that boys are also selectively aborted in India, ${ }^{27}$ in the interest of keeping the model tractable, I rule out this possibility.

All couples become sterilized after achieving their desired fertility, i.e. the decision about whether and when to become sterilized is not examined separately from other fertility decisions. I also abstract away from factors that determine which spouse becomes sterilized, since it is almost always the wife (as mentioned previously in Section 2.2). Another simplifying assumption is that the utility function

\footnotetext{
${ }^{25}$ Sex-selection includes prenatal sex-detection through ultrasound (or amniocentesis) and sex-selective abortion.

${ }^{26}$ Pörtner (2010), independently, uses a similar set-up to examine the relationship between sex-selective abortions, fertility, and birth spacing.

${ }^{27}$ Jha et al. (2006) report that the second birth is slightly more likely to be a girl if the first child is a boy. However, they do not believe that this represents male feticide and offer differential misclassification of fetal sex by ultrasound machines as a potential explanation. Among others, Bhalotra and Cochrane (2010) provide a detailed discussion of Jha et al. (2006).
} 
is linear and separable in $b$ and $g$. However, if parents desire a minimum number of sons and follow son-biased stopping rules (Clark (2000)), or prefer to have children of both sexes, a non-separable utility function might be more appropriate. ${ }^{28}$ Lastly, I ignore the marriage market.

The underlying reasons behind son preference could be many. Previous literature has explored a wide range of factors such as religion, poverty, rigidly patrilineal kinship systems, absence of institutional old-age support, soil texture, and dowry payments, that might make sons more desirable. ${ }^{29}$ This disparity in desirability manifests itself not just as prenatal sex-selection, but also through postnatal discrimination against daughters in the provision of care and resources (Jayachandran and Kuziemko (2011)). Recently, Bharadwaj and Nelson (2012) have shown that Indian parents also practice sexselective discrimination in prenatal investments. This suggests that, contrary to my assumption, at least some couples choose not to abort even if an ultrasound test reveals that the fetus is female. A more realistic, but more complicated, model would allow a couple's choice set to comprise sexdetermination, sex-selective abortion, and discrimination in prenatal and postnatal investments. I ignore these other avenues for expression of son preference and allow parents to either sex-select or not choose sex-determination. Thus, all predictions generated by my model refer to sex ratios at birth.

\subsection{Equilibrium in the absence of PSDT and financial incentives}

Suppose a woman can become pregnant at most twice. This is essentially a simplifying assumption since Devirupak does not provide incentives to couples who have more than two children. When PSDT is unavailable and there are no incentives, a couple's decision about how many children to have depends only on their son preference, $\delta$, and the cost of children, $c$.

Proposition 1. In the absence of both PSDT and financial incentives, fertility increases in the intensity of son preference and decreases in the cost of children.

Proposition 1 is illustrated in Figure VI. Couples for whom children are "not costly" (i.e. $c \leqslant 1$ ), have two births. Among the rest, those with a high enough son preference have two children, while the remainder forgo having children altogether. In this scenario, couples cannot guarantee a son through sex-selection. As a result, while deciding to become pregnant, they compare the "risk" of a daughter

\footnotetext{
${ }^{28}$ The introduction of son-biased stopping rules (i.e. making parents more likely to stop child-bearing after a male birth than a female birth) in the model will not alter the basic theoretical predictions. In fact, if parents desire at least one son, the one-girl and two-girls incentives will clearly be less effective than they are in my model, and couples will be even more likely to choose the one-boy option. A preference for a mixed sex composition would also make Devirupak less effective since couples who have both boys and girls receive no benefits.

${ }^{29}$ Bardhan (1974), Boserup (1970), Bhaskar and Gupta (2007), Carranza (2012), Das Gupta and Shuzhuo (1999), Das Gupta (2010), Dyson and Moore (1983), Rahman and Rao (2004).
} 
with the potential "benefit" from a son. They become pregnant only if daughters are not too costly or sons are valuable enough. Note that in this case the sex ratio at birth in the population is balanced, ${ }^{30}$ i.e. son preference manifests itself in terms of fertility in the absence of PSDT.

Proposition 1 is also informative about the heterogeneity in fertility across socio-economic groups in the absence of PSDT. If the opportunity cost of child-bearing is lower for less educated women, e.g. due to low potential benefits from labor force participation, Proposition 1 suggests that they will have higher fertility compared to more educated women with the same degree of son preference. Although the marginal utility of children does not vary by income in this model, one way to understand how outcomes might differ for couples with different incomes in reality is the following. Instead of normalizing the marginal utility of a girl to one, we can modify the utility function as $U(b, g, s)=$ $\delta A b+A g-c(b+g)-c_{s}+S(b, g)$, where $A>0$. If income affects parents' marginal utility of children (e.g. poorer parents may be more dependent on children for old-age support or remittances; families with agricultural land might value children more for farm labor), it will be translated into a higher $A$. In terms of Figure VI, this will shift the line corresponding to $2 c-1$ downwards, and the threshold corresponding to $c=1$ to the right, thereby increasing the area with two births, i.e. couples with higher marginal utility of children will have higher fertility, given $\delta$ and $c$.

\subsection{Equilibrium with PSDT and no financial incentives}

Availability of PSDT expands the choice set of couples. While earlier a pregnancy necessarily implied a birth and the choice was between a birth or no birth, this is not the case anymore. Now a couple has three choices at each decision node: a) no pregnancy, b) pregnancy with an ultrasound test (US), or c) pregnancy without an ultrasound test. If (b) is chosen, either a male birth or an abortion (if the fetus is a girl) take place with equal probability. Along with son preference and the cost of children, the equilibrium outcomes now also depend on the cost of sex-selection. I define $c_{s}^{\prime}=2 c_{s}$.

Proposition 2. In the absence of financial incentives, the introduction of PSDT increases the sex ratio at birth, but the effect on fertility is ambiguous.

Proposition 2 is illustrated in Figure VII. Two types of couples are affected by the availability of PSDT. Earlier, some high son preference couples would have had two children in an attempt to have sons, despite a high cost of children (Type 1). PSDT allows them to perfectly avoid giving birth to

\footnotetext{
${ }^{30}$ This is true even if parents follow son-biased stopping rules. In fact, son-biased stopping rules, by themselves, do not imply male-biased sex ratios if parents are homogeneous in the probability of having a boy (Yamaguchi (1989), Goodman (1961)). Girls might, however, still be at a relative disadvantage (despite no discrimination in care) because they will, on average, have more siblings (Jensen (2005)). Moreover, postnatal discrimination in care might skew the child sex ratio further.
} 
"unwanted" daughters. Thus, fertility declines and the proportion of sons rises (and is equal to 1) for these couples. There is also a second type (Type 2) of couples who would have opted for no births when they could not sex-select. These "intermediate $\delta$ - high $c$ " couples will now find pregnancies with ultrasound tests optimal. Both fertility and the number of sons go up for these couples. The sex ratio at birth increases for the population as a whole because Type 1 couples have fewer daughters and Type 2 couples have more sons. Thus, this simple framework shows that the availability of PSDT unambiguously leads to a higher sex ratio at birth, but fertility may increase or decrease. ${ }^{31}$

Additionally, I can examine the effect of changes in the cost of sex-selection using this set-up. An increase in the cost of sex-selection, $c_{s}$, e.g. through stricter enforcement of PCPNDT laws, shifts the $1+c_{s}^{\prime}$ line to the right and the $c+c_{s}^{\prime}$ line upwards in Figure VII. As a result, fewer couples sex-select and the sex ratio at birth decreases. The opposite happens when it becomes cheaper to sex-select.

Since PSDT was widely available in India much before 2002 (Bhalotra and Cochrane (2010)), I expect couples with a stronger son preference and a higher cost of children to have more male-biased sex ratios even before Devirupak. I test this prediction in Section 4.2 by examining heterogeneity in the composition of children before 2002 across various socio-economic groups.

\subsection{Effects of financial incentives when PSDT is available}

For simplicity, assume that Devirupak provides monthly benefits for only one child - Rs. 500 for a girl and Rs. 200 for a boy - for a period of 20 years, conditional on no second births. Thus, in my model, "treatment" is limited to couples who are either childless or have one child when the scheme is announced. ${ }^{32}$ Along with son preference and the cost parameters, the equilibrium outcomes now also depend on the size of incentives, $S(b, g)$. I start by examining the effect of these incentives on couples who have one child when the scheme is announced.

\section{Proposition 3. (Couples who have one child when the scheme is announced)}

(a) The introduction of incentives makes these couples less likely to have a second birth.

(b) Those who stop child-bearing have a weaker son preference than those who become pregnant again.

(c) Second births are more likely to be male.

\footnotetext{
${ }^{31} \mathrm{Kim}(2005)$ derives a similar result. However, his argument relies on the relative effect of PSDT availability on nonselective abortions, selective abortions, and births without detection. In his model, fertility rises if more selective abortions are performed at the expense of non-selective abortions. On the other hand, if more women have selective abortions instead of births without detection, fertility falls.

${ }^{32}$ In reality, Devirupak also provides Rs. 200 per month to couples who have two girls (and no boys). The theoretical framework excludes them from the treatment group for computational ease.
} 
The intuition behind Proposition 3 is as follows. In the absence of incentives, all one-child couples would have chosen a second pregnancy (some with $U S$ and others without $U S$ ). This is because (i) utility is linear in the number of children, and (ii) these couples are not "high $c$ - low $\delta$ " types (who never become pregnant) since they already have a child. Introduction of one-child incentives makes it optimal for some of these couples to not become pregnant again, resulting in 3(a). Larger incentives for one child or a higher utility from incentives (if couples varied in terms of marginal utility of income) will decrease the likelihood of a second pregnancy even more.

Moreover, ultrasound test is now more likely to be used for the second pregnancy for two reasons. First, there is selection into second pregnancy by relatively high son preference couples (from $3(b)$ ), who are more likely to use ultrasound tests even in the absence of incentives. Second, the one-child incentives reduce the effective cost of selection for second pregnancies. If a couple finds out that the second child is a girl and aborts, they still receive Rs. 200 or Rs. 500 through Devirupak. Otherwise, they are guaranteed a boy who is more valuable for them than couples who stop at one child.

This increased use of ultrasound tests for second pregnancies underlies 3(c) and also contributes towards fewer second births in 3(a). The increase in the sex ratio at second birth is larger for a lower cost of sex-selection, relative to the size of incentives. Ultrasound tests and abortions are relatively cheap in India and each costs around Rs. 500 - Rs. 1,000 (\$10 - \$20) (Arnold et al. (2002)). Thus, $c_{s}^{\prime}$ (about Rs. 3,000 or $\$ 60$ ) is substantially smaller than the incentive amounts. ${ }^{33}$ In reality, one-girl couples also receive Rs. 200 if they have a second girl. This increases their utility from choosing the no US option and may lead to a smaller decrease in the likelihood of another birth and a smaller increase in the probability of next birth being male, relative to one-boy couples.

Differential effect on one-boy and one-girl couples. In Proposition 3, the direction of effects is the same for all one-child couples, irrespective of the sex of the first child, but the magnitudes might differ. The incentive amount to stop child-bearing is larger for one-girl couples. If the society mainly comprises couples who never choose $U S$, I expect one-girl couples to be more likely to not have a second child as compared to one-boy couples. In Figure B.3 they are represented by the 'striped' area. These couples were following a no US strategy before the scheme and are, thus, equally likely to have a boy or a girl at the start of the scheme. They stop child-bearing if they have a girl but not if they have a boy. This increases the proportion of one-girl couples more than the proportion of one-boy couples. In other words, the likelihood of a second birth decreases more for one-girl couples. However, Proposition 2 and Figure VII imply that while one-girl couples must necessarily be those who were following the no US strategy, one-boy couples also include those who were following the US strategy

\footnotetext{
${ }^{33}$ In terms of Figures B.1 and B.2, this means that we are more likely to be in Case 1.
} 
before Devirupak. These couples selected the sex of their first birth and only the one-boy incentives are relevant for them. The 'black' area in Figure B.3 represents one-boy couples who were sex-selecting before the scheme and stop child-bearing due to the Rs. 200 incentive, thereby contributing towards an increase in the proportion of one-boy couples. 'Grey' couples stop irrespective of the sex of their first child. If the distribution of $c$ and $\delta$ is such that the (mass in) 'black' area is larger than the (mass in) 'striped' area, then more couples stop after one boy than after one girl. Note that, if at least some people select at first birth, then there will be more one-boy couples than one-girl couples to begin with. Additionally, even in the absence of incentives, one-boy couples are less likely to have a second birth and their second child is more likely to be a boy because more of them choose $U S$ than one-girl couples. But after the scheme, a denser 'black' area implies that the likelihood of a second birth will decrease more for one-boy couples. ${ }^{34}$

Similarly, under certain conditions, the likelihood that the second birth is male may increase more for one-girl couples. The 'black', 'grey', and 'patterned' regions in Figure B.4 indicate couples who change their strategy for the second pregnancy after Devirupak. 'Patterned' couples switch to US irrespective of their first child's sex. However, 'grey' ('black') couples switch only if they have a girl (boy). Since all three groups were not sex-selecting before Devirupak, they are equally likely to have a boy or a girl at the start of the scheme. Therefore, the relative magnitude of the effect on the sex of second birth depends on the relative valuation of Rs. 200 versus Rs. 500 and the distribution of $\delta$ and $c$.

So far, apart from the incentive for one-girl couples to have a second girl which has been ignored in the model, the theoretical predictions do not imply more female births. Any positive effect on female births is likely to come from couples who were childless in 2002. Within this group, it is important to distinguish childless couples who were following the $U S$ strategy and had aborted their first girl from those who had not begun child-bearing by 2002, e.g. due to marriage after 2002. In the absence of incentives, the former group would have aborted again if the second pregnancy was female, but now some of them might find it optimal to choose no US. For this group, the likelihood of remaining childless decreases and their first-born is more likely to be a girl.

\footnotetext{
${ }^{34}$ In my model, couples either always sex-select or never sex-select in the absence of incentives. In reality, there is evidence that first births in India are not selected, while higher parity births are. This could reflect a preference for having children of both sexes or a lack of aversion for at most $x$ daughters, both of which imply that couples start selecting from $x+1$ parity onwards. For simplicity, my model ignores both the choice of parity at which to start selecting and an active pursuit of mixed families. However, allowing couples to desire at least one son and at most one daughter, for example, would still imply that one-boy families are more likely to stop, as long as the Rs 500 incentive does not sufficiently compensate for the "lost" son, i.e. the possibility of one-boy couples being more likely to stop child-bearing than one-girl couples is true more generally and does not require sex-selection at first birth in the real world.
} 
Proposition 4. Childless women who previously had one abortion are more likely to give birth and this child is more likely to be a girl.

The above effect is driven by 'intermediate- $\delta$ ' couples for whom the cost of children is high relative to the cost of sex-selection (which is why they were selecting earlier), but the Rs. 500 incentive is large enough to overcome the cost of a potential girl. Proposition 4 rests on the fact that these women have only one more chance to become pregnant since I limit the maximum number of pregnancies to two. In terms of testable predictions, this group can be thought of as women approaching the end of their fertile years.

Next I determine the effect of incentives on couples who begin child-bearing after Devirupak by solving for their optimal strategies through an exercise similar to the proof of Proposition 2, but with incentives. ${ }^{35}$ The intuitive predictions for these couples are straightforward. For given cost parameters, high $\delta$ couples might find it optimal to have just one child with sex-selection, whereas low $\delta$ couples might have one child without sex-selection. For a given degree of son preference, the incentives will reduce fertility more for couples with a higher cost of children. Overall, we expect lower fertility and an increased proportion of one-child families among these couples, but the effect on the sex ratio at first birth is ambiguous and depends on the distribution of $c$ and $\delta$.

The theoretical framework presented in this section clearly shows that Devirupak should decrease fertility in Haryana, irrespective of the composition of a couple's children in 2002. However, the effect on the sex ratio might not be as intended by the policymakers. The sex ratio will decrease only if a significant number of couples (a) have one girl in 2002 and stop child-bearing, or (b) decrease the use of sex-selection for their first and/or second pregnancies after 2002, and then stop child-bearing.

To summarize, my model yields the following predictions that I test in the next part of the paper:

1. High son preference and high cost of children couples have higher sex ratios before Devirupak.

2. Devirupak reduces the probability of a second birth for couples who had one child in 2002 .

3. Second births are more likely to be male for couples who had one child in 2002 .

4. Childless women approaching the end of their fertile years are more likely to give birth and this child is more likely to be a girl.

\footnotetext{
${ }^{35}$ Due to its computational complexity, this proof is omitted from the paper, but is available upon request.
} 


\section{Data}

I use three rounds of the National Family Health Survey of India (NFHS-1, 2, 3) and one round of the District-Level Household Survey of India (DLHS-2) in this paper. These are nationwide, repeated cross-sectional surveys, representative at the state-level. The NFHS rounds were conducted in 199293, 1998-99, and 2005-06 while DLHS-2 took place in 2002-04 (Figure VIII). These surveys report complete birth histories for all interviewed women, including the month and the year of birth, birth order, mother's age at birth, and the age at death for deceased children. They also report contraceptive use, including the year and the month of sterilization, if applicable. I combine the retrospective birth histories from these four cross-sections to construct an unbalanced woman-year panel for the period 1976 - 2005. ${ }^{36}$ A woman enters the panel in her year of first marriage ${ }^{37}$ and exits in her year of survey.

\section{Control States}

Since Devirupak was implemented at the same time throughout Haryana, I cannot use within-state geographical variation in my empirical strategy. Instead, I include other northern and north-western Indian states in my sample to control for all time-invariant state-specific factors that may affect the outcome variables. Indian states exhibit substantial heterogeneity in cultural, social, and economic factors that are considered important determinants of fertility and sex-selection decisions. These include potentially intertwined characteristics such as son preference, kinship structures, female autonomy, marriage customs, and cropping patterns. ${ }^{38}$ Since many of these variables are either unobservable or do not have credible proxies, it is important to restrict my control group to states that are similar to Haryana in these respects.

As the left panel of Figure IX shows, states from north and north-west India are systematically different from rest of the country in terms of child sex ratios. This persistent regional divide has been documented in the Indian Census reports for a long time, with mentions of son preference and female infanticide in Punjab ${ }^{39}$ and Rajasthan appearing as early as the 1881 Census. Therefore, I restrict my control group to the following seven (nine) states - Punjab, Rajasthan, Himachal Pradesh, Delhi,

\footnotetext{
${ }^{36}$ It is reasonable to pool DLHS and NFHS data since they have a similar survey context in terms of selection of respondents, modes of interviewing, and the exact questions asked. However, sample sizes are much larger for DLHS since it is also representative at the district level. As shown in Section 6.7, my results do not change if only one of these datasets is used.

${ }^{37}$ I define the year of marriage as the year of consummation for consistency across rounds.

${ }^{38}$ Bardhan (1974), Boserup (1970), Bhaskar and Gupta (2007), Carranza (2012), Das Gupta and Shuzhuo (1999), Das Gupta (2010), Dyson and Moore (1983), and Rahman and Rao (2004).

${ }^{39}$ Haryana was a part of Punjab until 1966.
} 
Gujarat, Uttar Pradesh (inclusive of Uttarakhand) and Madhya Pradesh (inclusive of Chhattisgarh). ${ }^{40}$ With the exception of Jammu and Kashmir, for which data is not consistently available, my sample states cover all of north and north-west India (right panel of Figure IX). A similar strategy has been adopted by previous literature that examines the impact of policies concerned with sex-imbalances (e.g. Stopnitzky (2012)). As Figure X shows, the average child sex ratio for the control group of states has followed a similar trend as Haryana in the last four decades. I also test the robustness of my findings by excluding one control state at a time and by using the synthetic control method in Section 6.7.

\section{Sample Period}

Although my sample comprises a large number of pre-Devirupak years (1976 - 2002), the number of post-program years is much smaller in comparison $(2003,2004,2005)$. While additional post-years can be useful in capturing the long-term effects of Devirupak, I restrict my sample to years before 2006 (i.e. exclude the 2006 observations from NFHS-3) to ensure that my results are not driven by the introduction of a different scheme, Ladli, that also seeks to decrease the sex ratio in Haryana. ${ }^{41} \mathrm{I}$ choose 1976 as the earliest year in my sample because only a few observations are available for prior years and they do not cover all states.

Despite Ladli's introduction on August 20, 2005, I do not exclude births that took place during September-December 2005 from my sample since they were conceived much before its announcement. The only way Ladli could have affected fertility or the sex ratios in 2005 is if it decreased the likelihood of conception or caused women who were pregnant on August 20, 2005 to selectively abort during September-December 2005. However, any such forgone conceptions or aborted pregnancies, ${ }^{42}$ if carried to term, would have resulted in births only next year. Since I exclude 2006 from my sample period, ignoring them is, therefore, not an issue for my empirical strategy (in Section 5). Moreover, since Ladli

\footnotetext{
${ }^{40}$ The states of Uttarakhand and Chhattisgarh were carved out of Uttar Pradesh and Madhya Pradesh, respectively, in November 2000.

${ }^{41} \mathrm{My}$ results, however, do not change even if I include the 2006 data from NFHS-3. I also have access to the most recent 2007-08 DLHS-3 round, but I do not include it in my main sample for the following reasons. DLHS-3 did not collect birth or survival information for children born before January 1, 2004, making it impossible to know the number of living children in years after 2004 for mothers who started child-bearing before 2004. This information is crucial for my empirical strategy since future fertility and eligibility for Devirupak's incentives are determined by the composition of surviving children and not just the number of births. I can, however, include in my sample women who either have zero fertility at the time of the survey, or whose first child was born after January 1, 2004 since their birth histories can be fully retrieved. Still, these women are likely to be, on average, younger and their fertility mechanically lower than that of women surveyed in other rounds. Nevertheless, my results are robust to the inclusion of these DLHS-3 women for whom I have the necessary information.

${ }^{42}$ These abortions were most likely first- or second-trimester pregnancies since PSDT is most effective and safest during that period (Epner et al. (1998)).
} 
does not seek to reduce fertility, it is not obvious why it would increase sex-selection in the first place.

In addition, I impose the following sample-selection criteria. First, I limit my sample to currentlymarried women in the 15-44 age-group at the time of survey for consistency across rounds. ${ }^{43}$ Second, I exclude women whose first child was born before they were 13 years old and those who have fertility greater than 10 to prevent any composition bias since these mothers are likely to be fundamentally different from rest of the sample. Third, I exclude women who have had twin or multiple births since these births are mostly unplanned and do not reflect parents' fertility preferences. Fourth, I drop women whose husband's age was below 15 or above 80 at the time of survey. ${ }^{44}$ Finally, I exclude women who were visiting the household when the survey took place, and were interviewed as a result, since there is no information on their actual state of residence. My final sample comprises 3,726,289 observations for 288,483 mothers with 806,326 births over 30 years.

Lastly, DLHS-2 top-codes the year of sterilization as eight years before the survey for women who had been sterilized for more than eight years at the time of survey. As a result, it will artificially appear that DLHS-2 women became sterilized later than comparable women in other rounds. In specifications where the exact year of sterilization is used, I restrict my sample to women who had been sterilized for less than 8 years at the time of survey to address this issue.

\subsection{Summary Statistics}

Table III presents the sample means of key variables for which information is available in both NFHS and DLHS, separately for treatment and control states before and after 2002. A comparison of preprogram means reveals that women in treatment and control states were similar in terms of their age, husband's age, age at marriage, years of schooling, the likelihood of birth in a year, age at birth, the number of living children, sons and daughters, the probability of having only one child or only two girls, and the self-reported ideal number of children and their sex-composition. However, the likelihood of a birth being male and the rate of sterilization are higher for couples in Haryana even in the absence of Devirupak. For both groups, the majority religion is Hinduism, but women in Haryana are more likely to belong to a high caste. A higher proportion of them resides in rural areas and within rural families, households in Haryana are less likely to own agricultural land. Based on their household wealth index, ${ }^{45}$ women in Haryana are richer.

\footnotetext{
${ }^{43}$ Survey questionnaires were administered to 13-49-year old ever-married women in NFHS-1, 15-49-year old ever-married women in NFHS-2,3, and 15-44-year old currently-married women in DLHS-2.

${ }^{44} \mathrm{My}$ results are similar even if these observations are included.

${ }^{45}$ The wealth index is a categorical variable that can take three values: low-, medium-, or high-SLI (standard of living index) based on a household's wealth score. NFHS and DLHS-2 use different methodologies to compute the wealth score. For comparability, I use the DLHS-2 method to compute the wealth score and to define the index for NFHS.
} 
To ensure that my estimates of the effects of Devirupak are not confounded by any differences in socio-economic characteristics between the Haryana and non-Haryana samples, I control for variables such as religion, caste, standard of living, years of schooling, and residence in an urban area in my regressions. To take into account state-specific factors, I include state fixed effects and also control for state-specific time trends. In Section 6.7, I present results from a number of robustness checks to establish that my findings are not driven by any pre-existing differences in Haryana and the control states. As previously mentioned, I also use the synthetic control method to construct a syntheticHaryana that closely matches Haryana in terms of pre-intervention characteristics relevant for my outcome variables. Moreover, in some specifications I include woman fixed-effects which control for any time-invariant heterogeneity in factors that might influence the decisions about child-bearing and sex-selection.

\subsection{Sex-selection before Devirupak}

My model suggests that couples with a stronger preference for sons and a higher cost of children are more likely to sex-select when technology for sex-selection is available. Therefore, I expect these couples to have fewer children and a higher proportion of sons before Devirupak (Prediction 1). As an illustrative exercise, I examine the cross-section of women interviewed in 1998-99 ${ }^{46}$ for NFHS-2 and compare the average proportion of sons and the average number of living children for various socioeconomic groups. While it is difficult to know which groups have a higher degree of son preference a priori, previous literature ${ }^{47}$ suggests that high-caste Hindus, Sikhs, and land-owning families are more likely to, and Muslims are less likely to prefer sons over daughters. In terms of the opportunity cost of children, I expect more educated women from wealthy families in urban areas to have better labor market opportunities, and hence a higher opportunity cost of children. I divide women into overlapping socio-economic groups based on these characteristics and calculate the average number of children and the average proportion of sons for each group.

Table IV lists these groups in decreasing order of the average proportion of sons. A few broad patterns emerge. Women who have more than primary education, who work outside the home and who belong to Sikh, high-caste Hindu, rich, and (agricultural) land-owning households have, on average, a higher proportion of sons and fewer living children than women who work from home, and who belong to poor, low-caste, uneducated, landless, and Muslim families. The highest sex ratios are reported by rural Sikh landowners, rural rich, and relatively educated high-caste Hindu women from wealthy

\footnotetext{
${ }^{46}$ PSDT was widely available in India by 1998-99 (Bhalotra and Cochrane (2010)).

${ }^{47}$ Tambiah (1973), Dickenmann (1979), Oldenburg (1992), Bhat and Zavier (2003), Bhalotra and Cochrane (2010).
} 
families in urban areas. Similarly, fertility levels are lowest for the same socio-economic groups. This admittedly crude comparison, nevertheless, provides evidence in favor of Prediction 1 from my model. Moreover, it reveals information about the correlations between socio-economic characteristics and son preference that is useful when I examine the heterogeneous effects of Devirupak later on.

\section{Empirical Strategy}

The goals of my empirical strategy are to test the predictions generated by the theoretical framework in Section 3 and to estimate the causal effect of Devirupak. I exploit the quasi-experimental nature of Devirupak's implementation to estimate the impact of financial incentives on the number and the sex composition of children, birth spacing, and sterilization take-up. In particular, my identification strategy relies on three sources of variation: the year and the state of program initiation, and differences in future incentives by the composition of pre-existing children (born before Devirupak was launched).

Table II describes how Devirupak's monthly incentives vary for couples in Haryana by the composition of their pre-existing children at any point in time. Conditional on sterilization, childless couples receive no money if they remain childless, Rs. $500(\$ 10)$ if they have a daughter, and Rs. $200(\$ 4)$ if they have either a son or two daughters. One-girl couples receive Rs. $500(\$ 10)$ if they stop childbearing and Rs. $200(\$ 4)$ if they have a second girl and then become sterilized. The only way one-boy or two-girl couples can receive benefits is if they do not have any more children. For couples who are at different points in their fertility path in 2002, Devirupak can, thus, be considered an exogenous shock that alters their incentives for subsequent births and sex-selection differently.

My regression analysis is based on two main specifications. First, I use a triple-differences-indifferences (DDD) strategy to estimate Devirupak's effect on the probability of a marginal birth and its sex (conditional on birth). My second specification examines the scheme's effect on the number of living sons and daughters, as well as indicators for specific child compositions (e.g. "only one son") in a differences-in-differences (DD) framework. I also include woman fixed effects in some regressions to control for all time-invariant woman-specific sources of variation in these outcomes. One advantage of using indicators like "only one son" as outcomes (as opposed to separate dummies for birth and child's sex conditional on birth) is that they allow me to capture Devirupak's combined effect on fertility and sex-selection since these decisions are jointly made. Taken together, these two specifications capture couples' response to Devirupak on both "stock" and "flow" margins of fertility.

Given the incentive structure in Table II, for the DDD specification I assign each woman to one of the following five mutually exclusive groups based on the number and the sex composition of her surviving children in any year: No living children $(g=1)$; One boy only $(g=2)$; One girl only 
$(g=3)$; Two girls only $(g=4)$; and Other compositions $(g=5)$. The "treatment" groups comprise of $g=1,2,3,4$, while couples in $g=5$ were not affected by the scheme. For a woman $i$ in state $s$ who is of age $a$ in year $t$ and belongs to group $g$ at the end of year $(t-j)$, I then estimate the following equation:

$$
Y_{\text {isatg }}=\alpha+\sum_{g=1}^{g=4} \beta_{g} \text { Hry }_{s} * \text { Post }_{t} * 1\left[\text { Group }_{i, t-j}=g\right]+X_{i}^{\prime} \delta+\gamma_{s t}+\theta_{s g}+\psi_{\text {ag }}+\phi_{g} * t+\epsilon_{\text {isatg }}
$$

where $Y_{\text {isatg }}$ are the outcomes of interest, such as an indicator for birth in year $t ; H r y_{s}$ is an indicator for residence in Haryana; ${ }^{48}$ Post $_{t}$ equals 1 if $t>2002$, and 0 otherwise; Group $p_{i, t-j}$ refers to the child composition at the end of period $(t-j)$; and $X_{i}$ is a vector that includes woman $i$ 's years of schooling, indicators for her religion, caste, residence in an urban area, and the household standard of living. State-year fixed effects $\left(\gamma_{s t}\right)$ provide full non-parametric control for state-specific time effects that are common across groups. Age-group fixed effects $\left(\psi_{a g}\right)$ control for age-specific group effects such as the higher likelihood of older women to be in certain groups. Lastly, I also control for state-group effects $\left(\theta_{s g}\right)$ and group-specific time trends. The coefficients of interest, $\beta_{g}$, measure the effect of Devirupak on the outcome of interest for women in group $g$ relative to group 5, before and after 2002 in Haryana, relative to other states. These coefficients are identified under the assumption that, in the absence of Devirupak, the difference in the outcomes of women in group $g$ and group 5 in Haryana would have followed the same trend as this difference in control states. I estimate specification (1) separately for $j=1,2$, and 3 to examine how the effect varies with the length of exposure to the scheme.

It is important to note that the incentive structure of Devirupak introduces a sequence of treatments as opposed to multiple static treatments. Consequently, conditioning on past fertility can bias the estimates of treatment effect (Lechner and Miquel (2010)). To illustrate, if Devirupak causes couples to be more or less likely to select the sex of their first child, then comparing higher birth order outcomes of women whose first child was born before and after Devirupak in Haryana will lead to biased estimates. More generally, this problem arises because the variable Group $_{i, t-j}$ is affected by the scheme when $t-j>2002$. To ensure that my estimates are not biased by this selection that occurs due to the treatment itself, I restrict my sample to $t \leqslant 2002+j$ while estimating specification (1). This guarantees that group affiliation, $G_{r o u p}, t-j$, is always defined using a couple's child composition

\footnotetext{
${ }^{48}$ Since the survey only provides information about the state of residence at the time of interview, I am assuming that a woman lived in the same state for the entire duration of her marriage. This might seem like an unreasonable assumption, but in practice, inter-state migration in India is low and mostly consists of women relocating as a result of marriage. I would expect migration to be even lower for women who have already given birth to their first child.
} 
in a pre-Devirupak year and is free of any change that takes place due to Devirupak.

An alternative to the DDD strategy would be to estimate DD specifications similar to (1) separately for each group $g$. However, group affiliation is unlikely to be random even before Devirupak. I prefer specification (1) since it not only controls for all possible time-invariant group-specific sources of variation but also allows the treatment effect to vary across groups. It also allows me to flexibly control for state-year fixed effects.

To examine if the effects on marginal births identified by specification (1) also translate into changes in total fertility, I estimate the following DD specification for a woman $i$ in state $s$ of age $a$ in year $t$ :

$$
Y_{\text {isat }}=\alpha+\beta \text { Hry }_{s} * \text { Post }_{t}+X_{i}^{\prime} \delta+\gamma_{s}+\omega_{a}+\theta_{t}+\phi_{s} * t+\epsilon_{\text {isat }}
$$

The "stock" outcome variables for this specification are the number of living children, sons, and daughters, as well as indicators for specific child compositions. Equation (2) includes fixed effects for state $\left(\gamma_{s}\right)$, woman's age $\left(\omega_{a}\right)$, year $\left(\theta_{t}\right)$, as well as state-specific linear time trends. The remaining variables are defined as earlier. Despite the inclusion of individual-level covariates, $X_{i}$, the independent variables in specification (2) do not adequately control for all possible sources of variation in outcomes within a state. In order to deal with potential biases due to these omitted variables, I also estimate a woman fixed effects specification, $\left(2^{\prime}\right)$ that is otherwise similar to (2).

$$
Y_{\text {isat }}=\alpha+\beta \text { Hry }_{s} * \text { Post }_{t}+\pi_{i}+\omega_{a}+\theta_{t}+\phi_{s} * t+\epsilon_{\text {isat }}
$$

The woman fixed effects $\left(\pi_{i}\right)$ control for any time-invariant unobserved heterogeneity in factors that influence the fertility and sex-selection decisions of a woman. The coefficient of interest, $\beta$, estimates the change in the number of children or the likelihood that a woman reports a particular child composition before and after 2002 in Haryana, relative to control states.

Before I proceed to the results section, a few points must be noted. First, inference is based on cluster-robust standard errors. I employ several different levels of clustering (state-year, state-group, state) and use the most conservative standard error to determine the significance of my estimated coefficients. Second, although I know the month in which Devirupak was introduced (September 2002), I define Post $_{t}$ at the year level as $t>2002$. This is because births that took place during October - December 2002 were conceived before the scheme was initiated and are unlikely to have been affected by it. It is improbable that mothers aborted late-term pregnancies in these months due to the health risks involved. Third, one of the eligibility conditions of Devirupak is that neither 
the husband nor the wife should be an income-tax payer. Unfortunately, my data does not provide information on income, and hence there is no direct way of determining the taxpayer status of a couple. However, the number of income-tax payers in India is small due to several exemptions. ${ }^{49}$ Moreover, tax evasion is widespread. For these reasons, it is unlikely that the income-tax status of a couple is a strictly enforced or a binding condition for eligibility. Instead, I examine heterogeneity in the effects of Devirupak by household wealth in Section 6.4, using an index based on asset ownership. Lastly, Devirupak also requires that the husband and the wife should be less than 45 and 40 years old, respectively, on the date of sterilization, presumably to target couples who are still in their fertile years. Since more than 80 percent of sterilized couples undergo the operation before the wife is 30 years old, and 93 percent of births in my sample take place before the mother is 31 years old, age is also unlikely to be a binding criterion. In Section 6.4 I analyze heterogeneity in the effects by woman's age instead.

\section{Results}

I begin by graphically describing the effect of Devirupak on the likelihood that a woman reports a particular child composition in a year using an event-study framework. The plotted coefficients in Figure XI show the trends in the child composition of married couples in Haryana relative to other states, after controlling for socio-economic characteristics of the woman and fixed effects for state, year, and woman's age. ${ }^{50}$ Since Devirupak provides incentives to couples with either one child or two girls, the outcome variables are indicators for these categories.

There are no noticeable trends in the differential likelihood of a particular child composition immediately before 2002. This lack of significant differences in the years prior to Devirupak provides an important test for the validity of the identifying assumption; the trends in outcomes across comparison groups evolve smoothly except through the change in incentives in 2002. After 2002 there is an increase in the likelihood that a woman has only one child (boy or girl), but there is no visible change in the two-girls outcome. These trends reflect the combined effect of Devirupak on couples who had a child in 2002 as well as those who started child-bearing after 2002. Figure XII overlays the graphs for the one-child outcomes and suggests that the likelihood of having only one son has increased more sharply, despite the higher incentive for one-girl couples.

\footnotetext{
${ }^{49}$ According to Banerjee and Piketty (2005), incomes below the top one percent are largely exempt from taxation in India. ${ }^{50}$ Specifically, Figure XI plots the $\beta_{k}$ coefficients from the following regression, with 2002 as the omitted year: $Y_{\text {isat }}=$ $\sum_{k=1976}^{2005} \beta_{k} H_{r y} * 1\left[\right.$ Year $\left._{t}=k\right]+X_{i}^{\prime} \delta+\gamma_{s}+\omega_{a}+\theta_{t}+\epsilon_{\text {isat }}$.
} 


\subsection{Effects on Marginal Births}

In this section, I test Predictions 2 and 3 from my model using specification (1). Table V presents estimation results for two outcome variables. In Panel $\mathrm{A}$, the dependent variable is an indicator that equals one if a woman gives birth in a year, and zero otherwise. In Panel B, the sample is restricted to years when a birth takes place, and the outcome variable is an indicator for the birth being male. The triple-difference estimates in this table compare the change in the probability of a marginal birth (or the likelihood of a marginal birth being male) in year $t$, before and after 2002, in Haryana and non-Haryana, by the composition of children in year $(t-j)$. In columns (1)-(3), the sample is restricted to $t \leqslant 2003$ and $j=1$, i.e. the coefficients measure the effect of Devirupak in the first year of implementation, conditional on the child composition in year $(t-1)$ which is pre-determined and not affected by the scheme. In the next three columns, I add one more post year while simultaneously increasing the time lag used to define the past child composition. Restricting the sample to $t \leqslant 2004$ when $j=2$ ensures that the lagged composition remains unaffected by the scheme. Lastly, columns (7)-(9) use $j=3$ and the entire sample period.

Prediction 2 says that couples in Haryana who had one child when Devirupak was implemented should be less likely to have subsequent births. The same result is expected to hold for couples with two daughters, although the model does not explicitly solve for this case. The first row of Panel A shows that conditional on having only a son in year $(t-j)$, couples in Haryana are less likely to have another child after Devirupak relative to the control group. The coefficients are negative and highly significant across all columns. Columns (3), (6), and (9) imply that the likelihood of a subsequent birth decreases by, respectively, 2.4, 4.1, and 3.7 percentage points after Devirupak for couples whose only child one, two, and three years ago was a boy. Although it is possible that this decrease merely reflects a postponement of higher parity births and not necessarily a decrease in completed fertility, the fact that couples are consistently less likely to give birth over a three-year period suggests otherwise. As Figure XIII shows, a vast majority of second births following a first-born son take place within three years of the birth of the first child, suggesting that the decrease in marginal births I observe in Table V does not simply reflect a retiming of second births. In Section 6.5 I show that this decline is also accompanied by an increase in the probability of sterilization, which is consistent with a decrease in completed fertility for couples who had one son in 2002.

However, for one-girl couples in the second row, I observe an increase in the likelihood of birth in columns (1)-(3) and a decrease thereafter. This pattern can potentially be explained by the presence of incentives for two girls. At the margin, the availability of two-girl incentives lowers the cost of a second pregnancy without selection (in terms of the "risk" of a second girl) for one-girl couples, 
thereby increasing the probability of a second birth. But since no incentives are available for more than two children, I still expect to see a decrease in their completed fertility, which is reflected in a negative coefficient after two and three years.

Parents of two girls also exhibit a decrease in marginal births, but the effect is small in the first year of policy implementation. For couples who were childless in year $(t-j)$, I observe a pattern similar to the one-girl couples. Initially, there is an increase in the likelihood of birth (for $j=1)$ which turns negative in columns (4)-(9). Since there are no incentives for childless couples under Devirupak, it encourages couples who would have remained childless in the absence of incentives (Proposition 4) and those who had not started child-bearing by 2002 to have one child but not more.

A comparison of coefficients in the first two rows shows that one-boy couples are more likely to stop child-bearing as compared to one-girl couples despite a higher incentive to stop for the latter. According to column (9), couples who had one boy in year $(t-3)$ are 3.7 percentage points less likely to give birth in year $t$ as compared to a 2.2 percentage point decrease for couples who had one girl. This finding (along with Figure B.3) suggests that couples in Haryana, on average, have a strong son preference and their cost of children is high relative to the cost of sex-selection.

Next I test prediction 3 which says that conditional on having one child before the scheme, couples who choose to have another child after the scheme should be more likely to practice sex-selection, i.e. if there is a marginal birth, it is more likely to be male for one-child couples. This finding is also borne out by the results in Panel B. The triple-interaction coefficients are always positive and significant for both one-boy and one-girl couples. However, the increase is smaller for one-girl couples relative to one-boy couples for the first two years and then becomes larger in the third year. This pattern may also reflect that at least some one-girl couples experience a smaller increase in the use of ultrasound technology for second pregnancies due to the availability of two-girl incentives. This effect disappears when $j=3$ suggesting that one-girl couples who select into giving birth three years into the scheme have a very strong desire for sons which makes them 5.3 percentage points more likely to give birth to a male child as compared to one-boy couples in the same situation. ${ }^{51}$

Recall that my model does not provide a clear prediction about the effect of Devirupak on the sex ratio of first births. However, as shown by the coefficients in the last row of Panel B, births to couples who were childless at the start of Devirupak are significantly more likely to be male even as early as the first year of implementation. ${ }^{52}$ The coefficients imply that first births in the first year of implementation are about 4.3 percentage points more likely to be male. This translates into an

\footnotetext{
${ }^{51}$ The 5.3 percentage point figure is the difference between the one-boy and one-girl coefficients in Panel B-column (9).

${ }^{52}$ I have also estimated specification (1) conditional on the composition in $(t-1)$ without restricting the sample to years until 2003, and find a similar result for the sex ratio of first births.
} 
7.8 percent increase in the probability that the first birth is male. ${ }^{53}$ Prior literature (Bhalotra and Cochrane (2010)) finds that sex-selective abortions in India take place at higher parities and the sex ratio at birth for first-borns is not significantly above normal. But Devirupak's incentive structure, in an attempt to promote a one-child norm, makes the sex-selection decision salient at first birth in a manner similar to China's One-Child Policy.

\subsection{Effects on the Number and the Composition of Children}

Next I estimate the effect of Devirupak on the "stock" of a couple's children. Since Table V shows that couples who have one child when Devirupak is announced are less likely to have another child and this effect is stronger for one-boy couples, I expect them to be more likely to have only one son after 2002. Similarly, I expect those who are childless in 2002 to be more likely than earlier to report a one-child composition after 2002 since remaining childless or having more than one child yield lower benefits. Moreover, if son preference is strong enough, these couples may prefer one son over one daughter.

Table VI reports the DD coefficients from specifications $(2)$ and $\left(2^{\prime}\right)$ using indicators for specific child compositions (Panel A) and the number of children (Panel B) as the outcome variables. Column (1) presents the base specification with fixed effects for states and years. Column (2) also controls for fixed effects for woman's age, time-invariant woman-specific covariates, and state-specific linear time trends. Column (3) adds woman fixed-effects, and therefore excludes covariates and state fixed effects as they do not vary over time for a woman. However, not every woman in my panel is observed both before and after 2002. The coefficients in column (3) are essentially driven by the sub-sample of women who married before 2002 but were surveyed after 2002, and were hence observed both before and after the treatment year. Although I control for a variety of individual characteristics, these women may still be different from those who were observed either entirely before or entirely after 2002. Thus, in order to make estimates comparable across specifications, in columns (4) and (5) I limit my data to this "overlap" sub-sample and re-estimate specifications $(2)$ and $\left(2^{\prime}\right)$.

Panel A supports the graphical evidence presented in Figures XI and XII. As the first row shows, the likelihood that a couple has only one son has increased across all columns. The coefficients are significant everywhere except in column (1). The coefficient in column (2) implies a 0.4 percentage point or a 4.9 percent increase in the proportion of one-boy couples. ${ }^{54}$ There is also a positive and significant

\footnotetext{
${ }^{53}$ The percentage change is calculated as follows. The double-difference in the pre-post, Group1 - Group5 averages implies that the probability of first birth being male increased in non-Haryana by 0.0093. If Haryana had experienced the same increase as non-Haryana, its post-average for Group 1 would have been $0.5441+0.0093=0.5534$, where 0.5441 is the pre-Group5 average in Haryana. The triple-difference coefficient of 0.0430 , thus, represents an 7.8 percent increase.

${ }^{54}$ The percentage change is calculated as follows. The pre-post difference in averages implies that the probability of "only one boy" decreased in non-Haryana and Haryana by -0.0281 and -0.0220 , respectively. If Haryana had experienced the same
} 
increase in the one-girl outcome in column (1), but the effect disappears once other covariates and time trends are included in column (2). When I restrict the sample to women who are observed both before and after ("overlap sub-sample"), the coefficient becomes significant and negative. This suggests that couples who start child-bearing after the scheme are responding differently to the incentive for the first girl as compared to those who already have a girl in 2002.

The coefficients for the two-girls outcome are either insignificant or negative, suggesting that the Rs. $200(\$ 4)$ incentive is not effective in inducing couples to have only two daughters. Although we observe some decrease in the likelihood of subsequent births for two-girl couples in Table V, it is not sufficient to significantly increase the share of two-girl couples in the population. The significantly negative coefficients in the first two columns suggest that couples who start child-bearing after 2002 are even less likely to have two girls as compared to couples before the scheme. The effect on the likelihood of remaining childless is mostly insignificant, except in column (2). Since only a small percentage of married couples in Haryana remain childless, a zero effect is not surprising. In fact, if more new couples are now sex-selecting at first parity, we expect them to give birth later since abortion and re-conception take time. They will, therefore, remain childless longer and this might explain why we see a positive and significant effect in column (2). I examine the effect of Devirupak on the spacing of births shortly. Since Devirupak provides no incentives for a couple to have any other composition of boys and girls, ${ }^{55}$ the coefficients in the last row of Panel A are consistent with negative effects.

To test if the effects presented in Panel A also translate into lower fertility, I next estimate the same specification(s) using the number of living children, sons, and daughters as the outcome variables. Couples who already have one child or two girls in 2002 are more likely to stop child-bearing due to the incentives, thus, for them the number of children (boys as well as girls) should decrease. But, as shown earlier, parents of one son are more likely to stop than those who have one or two daughters. If this is because the latter want a minimum number of sons, the decrease in the number of boys may be less than the decrease in the number of girls. Similarly, if couples who started child-bearing after 2002 sex-select sooner now and forgo the "unwanted" daughters to have only one son, the decrease in the number of daughters will be larger than the decrease in the number of sons.

The first row in Panel B of Table VI shows that Devirupak has significantly decreased the number of daughters. Apart from column (1), the coefficients are stable in magnitude and reflect a 0.02 percentage point or a 1.9 percent reduction in the number of daughters. ${ }^{56}$ The coefficients for the

decrease as non-Haryana, its post-average would have been $0.1091-0.0281=0.081$. The DD coefficient of 0.004 represents a 4.9 percent increase over the counterfactual assumption that Haryana followed the same trend as non-Haryana.

${ }^{55}$ Other compositions comprise more than two children or two children with one boy and one girl.

${ }^{56}$ Calculated as $\frac{\text { Coeff }}{H_{r y} y^{\text {Pre }}+\left(\text { NH }^{\text {Post }}-N H^{\text {Pre }}\right)} * 100$ where Hry ${ }^{\text {Pre }}$ is the pre-2002 average number of daughters in Haryana etc. 
number of sons are also mostly negative but not always significant, and the magnitudes are generally smaller than those for the number of daughters. The combined effect on the total number of children is always negative and also significant in the first three columns. In the last two columns, the coefficients are still meaningful, but I lose significance at conventional levels. The coefficient of -0.023 implies an approximately 0.9 percent reduction in the number of living children per woman.

On the whole, Table VI suggests that Devirupak has caused couples to have fewer children, but mainly in order to have just one son. The decrease in the number of children is largely driven by a decline in the number of daughters.

\subsection{Effects on Birth Timing and Spacing}

Next I examine the effect of Devirupak on the timing of the first two births. To the extent that there is greater sex-selection due to Devirupak, we expect the birth intervals to increase simply because conception, abortion, and re-conception take time. Each abortion delays the next birth, at the minimum, by a year (Bhalotra and Cochrane (2010)). On the other hand, couples may start planning births sooner in order to hasten the receipt of benefits. To examine which of these effects dominates, I compare the interval between marriage, first birth, and second birth before and after 2002 in Haryana, relative to other states, using a version of specification (2). To prevent any composition bias, I exclude women whose age at marriage was less than 13 years or whose first child was born more than ten years after marriage.

In Panel A of Table VII, the dependent variables are indicators for first birth in the $j^{\text {th }}$ year of marriage, where $j=0,1,2,3$. The reason I measure the gap in years is because DLHS-2 does not report the month of marriage, making year the finest level at which the timing of first birth can be measured. Before Devirupak, 20, 34, and 21 percent of first births in Haryana took place in the first, second, and third year of marriage, respectively. After Devirupak, first births are significantly less likely to take place in the first year of marriage and more likely to take place in the second year. The delay becomes larger when I exclude women who were married before 2002 but gave birth to their first child after 2002 (Panel A1). These results lend support to the findings from Table V that imply an increase in the practice of sex-selection for first-borns.

Since second births after Devirupak are more likely to be male for couples who had a child in 2002 (from Table V), I also expect an increase in the interval between first and second births as a result of greater sex-selection. I examine this in Panel B of Table VII using dependent variables that are indicators for the number of months (in multiples of twelve) between first and second births. Unlike the month of marriage, DLHS-2 reports the month of birth so the gap between births can be measured more precisely. I restrict the sample to women whose first birth took place before Devirupak to avoid 
selection-bias due to the effect on first births. In addition, I require that the first child is alive when the second birth takes place and I drop 72 observations where the second child is born less than 9 months after the first birth. The coefficients indicate that second births are less likely to take place within 9-12 months of the first birth and more likely to occur within 12-24 months. I find similar results when I examine the effects separately by the sex of the first child in Panels B1 and B2. These findings are consistent with Prediction 3 and Table V and indicate increased use of sex-selection for second births as a result of Devirupak's incentives.

\subsection{Heterogeneity}

I start by examining heterogeneity in the effects of Devirupak by a woman's age. I divide my sample into four age-groups and estimate specification (2) separately for each of them. The main findings from Table VIII are as follows. Firstly, the overall increase in the one-boy outcome is being mainly driven by women 25 years or younger. The coefficients are positive in the first two columns and also highly significant in column (2). On the other hand, the effect is neither positive nor significant for women more than 25 years old. This seems reasonable since Devirupak's incentives are available only for the first two births and most women give birth to their first child before they are 25 years old. Secondly, as predicted by Proposition 4, women nearing the end of their fertile years (30-44 age group) are significantly less likely to remain childless and more likely to have one girl. This suggests that at the margin, the one-girl option induces women who would have remained childless in the absence of incentives to have one daughter instead. However, since only a small percentage of women are childless by the time they are 30-44 years old, this increase is insufficient to result in a significant rise in the proportion of one-girl couples in Table VI. Thirdly, I also observe a significant increase in the likelihood that women in the 13-20 year age-group are childless. This is consistent with first births occurring at a later age, as suggested by Table VII. Lastly, no age-group exhibits a significant increase in the likelihood of two girls. The effects on the number of children, boys, and girls are also consistent with these compositional changes. ${ }^{57}$

Next I analyze heterogeneity in the effects of Devirupak on the one-child outcomes by socioeconomic characteristics such as caste, religion, education, wealth, landownership, and employment status (Table IX). Due to differential soil texture, agricultural employment in north India is relatively unfavorable to female labor as shown by Carranza (2012). Consequently, I expect sons to be more valuable to rural families that own agricultural land. Indeed, my results show that rural families that own agricultural land experience a significant 2.2 percentage point increase in the one-boy outcome and

\footnotetext{
${ }^{57}$ The woman fixed effects specification $\left(2^{\prime}\right)$ yields very similar results.
} 
a decrease in the one-girl outcome. Das Gupta (1987) and others have also emphasized the importance of caste-religious composition in explaining gender inequality in north India. Jat Sikhs and Jat Hindus are the dominant owner-cultivator groups in Haryana and Punjab and have historically exhibited the most imbalanced sex ratios. Since detailed caste data is not available, I examine how religion and broadly-defined caste affiliation interact with other characteristics such as landownership and wealth status to further explore heterogeneity in the effects of Devirupak. Within rural landowners, I find an even stronger increase in the one-boy outcome for Sikhs (3.6 percentage points) and a smaller but still highly significant increase for Hindu landowners (1.6 percentage points). The likelihood of one-girl also declines for both these groups. In addition, medium-SLI families, urban rich, and Hindus exhibit a significant increase in the one-boy outcome. On the contrary, I find that the likelihood of one-girl has increased significantly for landless, low-SLI, poor SC and rural poor households. These latter results suggest that the one-girl incentives are effective only for the financially disadvantages families. However, since these effects are relatively small in magnitude (0.7 - 0.9 percentage points), they do not translate into a significant increase in the proportion of one-girl couples in Haryana.

In terms of education, I find that women who have 1-5 years of education are significantly more likely to have only one boy and significantly less likely to have only one girl. The effects for uneducated women or those with more than 5 years of education are positive but insignificant. In terms of employment, I find that women who work outside the home as well as unemployed women are more likely to have only one son, although the effect is larger and more significant for the former. On the other hand, women who work from home or are self-employed do not exhibit a significant change in the one-boy outcome. The coefficients for the one-girl outcome are insignificant for all employment groups. These results are not surprising since the opportunity cost of child-bearing is likely to be higher for women who are more educated and who work outside their home. They are also more likely to be aware of and have easier access to ultrasound and abortion clinics.

Next I examine how my estimates vary by a woman's self-reported "ideal" proportion of sons to further assess the role played by son preference in determining the effectiveness of incentives. ${ }^{58}$ Selfreports of the desired number of sons and daughters may be highly correlated with actual fertility to avoid cognitive dissonance. Unfortunately, I only have access to ex-post information on this variable from the year of survey since my dataset is a retrospective panel. ${ }^{59}$ Nevertheless, in the absence of better alternate measures, recent literature (Jayachandran and Kuziemko (2011)) has used reported

\footnotetext{
${ }^{58}$ Ideal proportion of sons $=\frac{\text { ideal }_{\text {boys }}+\left(0.5 * i d e a l_{\text {either }}\right)}{\text { ideal }_{\text {kids }}}$ if $i d e a l_{k i d s}>0$, where $i d e a l_{\text {boys }}$ is the ideal number of boys, $i d e a l_{\text {either }}$ is the ideal number of children of either sex, and $i d e a l_{k i d s}$ is the ideal number of total children as reported by a woman.

${ }^{59}$ DLHS questionnaires did not collect this information. NFHS-1 only reports the ideal number of children and not their composition. NFHS-2,3 report both.
} 
number of ideal children and sons as proxies for fertility and son preference. Only a negligible fraction of women in my sample would ideally remain childless, while most prefer to have two children. Among women who desire at least one child, the average ideal proportion of sons is greater than half, reflecting positive son preference. The results in Table $\mathrm{X}$ show that the increased likelihood of the one-boy outcome is being driven by women who want more than half of their children to be sons, further highlighting the role of son preference in explaining my findings.

\subsection{Effects on Sterilization}

Since the receipt of Devirupak's benefits is conditional on the adoption of sterilization by either the husband or the wife, next I examine its effect on sterilization rates. Sterilization is a widely prevalent method of contraception in India and most couples who adopt this method do so at an early age. An average woman is 26 years old, has 3.3 children, and 1.8 sons at the time of sterilization. ${ }^{60}$ More than 80 percent of sterilized couples get operated before the wife is 30 years old. Couples are less likely to become sterilized if they do not have sons - only 5 percent of sterilized couples have no sons, whereas 19 percent have no daughters. The average gap between last birth and sterilization is 1.6 months.

To the extent that couples start receiving the benefits only after they are sterilized, I expect sterilization rates to increase and the interval between last birth and the operation to decrease after Devirupak. However, if the risk of mortality for infants and children is high, couples may now wait longer to ensure that their only child survives. The under-five child mortality rate in Haryana is about 60 deaths per 1000 live births suggesting that the survival of an only child may be an important concern for couples deciding on when to become sterilized. This is probably why Devirupak allows couples to wait for up to five years from the birth of their last child before getting operated, despite the fact that almost every sterilization procedure before 2002 took place within a year of last birth.

I assess the effect of Devirupak on sterilization behavior by comparing women interviewed before and after 2002 in Haryana, relative to other states, conditional on their child composition. Instead of using the woman-year panel, now I have one observation per woman and four repeated cross-sections. The first outcome variable I look at is an indicator for the woman being sterilized at the time of survey. However, a small number of post-Devirupak years in my sample along with a potentially longer waiting period before sterilization implies that an indicator variable for sterilization status at the time of survey might not fully capture the effect of Devirupak's incentives. It also does not take advantage of the information on the year of sterilization that my data provides. Therefore, in addition to the sterilization dummy, I construct a second outcome variable that captures the length

\footnotetext{
${ }^{60}$ All summary statistics in this section are based on NFHS data.
} 
of a woman's fertile period in years. If she is sterilized at the time of survey, this variable is equal to the number of years between marriage and sterilization, otherwise it is equal to her marital duration at the time of survey. If Devirupak increases the probability of sterilization for couples with eligible child compositions, then women interviewed in Haryana after 2002 should display a higher likelihood of being sterilized and a shorter fertile period as compared to similar women interviewed before 2002 in Haryana, relative to other states.

To examine these effects, I estimate a DDD specification similar to (1). I divide women into four groups based on their child composition at the time of survey: one boy only, one girl only, two girls only and the rest. In addition to the triple-interaction terms, I include fixed effects for state-group, group-age, year of survey, marital duration, state- and group-specific linear time trends, and controls for socio-economic characteristics. Columns (1) and (2) in Table XI suggest that the number of fertile years decreases and the probability of sterilization increases for women in all three "eligible" groups. One-boy couples surveyed in Haryana after 2002 are 3 percentage points more likely to be sterilized relative to the control group. Columns (3) - (5) show that these results are robust to the exclusion of NFHS data, DLHS data, as well as pre-1995 years of survey.

\subsection{Additional Results}

According to Proposition 3(b), conditional on having a child in 2002, couples who stop child-bearing have a weaker son preference or a higher cost of children, relative to those who become pregnant again despite the risk of losing the one-child incentives. To test this prediction, I restrict my sample to couples who had a child in period $(t-3)$ and compare the characteristics of those who gave birth again in period $t$ with those who did not, separately by the sex of the first child, before and after 2002 in Haryana, relative to control states. Table XII shows that women in Haryana who had one child in $(t-3)$ and stop child-bearing after 2002 are less likely to belong to land-owning, rural, high-caste, Hindu families relative to women who have another birth. On the other hand, they are more likely to come from poor, rural, low-caste, Hindu families. Similarly, I find that couples who stop after one child, irrespective of its sex, are more likely to be Muslim. In addition, they are more likely to belong to poor SC and poor $\mathrm{OBC}$ households and less likely to come from rich SC families. Together, these findings lend support to Proposition 3(b) and imply that the incentives are less likely to be effective in reducing fertility and decreasing the sex ratio for socio-economic groups with stronger son preference or lower cost of children who have already given birth to their first child in the absence of incentives. 


\subsection{Robustness}

I conduct a number of other robustness checks to further establish that my results can be interpreted as the causal effects of Devirupak. One concern about my empirical strategy may be that states like Delhi and Punjab are, for various reasons, not good control groups for Haryana, e.g. Delhi is largely an urban state, while Punjab's population is predominantly Sikh. Although I control for several socioeconomic characteristics that might systematically vary across states in all regressions, to ensure that the inclusion of any particular control state is not driving my results, I re-estimate all specifications by dropping one control state at a time. Table XIII presents the results from this exercise for specification $\left(2^{\prime}\right)$. I continue to find a significant increase in the one-boy outcome in all columns except when Uttar Pradesh (UP) is dropped. Since UP is the most populous state in India, I lose significance at conventional levels likely due to a large reduction in sample size. Nevertheless, the magnitude of the coefficient is still meaningful. Moreover, in all cases I still observe a significant decrease in the number of girls and the total number of children. ${ }^{61}$ A similar exercise for specification (1) in Table XIV reinforces my earlier findings.

Next I conduct two placebo tests by first reassigning the intervention to alternate control states and then to pre-2002 years within Haryana. If my results are truly capturing the causal effect of Devirupak, I should not find significant effects in these placebo regressions. Table XV presents the results from the first placebo test. Since these laws are fictitious, a significant "effect" at the 5 percent level may be found roughly 5 percent of the time i.e. in 2 out of 35 regressions in Table XV. There are only 3 cells where I find significant effects in the same direction as my main results in Table VI - column(3), which seems reasonable. Similarly, when I reassign the intervention to an alternate year before 2002 in Haryana (Table XVI), I find mostly insignificant effects, especially for the one-boy outcome. These tests also lend support to my DD estimation strategy and make a causal interpretation more credible.

While the large time span of my dataset allows me to control for state and group-specific time trends, a wider time window introduces the possibility that my estimates are capturing the effect of other government programs that also target fertility and sex ratios. Since I include year fixed-effects in all regressions, my results are not driven by any schemes implemented by the national government in 2002. However, it is still possible that alternate schemes specific to a control state are confounding my results. There are two reasons why this is unlikely. First, my sample includes only years up to 2005 while most of the Devirupak-like programs in other states were introduced after 2008 e.g. Punjab's Balri Rakshak Yojana began in 2009. Secondly, I have already shown that my results are robust to

\footnotetext{
${ }^{61}$ Specification (2) yields similar results that are available upon request.
} 
the exclusion of any particular control state.

I also check if my results remain robust when only NFHS data or DLHS data is used to address concerns about the bias introduced by any unobserved differences in data collection, or small variations in the sampling methodology for NFHS and DLHS. In addition, my next robustness check excludes years before 1995 from the sample to ensure that my results are not affected by (1) an alternate scheme, Apni Beti Apna Dhan (APAD), implemented by the Government of Haryana in $1994,{ }^{62}$ and (2) the 1995 break-point in the long-term trend in the availability of PSDT mentioned in Bhalotra and Cochrane (2010). Table XVII presents the results from these tests. My findings remain the same.

So far, my analysis has used 2002 as the treatment year. However, Devirupak's rules underwent a revision in November 2003, so it is possible that 2003 is the more relevant cut-off for defining the Post variable. To test this and to compare the effects before and after the revision, I define 2003 as the "transition" period and redefine Post as year $>$ 2003. Then I re-estimate specifications (2) and $\left(2^{\prime}\right)$ by including Hry*Transition as an explanatory variable in addition to the redefined Hry* Post. Table XVIII presents the results for specification $\left(2^{\prime}\right)$. Column (2) shows that couples are significantly more likely to have only one son not just during the transition period, but also after that. Similarly, the number of girls also decreases significantly during both periods. Estimation using a probit instead of a linear probability model and inclusion of additional control states, the 2006 data from NFHS-3, and the DLHS-3 data yield very similar results that are available upon request.

Lastly, I use the synthetic control method proposed by Abadie and Gardeazabal (2003) and Abadie et al. (2010) to construct a synthetic-Haryana that best approximates the relevant characteristics of Haryana during the pre-treatment period. I then use the post-intervention outcomes for this synthetic control state to approximate the outcomes that would have been observed for Haryana in the absence of Devirupak. My donor pool comprises $17^{63}$ major Indian states. In order to conduct the analysis at an aggregate level, I collapse my individual-level panel data into a state-year panel. The outcome variables are the proportion of couples who have only one boy, only one girl, or only two girls. To predict the outcome variables at the state level, I use the average years of schooling, age, and age at marriage for women along with the proportion of women who reside in an urban area, are Hindu, Muslim, Christian, SC, ST, and who belong to low- and high-SLI households. Table XIX displays

\footnotetext{
${ }^{62}$ Sinha and Yoong (2009) examine APAD and conclude that it led to reductions in the sex ratio of living children. APAD is substantially different from Devirupak. Under the former, there is no restriction on fertility or the number of sons; couples who have both boys and girls are also eligible to receive benefits; the incentive amounts are smaller and available only after the daughter has turned 18; eligibility is not conditional on sterilization; and the scheme only targets below poverty line, SC and OBC families. As a result, the variation in incentives introduced by APAD is uncorrelated with the variation induced by Devirupak.

${ }^{63}$ In terms of the current classification of states, these represent 20 states.
} 
the weights assigned to each control state in the construction of synthetic-Haryana. As Figure XIV shows, synthetic-Haryana closely resembles Haryana in terms of pre-2002 prevalence of various child compositions. The estimate of the effect of Devirupak is given by the difference between the proportion of couples with a certain child composition in Haryana and in its synthetic version after 2002. Similar to my earlier findings, there is a noticeable divergence in the two lines after 2002 for the "only one boy" outcome, but not for the one or two girls outcomes. This method also supports my conclusion that Haryana experienced an increase in the share of one-boy couples after 2002.

\section{Conclusion}

This paper explores whether financial incentives can simultaneously decrease both fertility and the sex ratio. My theoretical model shows that decisions about fertility and sex-selection depend not just on the cost of children but also on the degree of son preference. When son preference is strong, rewarding couples who have only one boy may increase the sex ratio through differential stopping behavior and sex-selection at first and second parities, despite higher incentives for a girl relative to a boy. I find, empirically, that this is indeed what happens in the case of Devirupak. The scheme lowers fertility, but increases the sex ratio at birth. ${ }^{64}$ Thus, an understanding of the strength of son preference in the society is crucial for the design of an optimal scheme.

This paper presents the first comprehensive analysis of a broadly-targeted financial incentives program that attempts to induce parents to give up sons entirely by "compensating" them substantially in return. I find that a subsidy worth ten months of average household consumption expenditure is insufficient to achieve this objective in Haryana. My results have the following policy implications. First, the one-boy incentives being offered by Devirupak are sufficient to make couples forgo unwanted daughters. Second, if a lower sex ratio is also desired, it may be preferable to not incentivize couples to have only sons. Third, the targeting of such programs can be improved. Since sex-selection is practiced more frequently by socio-economic groups that have a strong preference for sons and a high cost of children, policies that attempt to alter the behavior of these groups might be more successful. More broadly, an "intermediate" policy that (1) incentivizes couples to have more daughters and fewer sons, (2) while allowing them to have a minimum number of boys, but only if they also have a minimum

\footnotetext{
${ }^{64}$ It is worth pointing out that Devirupak is different from the One-Child Policy despite similar outcomes. The One-Child Policy is aimed at lowering fertility and until the recent relaxations, it has not explicitly targeted the sex ratio. In comparison, Devirupak proactively seeks to achieve both a one-child norm and a lower sex ratio. The modified "1.5-Child Policy" allows parents of one girl to have a second child of either sex, which essentially shifts the decision to sex-select from first to second parity while potentially increasing fertility. Under Devirupak, there are no incentives for couples who have both a boy and a girl. The only way parents can have more than one child and receive benefits is by having two daughters.
} 
number of girls may be more effective in decreasing the number of children without increasing the sex ratio in India since fertility rates are still above replacement-level. ${ }^{65}$

More research is needed on the optimal design of incentives that can lower both fertility and the sex ratio. Ultimately, the fertility-sex ratio trade-off will persist unless son preference weakens. Das Gupta et al. (2003) suggest that the recent decline in sex ratios in South Korea can be explained by a change in social norms. Even if optimal incentives are able to alter behavior in the short run, whether they can change son preference and norms remains an open question (Bowles and Polania-Reyes (2012)).

DEPARTMENT OF ECONOMICS, BOSTON COLLEGE

${ }^{65}$ However, this policy may not work in case of China since average fertility rates are already very close to one. 


\section{A Devirupak's Rules before November 2003}

Under the original set of rules, couples were divided into two categories: i) those married before Devirupak, i.e. before September 25, 2002, had to register their intent to undergo sterilization before January 26, 2003 in order to be eligible; and ii) couples married on or after September 25, 2002 had to register and state that their first child would not be born before two years of marriage and that their second child would not be born until two years after the birth of their first daughter. This condition was aimed at increasing the space between births. In addition, the couple was required to undergo sterilization immediately after birth in order to receive benefits. If the beneficiary couple underwent re-canalization for whatever reason, they were required to refund the benefits received until then,

along with interest at the rate of 9 percent per annum. These rules were revised in November 2003 in order to make the scheme simpler. Under the new set of rules, eligibility does not depend on the year of marriage or birth spacing.

\section{B Proofs}

Proof of Proposition 1: Since the maximum number of pregnancies is two, a couple has three choices: zero, one or two children. I solve for the equilibrium by backward induction. Conditional on having one child, a couple can either choose to stop child-bearing (Stop) or have a second child (Birth). The difference between utility from Birth and Stop is independent of the sex of their first child, and is given by:

$$
\Delta U=U(\text { Birth })-U(\text { Stop })=0.5+0.5 \delta-c
$$

If $\delta \geqslant 2 c-1$, then $U($ Birth $) \geqslant U($ Stop $)$. Otherwise, Stop is preferred over Birth.

Since $\delta \geqslant 1$ and $c>0$, there are three possible scenarios:

Case $1: c \leqslant 1 \Longrightarrow 2 c-1 \leqslant 1 \leqslant \delta \Longrightarrow \Delta U \geqslant 0$.

Case $2: c>1$ and $\delta \geqslant 2 c-1 \Longrightarrow \Delta U \geqslant 0$.

Case $3: c>1$ and $\delta<2 c-1 \Longrightarrow \Delta U<0$.

The same choices are optimal at the first decision node, i.e. the decision about the first pregnancy. In equilibrium, Case 3 couples have no children and the rest have two children.

Proof of Proposition 2: Let $U(S t o p)$ denote utility if a couple stops child-bearing after their first 
pregnancy. Utility from a second pregnancy with and without an ultrasound test is given by:

$$
\begin{array}{r}
U(U S)=U(\text { Stop })+0.5\left(\delta-c_{a}-c\right)-c_{u} \\
U(N o U S)=U(\text { Stop })-c+(1+\delta) / 2
\end{array}
$$

If $\delta>c+c_{s}^{\prime}$, then $U S \succ$ Stop. If $\delta>2 c-1$, then No US $\succ$ Stop. If $c<1+c_{s}^{\prime}$, then No US $\succ U S$.

Case $1: c \leqslant 1 \Longrightarrow c<1+c_{s}^{\prime} \Longrightarrow N o U S \succ U S$. Also, $c \leqslant 1 \Longrightarrow 2 c-1 \leqslant 1 \leqslant \delta \Longrightarrow$ No US Stop. These couples choose a second pregnancy with $U S$.

Case 2: $1<c \leqslant 1+c_{s}^{\prime} \Longrightarrow N o U S \gtrsim U S$. If $\delta>2 c-1>1$, they choose a second pregnancy without $U S$ and if $\delta \leqslant 2 c-1$, they stop child-bearing.

$\underline{\text { Case 3: }}: c>1+c_{s}^{\prime} \Longrightarrow U S \succ N o$ US. If $\delta>c+c_{s}^{\prime}$, they choose a second pregnancy with $U S$ and if $\delta \leqslant c+c_{s}$, they stop child-bearing.

The same choices are optimal at the first decision node i.e. the decision about the first pregnancy. Thus, couples in Case 1 choose two pregnancies without $U S$. In Case $2, \delta<2 c-1$ couples never become pregnant, and the remaining choose two pregnancies without $U S$. In Case 3, couples with $\delta \leqslant c+c_{s}$ never become pregnant and those with $\delta>c+c_{s}^{\prime}$ choose two pregnancies with $U S$.

Proof of Proposition 3: This proof has two parts. Part 1 analyzes the effect of Devirupak on couples who had one boy in 2002. Part 2 examines couples who had one girl in 2002.

\section{Part 1: One-boy couples}

Three types of couples can possibly have one boy (and no girl) when the scheme starts:

Type A: $c \leqslant 1$

Type B: $1<c \leqslant 1+c_{s}^{\prime}$ and $\delta>2 c-1$

Type C: $c>1+c_{s}^{\prime}$ and $\delta>c+c_{s}^{\prime}$.

In the absence of the scheme, all three types would have chosen a second pregnancy - Types A and B without US and Type C with US. After the scheme, they face the same three choices as earlier, but with incentives. Let $f(X)$ denote the present discounted value of Rs. $X$ per month for 20 years. The additional utility from each option, conditional on already having a boy, is as follows:

$$
\begin{gathered}
\Delta U(U S)=-c_{u}+0.5\left(-c_{a}+f(200)\right)+0.5(\delta-c) \\
\Delta U(\text { noUS })=0.5+0.5 \delta-c \\
\Delta U(\text { Stop })=f(200)
\end{gathered}
$$


If $c>1+c_{s}^{\prime}-f(200)$, then $U S \succ N o$ US. If $\delta<2 c-1+2 f(200)$, then Stop $\succ N o$ US. If $\delta<c+c_{s}^{\prime}+f(200)$, then Stop $\succ U S$.

For Type C couples, US $\succ N o$ US even after the incentives. But those with $c+c_{s}^{\prime}<\delta<c+$ $c_{s}^{\prime}+f(200)$ will switch from $U S$ to Stop. The remaining Type C couples will continue with US as before. Thus, for Type $\mathrm{C}$ couples as a whole, fertility and the number of sons decrease. The proportion of sons remains the same (equal to 1) since they were going to have only boys even without the incentives.

For Types A and B, there are two scenarios:

Case 1: $1+c_{s}^{\prime}-f(200)<1$, i.e. $c_{s}^{\prime}<f(200)$. Type A couples with $c<1+c_{s}^{\prime}-f(200)$ still prefer no US to US. They Stop if $\delta<2 c-1+2 f(200)$, otherwise continue with no US as before. Type A couples with $1+c_{s}^{\prime}-f(200)<c<1$ prefer $U S$ over no US. They Stop if $\delta<c+c_{s}^{\prime}+f(200)$, otherwise choose US. Similarly, for all Type B couples, US $\succ$ No US. They Stop if $\delta<c+c_{s}^{\prime}+f(200)$, otherwise opt for US. Thus, some Type A and all Type B change their optimal strategy. Fertility falls and the proportion of sons rises for both Types A and B. Moreover, their second child is more likely to be a boy because some of them now opt for US.

Case 2: $1+c_{s}^{\prime}-f(200) \geqslant 1$, i.e. $c_{s}^{\prime} \geqslant f(200)$. In this case, all Type A couples still prefer no US to $U S$. If $\delta<2 c-1+2 f(200)$, they Stop, otherwise continue with no US as before. For Type B couples with $1<c<1+c_{s}^{\prime}-f(200)$, no $U S$ is preferred over $U S$. If $\delta>2 c-1+2 f(200)$, they continue with no US. However, if $2 c-1<\delta<2 c-1+2 f(200)$, they Stop. For the remaining Type B couples, US is now preferred over no US; they Stop if $\delta<c+c_{s}^{\prime}+f(200)$, otherwise choose US. Fertility falls and the proportion of sons rises for both Types A and B. Moreover, the second child for Type B couples is more likely to be a boy because some of them now choose US.

These findings can be summarized as follows:

\begin{tabular}{ccccc}
\hline \multirow{2}{*}{ Type } & Fertility & Proportion of sons & \multicolumn{2}{c}{ 2nd birth is male } \\
\cline { 3 - 5 } & & + & $c_{s}^{\prime}<f(200)$ & $c_{s}^{\prime} \geqslant f(200)$ \\
\hline A & - & + & + & No change \\
B & - & + & + & + \\
C & - & No change & \multicolumn{2}{c}{ No change } \\
\hline
\end{tabular}

Figure B.1 illustrates the new equilibrium choices. Couples in the yellow region stop child-bearing after the scheme, i.e. fertility declines for them. Their proportion of sons increases since some of them were earlier following a no US strategy and may have had a girl. Couples in the blue region switch from no $U S$ to $U S$ for their second pregnancy. For them, fertility decreases and their second child is 
more likely to be a boy, i.e. the proportion of sons rises. The remaining couples with one boy continue with their original strategy.

In both Cases 1 and 2, the incentive increases the probability that couples who had one boy in 2002 stop child-bearing. Moreover, it encourages some high son preference couples to switch from no US to $U S$ in case of a second pregnancy. This is because the incentive reduces the net cost of selection. Both these effects are stronger when $f(200)$ is larger relative to $c_{s}^{\prime}$. Moreover, larger incentives for one child or a higher utility from incentives (if couples varied in terms of marginal utility of income), decrease the likelihood of a second pregnancy, for given cost parameters and son preference.

How do couples who stop child-bearing differ from those who become pregnant again? Within Type C, those with $\delta<c+c_{s}^{\prime}+f(200)$ stop and the rest become pregnant again. Thus, for a given $c$ (and $c_{s}^{\prime}$ ), couples who have a second birth will have a stronger son preference than those who choose Stop. The same is true for Types A and B.

Figure B.1: Effect on couples who had one son and no daughters in 2002
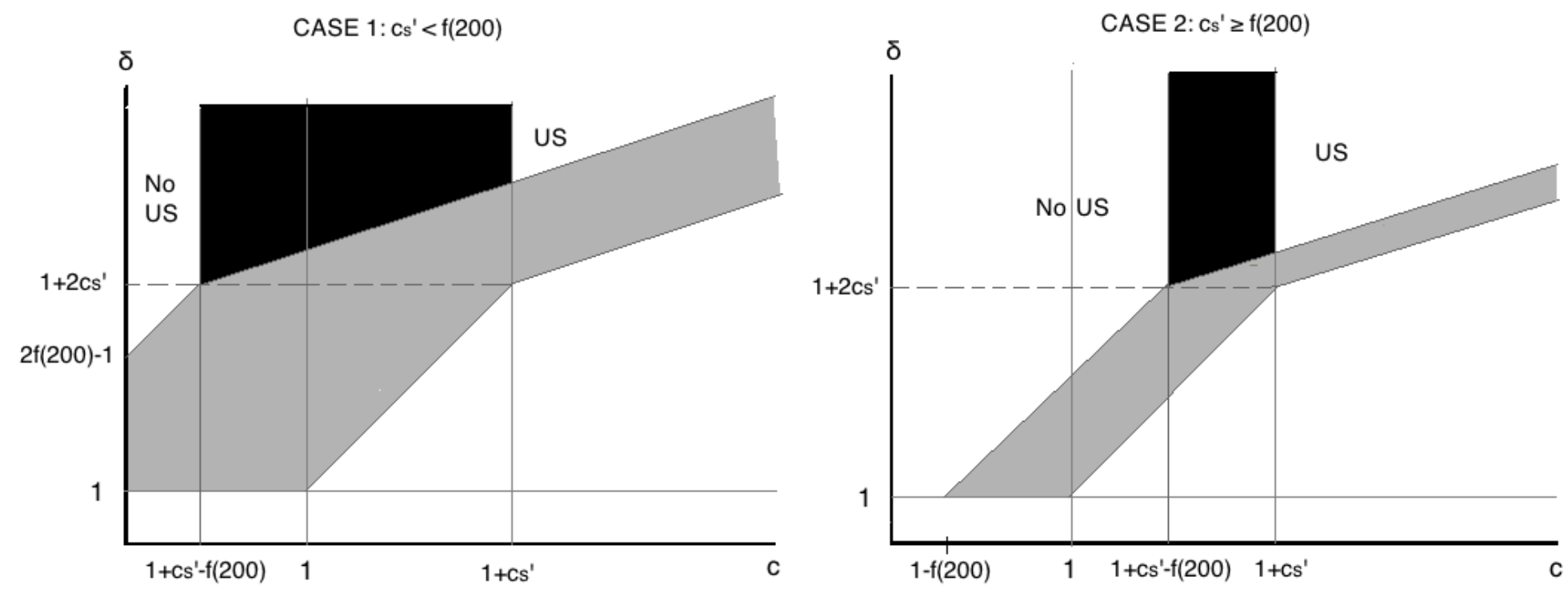

NOTES: Couples in the grey region stop child-bearing. Those in black have a second child, who is more likely to be male than in the absence of incentives. For expositional purposes, the left panel has been drawn under the assumption that $1>f(200)-c_{s}^{\prime}$ and the right panel assumes that $1>f(200)$. However, neither is necessary for Proposition 3.

\section{Part 2: One-girl couples}

Two types of couples can possibly have one girl when the scheme starts:

Type A: $c<1$

Type B: $1<c<1+c_{s}^{\prime}$ and $\delta>2 c-1$

In the absence of incentives, both types would have chosen a second pregnancy without US. The 
additional utility from the three available choices, conditional on already having a girl, is as follows:

$$
\begin{gathered}
\Delta U(\text { Stop })=f(500) \\
\Delta U(U S)=-c_{u}+0.5(\delta-c)+0.5\left(-c_{a}+f(500)\right) \\
\Delta U(\text { noUS })=0.5+0.5 \delta-c
\end{gathered}
$$

If $c>1+c_{s}^{\prime}-f(500)$, then $U S \succ N o$ US. If $\delta<2 c-1+2 f(500)$, then Stop $\succ N o$ US. If $\delta<c+c_{s}^{\prime}+f(500)$, then Stop $\succ U S$.

Case 1: $1+c_{s}^{\prime}-f(500)<1$, i.e. $c_{s}^{\prime}<f(500)$. If $c<1+c_{s}^{\prime}-f(500)$, No US $\succ U S$. Stop is chosen if $\delta<2 c-1+2 f(500)$, otherwise Type A couples continue with $N_{o} U S$. If $1+c_{s}^{\prime}-f(500)<c<1$, $U S \succ n o$ US. These Type A couples choose Stop if $\delta<c+c_{s}^{\prime}+f(500)$, otherwise they switch to US. Type B couples also prefer $U S$ to no $U S$ now, and choose Stop if $2 c-1<\delta<c+c_{s}^{\prime}+f(500)$, and otherwise switch to US. Note that stopping at one girl implies a decrease in the proportion of sons because these couples were following a no US strategy earlier. Fertility decreases for both types. The proportion of sons declines for some Type A couples $\left(c<1+c_{s}^{\prime}-f(500)\right)$, but the effect is ambiguous for the remaining Type A couples $\left(1+c_{s}^{\prime}-f(500)<c<1\right)$ and all Type B couples. This is because the couples who choose Stop experience a decline in the proportion of sons, but those who have a second child with $U S$ have a larger proportion of sons.

Case 2: $1+c_{s}^{\prime}-f(500) \geqslant 1$, i.e. $c_{s}^{\prime} \geqslant f(500)$. For Type A couples, No US $\succ U S$. They choose to Stop if $\delta<2 c-1+2 f(500)$, otherwise they continue with No US. The same holds for Type B couples with $c<1+c_{s}^{\prime}-f(500)$. But Type B couples with $c>1+c_{s}^{\prime}-f(500)$ now prefer $U S$ over No US. They Stop if $\delta<c+c_{s}^{\prime}+f(500)$, otherwise change to $U S$. Fertility decreases for both types. The

\begin{tabular}{|c|c|c|c|c|c|}
\hline \multirow[t]{2}{*}{ Type } & \multirow[t]{2}{*}{ Fertility } & \multicolumn{2}{|c|}{ Proportion of sons } & \multicolumn{2}{|c|}{2 nd birth is male } \\
\hline & & $c_{s}^{\prime}<f(500)$ & $c_{s}^{\prime} \geqslant f(500)$ & $c_{s}^{\prime}<f(500)$ & $c_{s}^{\prime} \geqslant f(500)$ \\
\hline $\mathrm{A}$ & - & $+/-$ & - & + & No change \\
\hline B & - & \multicolumn{2}{|c|}{$+/-$} & \multicolumn{2}{|c|}{+} \\
\hline
\end{tabular}
proportion of sons declines for Type A, but the effect is ambiguous for Type B couples.

These findings can be summarized as follows:

Figure B.2 illustrates the new equilibrium choices for one-girl couples. Those in the yellow region stop child-bearing, i.e. fertility declines for them. Couples in the blue region were earlier going to have a second child without $U S$, but now opt for an $U S$. For them, fertility decreases and their second 
child is more likely to be a boy.

Figure B.2: Effect on couples who had one daughter and no sons in 2002
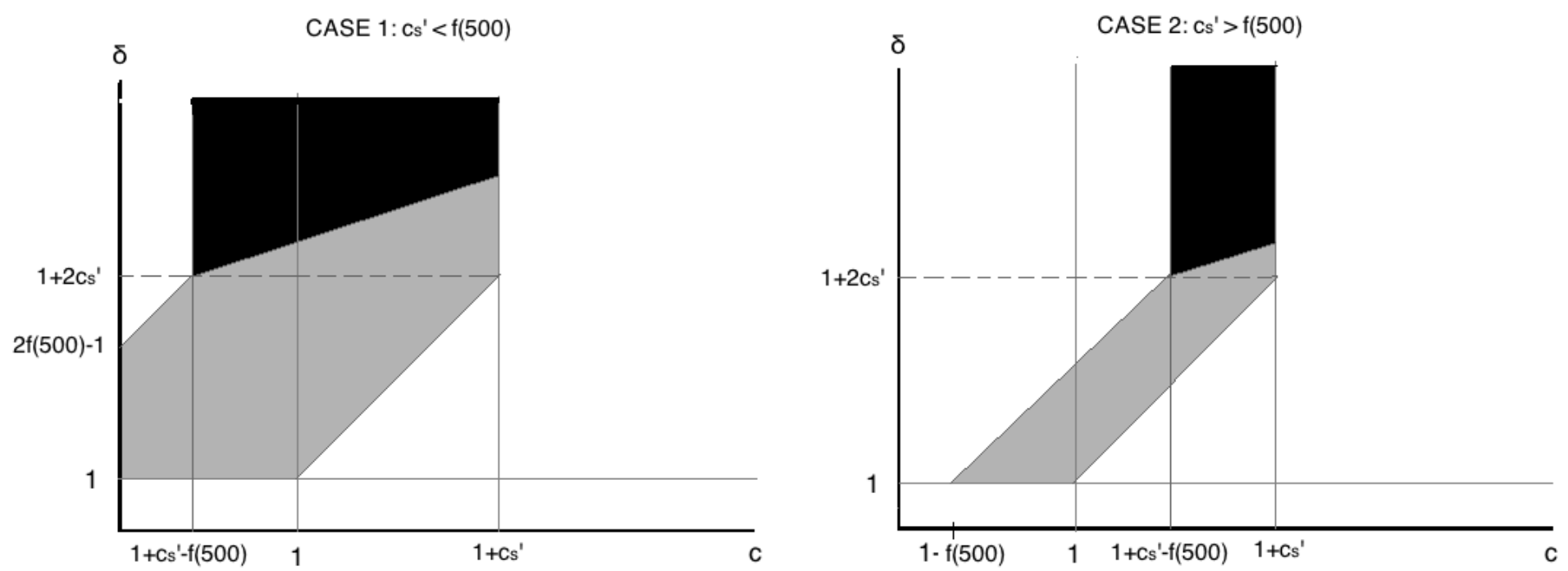

NOTES: Couples in the grey region stop child-bearing. Those in the black region have a second child who is more likely to be male than in the absence of incentives. 


\section{Who is more affected? One-boy versus one-girl couples}

In Figure B.3, couples in the grey area stop child-bearing due to the incentives irrespective of the sex of their first child. Those in the striped area stop if they already have a girl when the scheme starts, but not if they have a boy. Since both these groups were following a no US policy, they are equally likely to have a boy or a girl in 2002. Thus, their fertility and the sex ratio decrease and the likelihood that they have only one girl rises. Couples in the black area stop child-bearing at one boy. However, the one-girl incentives are inconsequential for them since their optimal choice is to only have boys. Thus, their fertility declines and the likelihood that they have only one boy increases, but there is no effect on their sex ratio. If the society mostly comprises high $\delta$ - high $c$ couples, it is possible that the dominant effect is an increase in the proportion of one-boy couples, among those who had one child when the scheme began.

Figure B.3: Likelihood of second birth

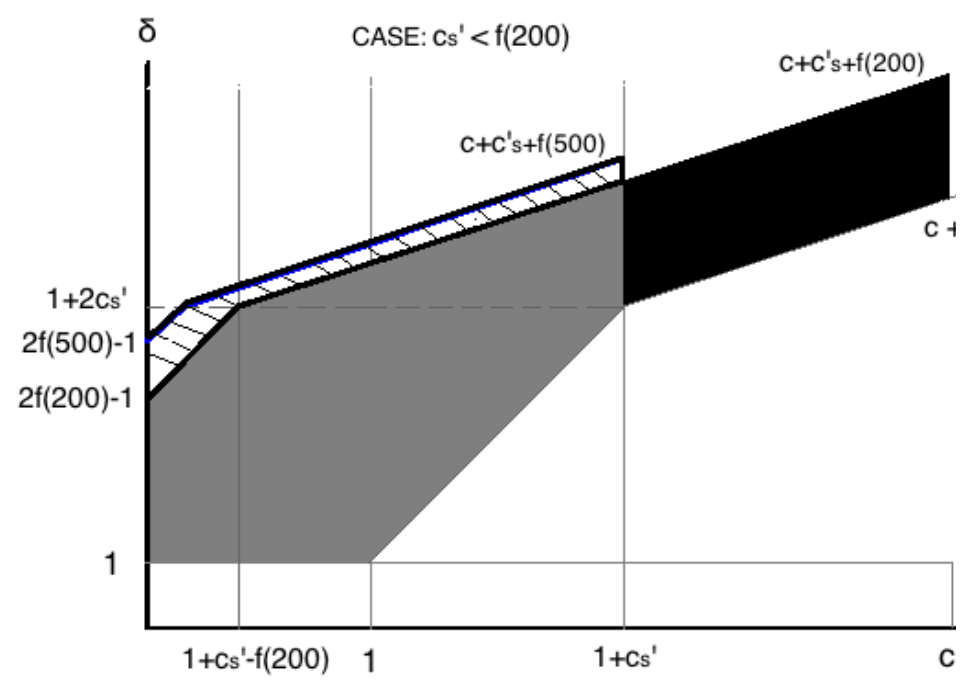

Figure B.4: Sex of second birth

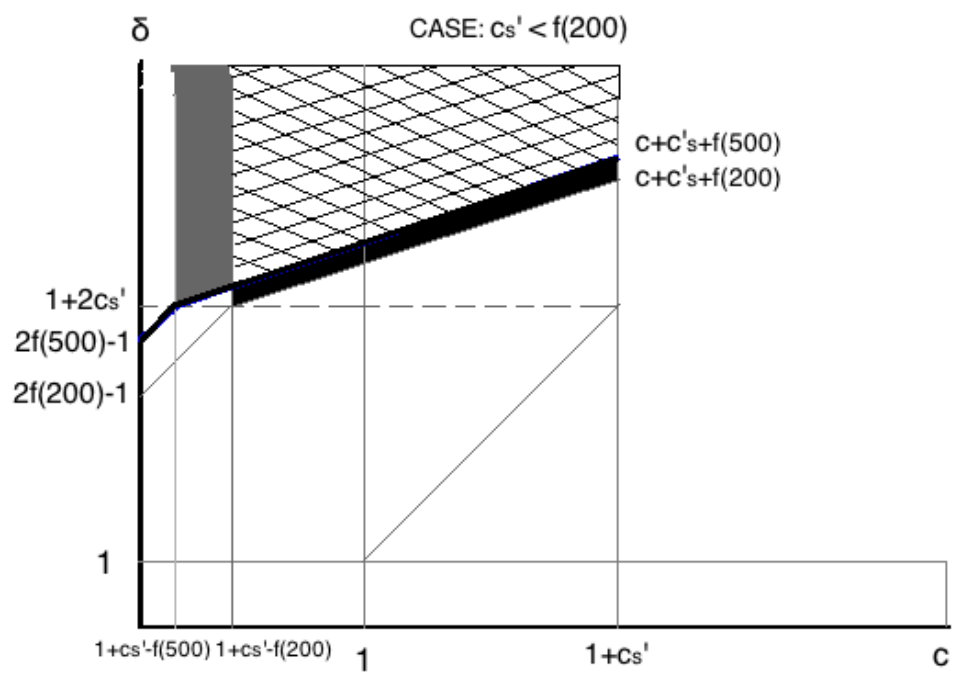

Proof of Proposition 4: In the absence of incentives, childless women who previously had one abortion $\left(c>1+c_{s}^{\prime}\right.$ and $\delta>c+c_{s}^{\prime}$ for them) would have continued with their $U S$ strategy. As a result, they would have either remained childless or had a boy at the end of their fertile period. After Devirupak, their utilities from the three options are:

$$
\begin{gathered}
\Delta U(\text { Stop })=0 \\
\Delta U(U S)=-c_{u}+0.5(\delta-c+f(200))-0.5 c_{a} \\
\Delta U(n o U S)=0.5(\delta+f(200))+0.5(1+f(500))-c
\end{gathered}
$$


Since $\delta>c+c_{s}^{\prime}-f(200)$ for these couples, $U S \succ$ Stop. If $c>1+c_{s}^{\prime}+f(500), U S \succ N o$ US. Thus, couples with $1+c_{s}^{\prime}<c<1+c_{s}^{\prime}+f(500)$ switch from $U S$ to no US. They are now less likely to remain childless and more likely to have a daughter than earlier. Figure B.5 indicates them in blue.

Figure B.5: Effect of Incentives on Childless Couples with a Previous Abortion

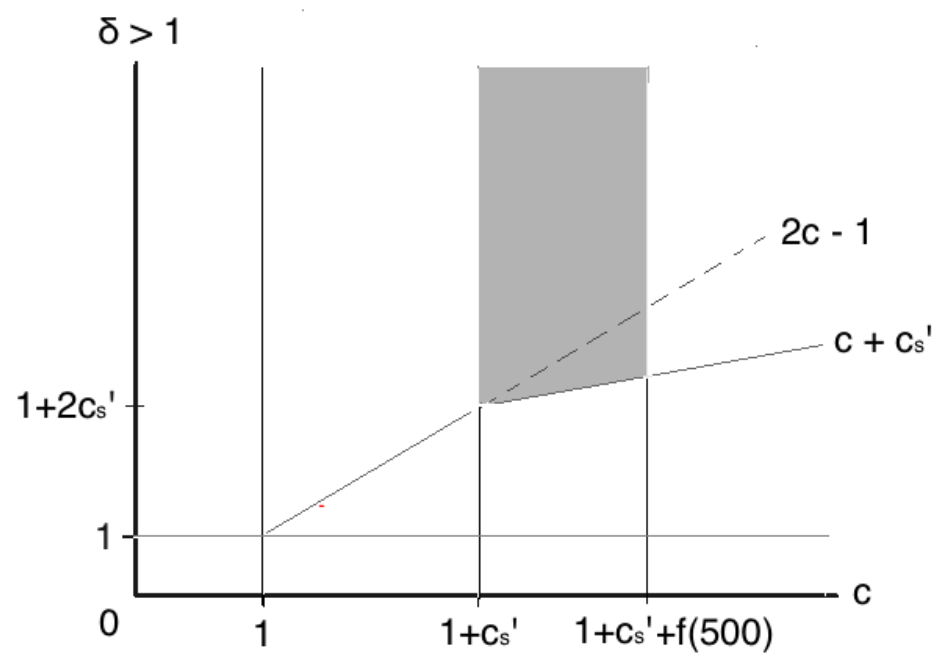




\section{References}

Abadie, A., A. Diamond, And J. Hainmueller (2010): "Synthetic Control Methods for Comparative Case Studies: Estimating the Effect of California's Tobacco Control Program," Journal of the American Statistical Association, 105, 493-505.

Abadie, A. And J. Gardeazabal (2003): "The Economic Costs of Conflict: A Case Study of the Basque Country," The American Economic Review, 93, 113-132.

Abrevaya, J. (2009): "Are There Missing Girls in the United States? Evidence from Birth Data," American Economic Journal: Applied Economics, 1, 1-34.

Almond, D. And L. Edlund (2008): "Son Biased Sex Ratios in the US 2000 Census," Proceedings of the National Academy of Sciences of the United States of America, 105, 5681-5682.

Almond, D., L. Edlund, And K. Milligan (2011): "O Sister, Where Art Thou? The Role of Son Preference and Sex Choice: Evidence from Immigrants to Canada," NBER Working Paper 15391.

Arnold, F., S. Kishor, And T. Roy (2002): "Sex-selective Abortions in India," Population and Development Review, 28, 759-785.

BanerJee, A. And T. Piketty (2005): “Top Indian Incomes, 1922-2000," World Bank Economic Review, 19, 1-20.

Bardhan, P. (1974): "On Life and Death Issues," Economic and Political Weekly, 9, 1293-1304.

Bedi, A. S. And S. SRInivasan (2009): "Girl Child Protection Scheme in Tamil Nadu: An Appraisal," Economic and Political Weekly, XLIV, 10-12.

Bhalotra, S. And T. Cochrane (2010): "Where Have All the Young Girls Gone? Identification of Sex Selection in India," IZA Discussion Paper No. 5381.

BharadwaJ, P. (2008): "Fertility and Rural Labor Market Inefficiencies: Evidence from India," Unpublished manuscript, University of California, San Diego.

Bharadwaj, P. And L. K. Nelson (2012): "Discrimination Begins in the Womb - Evidence of Sex Selective Prenatal Investments," Journal of Human Resources (forthcoming).

Bhaskar, V. (2011): "Sex Selection and Gender Balance," American Economic Journal: Microeconomics, 3, 214-244.

Bhaskar, V. And B. Gupta (2007): "India's Missing Girls: Biology, Customs, and Economic Development," Oxford Review of Economic Policy, 23, 221-238.

Bhat, P. And A. Zavier (2003): "Fertility Decline and Gender Bias in Northern India," Demography, 40, 637-657.

Boserup, E. (1970): Woman's Role in Economic Development, Earthscan.

Bowles, S. And S. Polania-Reyes (2012): "Economic Incentives and Social Preferences: Substitutes or Complements," Journal of Economic Literature, 50, 368-425.

Buch, N. (2006): The Law of Two Child Norm in Panchayats, Concept Publishing Company. 
Carranza, E. (2012): "Soil Endowments, Production Technologies and Missing Women in India," World Bank Policy Research Working Paper 5974.

Chiappori, P.-A., B. Fortin, and G. Lacroix (2002): "Household Labor Supply, Sharing Rule and the Marriage Market," Journal of Political Economy, 110, 37-72.

Chung, W. (2007): "The Relation of Son Preference and Religion to Induced Abortion: The Case of South Korea," Journal of Biosocial Science, 39, 707-719.

Chung, W. And M. D. Gupta (2007): "The Decline of Son Preference in South Korea: The Roles of Development and Public Policy," Population and Development Review, 33, 757-783.

Clark, S. (2000): "Son Preference and Sex Composition of Children: Evidence from India," Demography, 37, 95-108.

Cohen, A., R. Dehejia, and D. Romanov (2012): "Financial Incentives and Fertility," Review of Economics and Statistics (forthcoming).

Das Gupta, M. (1987): "Selective Discrimination Against Female Children in Rural Punjab, India," Population and Development Review, 13, 77-100.

(2010): "Family Systems, Political Systems, and Asia's 'Missing Girls': The Construction of Son Preference and Its Unraveling," Asian Population Studies, 6, 123-152.

Das Gupta, M., A. Ebenstein, And E. J. Sharygin (2010): "China's Marriage Market and Upcoming Challenges for Elderly Men," World Bank Policy Research Working Paper 5351.

Das Gupta, M. And L. Shuzhuo (1999): "Gender Bias in China, South Korea and India 1920-1990: The Effects of War, Famine and Fertility decline," Development and Change, 30, 619-652.

Das Gupta, M., J. Zhenghua, L. Bohua, X. Zhenming, W. Chung, and B. Hwa-Ok (2003): "Why is Son Preference So Persistent in East and South Asia? A Cross-country Study of China, India and the Republic of Korea," Journal of Development Studies, 40, 153-187.

Dickenmann, M. (1979): Evolutionary Biology and Human Social Behavior, North Scituate, MA: Duxbury Press, chap. Female Infanticide, Reproductive Strategies, and Social Stratification: A Preliminary Model.

Drèze, J. And R. Khera (2000): "Crime, Gender, and Society in India: Insights from Homicide Data," Population and Development Review, 26, 335-352.

Dubuc, S. and D. Coleman (2007): "An Increase in the Sex Ratio of Births to India-born Mothers in England and Wales: Evidence for Sex-Selective Abortion," Population and Development Review, $32,328-332$.

Dyson, T. And M. Moore (1983): "On Kinship Structure, Female Autonomy, and Demographic Behavior in India," Population and Development Review, 9, 35-60.

Ebenstein, A. (2010): "The "Missing" Girls of China and the Unintended Consequences of the One Child Policy," The Journal of Human Resources, 45, 87-115.

(2011): "Estimating a Dynamic Model of Sex Selection in China," Demography, 48, 783-811. 
Ebenstein, A. Y. And E. J. Sharygin (2009): "The Consequences of the Missing Girls of China," The World Bank Economic Review, 23, 399-425.

Edlund, L. (1999): "Son Preference, Sex Ratios and Marriage Patterns," The Journal of Political Economy, 107, 1275-1304.

Edlund, L. And C. Lee (2009): "Son Preference, Sex Selection and Economic Development: Theory and Evidence from South Korea," Columbia University Department of Economics Discussion Paper No. 0910-04.

Edlund, L., H. Li, J. Yi, And J. Zhang (2007): "Sex Ratios and Crime: Evidence from China's One Child Policy," IZA Discussion Paper 3214.

Epner, J. E. G., H. S. Jonas, And D. L. Seckinger (1998): "Late-term Abortion," The Journal of American Medical Association, 280, 724-729.

Goodkind, D. (1996): "On Substituting Sex Preference Strategies in East Asia: Does Prenatal Sex Selection Reduce Postnatal Discrimination?" Population and Development Review, 22, 111-125.

Goodman, L. (1961): "Some Possible Effects of Birth Control on the Human Sex Ratio," Annals of Human Genetics, 25, 75-81.

Jayachandran, S. And I. Kuziemko (2011): "Why Do Mothers Breastfeed Girls Less Than Boys: Evidence and Implications for Child Health in India," The Quarterly Journal of Economics, 126, $1485-1538$.

Jensen, R. (2005): "Equal Treatment, Unequal Outcomes? Generating Sex Inequality through Fertility Behavior," unpublished manuscript, Harvard University.

Jha, P., R. Kumar, And N. Dhingra (2006): "Sex Ratio in India, Author's Reply," Lancet, 367, $1727-1727$.

Kaur, R. (2010): "Khap Panchayats, Sex Ratio and Female Agency," Economic and Political Weekly, XLV, 14-16.

KIM, J. (2005): "Sex Selection and Fertility in a Dynamic Model of Conception and Abortion," Journal of Population Economics, 18, 41-67.

Kumar, D. (1983): "Male Utopias or Nightmares?" Economic and Political Weekly, 18, 61-64.

Laroque, G. and B. Salanié (2012): "Does Fertility Respond to Financial Incentives?" Columbia University Department of Economics Discussion Paper 0708-15.

Lechner, M. And R. Miquel (2010): "Identification of the Effects of Dynamic Treatments by Sequential Conditional Independence Assumptions," Empirical Economics, 39, 111-137.

Li, H., J. Yi, And J. Zhang (2011): "Estimating the Effect of the One-Child Policy on the Sex Ratio Imbalance in China: Identification Based on the Difference-in-Differences," Demography, 48, $1535-1557$.

Li, H. And H. Zheng (2009): "Ultrasonography and Sex Ratios in China," Asian Economic Policy Review, 4, 121-137. 
Lin, M.-J., J.-T. LIU, AND N. QIAN (2010): "More Missing Women, Fewer Dying Girls: The Impact of Abortion on Sex Ratios at Birth and Excess Female Mortality in Taiwan," NBER Working Paper 14541 .

Milligan, K. (2005): "Subsidizing the Stork: New Evidence on Tax Incentives and Fertility," The Review of Economics and Statistics, 87, 539-555.

Oldenburg, P. (1992): "Sex Ratio, Son Preference and Violence in India: A Research Note," Economic and Political Weekly, 27, 2657-2662.

PARK, C. B. And N.-H. Cho (1995): "Consequences of Son Preference in a Low-Fertility Society: Imbalance of the Sex Ratio at Birth in Korea," Population and Development Review, 21, 59-84.

Pop-Eleches, C. (2006): "The Impact of a Change in Abortion Regime on Socio-Economic Outcomes of Children: Evidence from Romania," Journal of Political Economy, 114.

Pörtner, C. C. (2010): "Sex Selective Abortions, Fertility and Birth Spacing," University of Washington, Department of Economics, Working Paper UWEC-2010-4-R.

Rahman, L. And V. RaO (2004): "The Determinants of Gender Equity in India: Examining Dyson and Moore's Thesis with New Data," Population and Development Review, 30, 239-268.

Sinha, N. And J. Yoong (2009): "Long-Term Financial Incentives and Investment in Daughters: Evidence from Conditional Cash Transfers in North India," World Bank Policy Research Working Paper 4860.

Stopnitzky, Y. (2012): "The Bargaining Power of Missing Women: Evidence from a Sanitation Campaign in India," Unpublished manuscript, University of San Francisco.

Tambiah, S. J. (1973): Bridewealth and Dowry: Cambridge Papers in Social Anthropology, Cambridge University Press, chap. Dowry, Bridewealth and Women's Property Rights, 7.

Yamaguchi, K. (1989): "A Formal Theory for Male-Preferring Stopping Rules of Childbearing: Sex Differences in Birth Order and in the Number of Siblings," Demography, 26, 451-465.

Zeng, Y., P. Tu, B. Gu, Y. Xu, B. Li, And Y. Li (1993): "Causes and Implications of the Recent Increase in the Reported Sex Ratio at Birth in China," Population and Development Review, 19, 283-302. 


\section{Tables}

Table I: Devirupak's Incentive Structure

\begin{tabular}{lcc}
\hline & Rupees per month & Present Discounted Value \\
\hline One girl (no boys) & $500(\$ 10)$ & $\$ 1800$ \\
One boy (no girls) & $200(\$ 4)$ & $\$ 715$ \\
Two girls (no boys) & $200(\$ 4)$ & $\$ 715$ \\
\hline
\end{tabular}

NOTES: The exchange rate used is $\$ 1=$ Rs. 50. The present discounted value is calculated @ 3 percent per annum.

Table II: Variation in Incentives by the Composition of Prior Living Children

\begin{tabular}{ccccc}
\hline & \multicolumn{4}{c}{ Monthly benefits receivable upon sterilization if: } \\
\cline { 2 - 5 }$\downarrow$ Prior living & No more births & One more girl & One more boy & Two more girls \\
children & $(1)$ & $(2)$ & $(3)$ & $(4)$ \\
\hline Childless & & 500 & 200 & 200 \\
One girl & 500 & 200 & & \\
One boy & 200 & & & \\
Two girls & 200 & & & \\
\hline
\end{tabular}

NOTES: This table shows the monthly incentive receivable by couples who are childless (first row), have one girl (second row), one boy (third row), or two girls (fourth row) if they become sterilized without any more births (1), after giving birth to one more girl (2), one more boy (3), or two more girls (4). No benefits are available for couples with any other child composition. 
Table III: Sample Means Before and After Devirupak, 1976-2005

\begin{tabular}{|c|c|c|c|c|}
\hline & \multicolumn{2}{|c|}{ Non-Haryana } & \multicolumn{2}{|c|}{ Haryana } \\
\hline & Post $=0$ & Post $=1$ & Post $=0$ & Post $=1$ \\
\hline Birth dummy & 0.23 & 0.11 & 0.21 & 0.10 \\
\hline \# Living children & 2.30 & 2.74 & 2.24 & 2.46 \\
\hline \# Living sons & 1.20 & 1.43 & 1.19 & 1.33 \\
\hline \# Living daughters & 1.10 & 1.31 & 1.05 & 1.13 \\
\hline Is Childless & 0.16 & 0.11 & 0.14 & 0.09 \\
\hline Has only one boy & 0.11 & 0.08 & 0.11 & 0.09 \\
\hline Has only one girl & 0.09 & 0.07 & 0.09 & 0.07 \\
\hline Has only two girls & 0.04 & 0.03 & 0.04 & 0.03 \\
\hline Birth is male* & 0.52 & 0.53 & 0.54 & 0.56 \\
\hline Mother's age at birth* & 22.79 & 23.99 & 22.24 & 22.90 \\
\hline Couple Sterilized & 0.42 & 0.33 & 0.53 & 0.40 \\
\hline Wife's age at survey & 34.28 & 30.56 & 34.39 & 30.56 \\
\hline Husband's age at survey & 35.52 & 31.78 & 35.64 & 31.65 \\
\hline Wife's age at marriage & 16.93 & 17.47 & 17.40 & 17.87 \\
\hline High-caste & 0.39 & 0.33 & 0.51 & 0.48 \\
\hline Hindu & 0.85 & 0.83 & 0.90 & 0.91 \\
\hline Muslim & 0.09 & 0.09 & 0.04 & 0.02 \\
\hline Sikh & 0.05 & 0.06 & 0.06 & 0.06 \\
\hline Urban & 0.34 & 0.35 & 0.30 & 0.27 \\
\hline Own agricultural land, if rural & 0.76 & 0.71 & 0.56 & 0.49 \\
\hline Wife's years of schooling & 3.25 & 4.14 & 3.65 & 5.18 \\
\hline Low HH Std of Living & 0.43 & 0.40 & 0.18 & 0.13 \\
\hline Medium HH Std of living & 0.29 & 0.31 & 0.45 & 0.47 \\
\hline High HH Std of Living & 0.28 & 0.29 & 0.37 & 0.40 \\
\hline Ideal number of children & 2.79 & 2.42 & 2.56 & 2.25 \\
\hline Ideal number of boys & 1.43 & 1.19 & 1.39 & 1.17 \\
\hline Ideal number of girls & 0.98 & 0.88 & 0.93 & 0.86 \\
\hline Ideal proportion of boys & 0.27 & 0.36 & 0.23 & 0.23 \\
\hline $\mathrm{N}$ (women) & \multicolumn{2}{|c|}{265,296} & \multicolumn{2}{|c|}{23,187} \\
\hline $\mathrm{N}$ (births) & 718,200 & 28,356 & 57,793 & 1,977 \\
\hline
\end{tabular}

NOTE: Post $=1$ if year $>2002$, and 0 otherwise. The ideal number of children, schooling, landownership, wealth index, and sterilization rates are measured at the time of survey. High-castes are those who are not from a scheduled caste (SC), a scheduled tribe (ST), or other backward castes (OBC). Means for the starred variables are calculated for the births sample, whereas the rest are for the woman-year sample. 
Table IV: Sample Means Before Devirupak, NFHS-2

\begin{tabular}{|c|c|c|c|c|}
\hline Socio-economic Category & Proportion of sons & $\mathrm{N}$ & \# Living Children & $\mathrm{N}$ \\
\hline Rural Sikh Landowner & 0.5781 & 658 & 2.25 & 718 \\
\hline Sikh & 0.5716 & 1,452 & 2.36 & 1,608 \\
\hline Urban Poor & 0.5616 & 648 & 3.10 & 722 \\
\hline Rural Rich & 0.5556 & 1,783 & 2.34 & 2,020 \\
\hline Rich & 0.5543 & 6,906 & 2.32 & 7,672 \\
\hline Urban Rich & 0.5538 & 5,123 & 2.31 & 5,652 \\
\hline$>6$ years of education & 0.5532 & 7,124 & 1.94 & 8,279 \\
\hline Rich, Educated, High-caste, Urban Hindu & 0.5510 & 2,494 & 1.96 & 2,751 \\
\hline High-caste & 0.5496 & 12,279 & 2.63 & 13,651 \\
\hline Rural High-caste Hindu Landowner & 0.5494 & 4,966 & 2.76 & 5,571 \\
\hline 1-5 years of education & 0.5460 & 3,783 & 2.79 & 4,212 \\
\hline $\mathrm{OBC}$ & 0.5456 & 6,720 & 2.94 & 7,468 \\
\hline Hindu & 0.5448 & 22,117 & 2.80 & 24,686 \\
\hline Rural Landowner & 0.5447 & 13,066 & 2.90 & 14,692 \\
\hline Works outside home & 0.5441 & 7,165 & 3.15 & 1,846 \\
\hline Employed by others & 0.5437 & 7,590 & 3.13 & 8,271 \\
\hline Rural Landless & 0.5427 & 4,676 & 3.06 & 5,158 \\
\hline $\mathrm{SC}$ & 0.5424 & 4,764 & 3.03 & 5,355 \\
\hline Rich SC & 0.5422 & 636 & 2.63 & 720 \\
\hline Uneducated & 0.5410 & 14,727 & 3.29 & 16,089 \\
\hline Works from home & 0.5330 & 1,665 & 3.00 & 1,846 \\
\hline Poor SC & 0.5378 & 2,504 & 3.24 & 2,790 \\
\hline Poor & 0.5359 & 10,845 & 3.18 & 12,078 \\
\hline Poor, Uneducated, SC, Rural Hindu & 0.5347 & 1,905 & 3.39 & 2,098 \\
\hline Rural Poor & 0.5342 & 10,197 & 3.18 & 11,356 \\
\hline Muslim & 0.5281 & 2,146 & 3.43 & 2,390 \\
\hline ST & 0.5235 & 2,280 & 3.05 & 2,578 \\
\hline
\end{tabular}

NOTE: This table reports the sample averages for various socio-economic categories using NFHS-2 data for the 8 sample states. Rich and Poor stand for high and low-SLI, respectively. High-castes are those who are not SC, ST, or OBC. Educated stands for $>6$ years of schooling for a woman. Landownership refers to agricultural land. The employment variables are from NFHS data. 


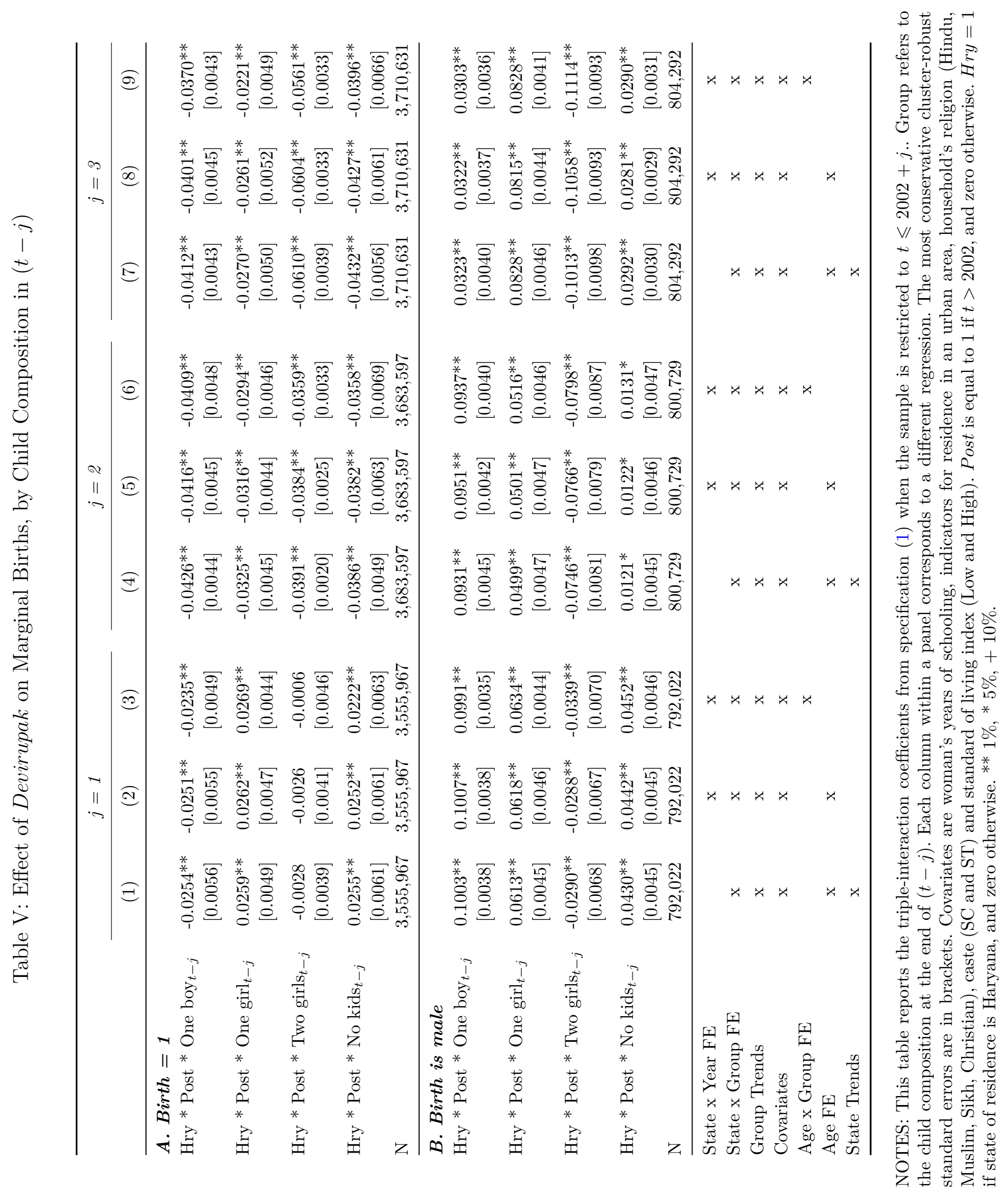


Table VI: Effect of Devirupak on the Number of Children and their Sex Composition

\begin{tabular}{|c|c|c|c|c|c|}
\hline \multirow[b]{3}{*}{$\downarrow$ Dependent Variables } & \multicolumn{5}{|c|}{ Coefficients of Hry * Post } \\
\hline & \multirow[b]{2}{*}{$(1)$} & \multirow[b]{2}{*}{$(2)$} & \multirow[b]{2}{*}{$(3)$} & \multicolumn{2}{|c|}{ Overlap sub-sample } \\
\hline & & & & $(4)$ & (5) \\
\hline \multicolumn{6}{|l|}{ Panel A } \\
\hline Only one boy $=1$ & $\begin{array}{c}0.0061 \\
{[0.0036]}\end{array}$ & $\begin{array}{c}0.0040^{* *} \\
{[0.0019]}\end{array}$ & $\begin{array}{c}0.0081^{* *} \\
{[0.0038]}\end{array}$ & $\begin{array}{l}0.0063^{*} \\
{[0.0034]}\end{array}$ & $\begin{array}{c}0.0088^{* * *} \\
{[0.0022]}\end{array}$ \\
\hline Only one girl $=1$ & $\begin{array}{c}0.0037^{* *} \\
{[0.0013]}\end{array}$ & $\begin{array}{c}0.0004 \\
{[0.0010]}\end{array}$ & $\begin{array}{l}-0.0009 \\
{[0.0034]}\end{array}$ & $\begin{array}{c}-0.0078^{* *} \\
{[0.0032]}\end{array}$ & $\begin{array}{c}-0.0057^{* * *} \\
{[0.0017]}\end{array}$ \\
\hline Only two girls $=1$ & $\begin{array}{c}-0.0037^{* * *} \\
{[0.0009]}\end{array}$ & $\begin{array}{c}-0.0016^{*} \\
{[0.0009]}\end{array}$ & $\begin{array}{c}0.0007 \\
{[0.0017]}\end{array}$ & $\begin{array}{l}-0.0002 \\
{[0.0013]}\end{array}$ & $\begin{array}{l}-0.0007 \\
{[0.0013]}\end{array}$ \\
\hline No children $=1$ & $\begin{array}{c}0.0044 \\
{[0.0041]}\end{array}$ & $\begin{array}{c}0.0097^{* *} \\
{[0.0042]}\end{array}$ & $\begin{array}{l}-0.0071 \\
{[0.0101]}\end{array}$ & $\begin{array}{c}0.0056 \\
{[0.0082]}\end{array}$ & $\begin{array}{c}0.0044 \\
{[0.0045]}\end{array}$ \\
\hline Other compositions $=1$ & $\begin{array}{c}-0.0105^{*} \\
{[0.0087]}\end{array}$ & $\begin{array}{c}-0.0125^{* * *} \\
{[0.0034]}\end{array}$ & $\begin{array}{l}-0.0009 \\
{[0.0060]}\end{array}$ & $\begin{array}{l}-0.0040 \\
{[0.0046]}\end{array}$ & $\begin{array}{c}-0.0068^{*} \\
{[0.0039]}\end{array}$ \\
\hline \multicolumn{6}{|l|}{ Panel B } \\
\hline \# Girls & $\begin{array}{c}-0.1277^{* *} \\
{[0.0428]}\end{array}$ & $\begin{array}{c}-0.0271^{* *} \\
{[0.0117]}\end{array}$ & $\begin{array}{c}-0.0392^{* *} \\
{[0.0153]}\end{array}$ & $\begin{array}{c}-0.0278^{*} \\
{[0.0150]}\end{array}$ & $\begin{array}{c}-0.0244^{* *} \\
{[0.0119]}\end{array}$ \\
\hline \# Boys & $\begin{array}{c}-0.0897^{*} \\
{[0.0432]}\end{array}$ & $\begin{array}{c}-0.0268^{* *} \\
{[0.0086]}\end{array}$ & $\begin{array}{l}-0.0176 \\
{[0.0152]}\end{array}$ & $\begin{array}{c}0.0047 \\
{[0.0117]}\end{array}$ & $\begin{array}{l}-0.0056 \\
{[0.0082]}\end{array}$ \\
\hline \# Children & $\begin{array}{c}-0.2174^{* *} \\
{[0.0859]}\end{array}$ & $\begin{array}{c}-0.0539^{* *} \\
{[0.0198]}\end{array}$ & $\begin{array}{c}-0.0568^{*} \\
{[0.0303]}\end{array}$ & $\begin{array}{l}-0.0232 \\
{[0.0261]}\end{array}$ & $\begin{array}{l}-0.0300 \\
{[0.0188]}\end{array}$ \\
\hline Year FE & $\mathrm{x}$ & $\mathrm{x}$ & $\mathrm{x}$ & $\mathrm{x}$ & $\mathrm{x}$ \\
\hline State FE & $\mathrm{x}$ & $\mathrm{x}$ & & & $\mathrm{x}$ \\
\hline Age FE & & $\mathrm{x}$ & $\mathrm{x}$ & $\mathrm{x}$ & $\mathrm{x}$ \\
\hline Covariates & & $\mathrm{x}$ & & & $\mathrm{x}$ \\
\hline State Trends & & $\mathrm{x}$ & $\mathrm{x}$ & $\mathrm{x}$ & $\mathrm{x}$ \\
\hline Woman FE & & & $\mathrm{x}$ & $\mathrm{x}$ & \\
\hline $\mathrm{N}$ & $3,723,443$ & $3,723,443$ & $3,726,289$ & $1,786,395$ & $1,786,001$ \\
\hline
\end{tabular}

NOTES: This table reports the DD coefficients from specifications (2) and $\left(2^{\prime}\right)$. Each cell corresponds to a different regression. Overlap sub-sample refers to women who were interviewed after, but were married before 2002. The most conservative clusterrobust standard errors are in brackets. Other variables as defined in Table V. ${ }^{* * *} 1 \%,{ }^{* *} 5 \%,{ }^{*} 10 \%$. 
Table VII: Effect of Devirupak on the Timing of First and Second Births

\begin{tabular}{|c|c|c|c|c|}
\hline A. Years b/w Marriage \& 1st birth $=$ & 0 & 1 & 2 & 3 \\
\hline Hry $*$ Post & $\begin{array}{c}-0.0298^{* *} \\
{[0.0132]}\end{array}$ & $\begin{array}{c}0.0432^{* *} \\
{[0.0182]}\end{array}$ & $\begin{array}{l}-0.0131 \\
{[0.0122]}\end{array}$ & $\begin{array}{l}-0.0034 \\
{[0.0095]}\end{array}$ \\
\hline $\begin{array}{l}\text { N } \\
\text { A1. Drop if } Y O M \leqslant 2002 \& Y O B>2002\end{array}$ & 220,159 & 220,159 & 220,159 & 220,159 \\
\hline Hry $*$ Post & $\begin{array}{l}-0.0231 \\
{[0.0165]}\end{array}$ & $\begin{array}{c}0.0047 \\
{[0.0105]}\end{array}$ & $\begin{array}{c}0.0297^{* *} \\
{[0.0108]}\end{array}$ & $\begin{array}{l}0.0119^{*} \\
{[0.0060]}\end{array}$ \\
\hline $\mathrm{N}$ & 214,478 & 214,478 & 214,478 & 214,478 \\
\hline B. Months b/w 1st \& 2nd births $=$ & $9-12$ & $12-24$ & 24-36 & $36-48$ \\
\hline Hry $*$ Post & $\begin{array}{c}-0.0127^{*} \\
{[0.0055]}\end{array}$ & $\begin{array}{l}0.0297^{*} \\
{[0.0131]}\end{array}$ & $\begin{array}{c}0.0338 \\
{[0.0269]}\end{array}$ & $\begin{array}{l}-0.0225 \\
{[0.0195]}\end{array}$ \\
\hline $\begin{array}{l}\mathrm{N} \\
\text { B1. 1st birth is male }\end{array}$ & $1,68,340$ & $1,68,340$ & $1,68,340$ & $1,68,340$ \\
\hline Hry $*$ Post & $\begin{array}{c}-0.0093^{*} \\
{[0.0055]}\end{array}$ & $\begin{array}{l}0.0429^{*} \\
{[0.0221]}\end{array}$ & $\begin{array}{c}0.0368 \\
{[0.0342]}\end{array}$ & $\begin{array}{l}-0.0141 \\
{[0.0153]}\end{array}$ \\
\hline $\begin{array}{l}\mathrm{N} \\
\text { B2. 1st birth is female }\end{array}$ & 85,680 & 85,680 & 85,680 & 85,680 \\
\hline Hry $*$ Post & $\begin{array}{c}-0.0161^{*} \\
{[0.0090]}\end{array}$ & $\begin{array}{c}0.0188 \\
{[0.0128]}\end{array}$ & $\begin{array}{c}0.0303 \\
{[0.0229]}\end{array}$ & $\begin{array}{l}-0.0326 \\
{[0.0290]}\end{array}$ \\
\hline $\mathrm{N}$ & 82,660 & 82,660 & 82,660 & 82,660 \\
\hline State FE & $\mathrm{x}$ & $\mathrm{x}$ & $\mathrm{x}$ & $\mathrm{x}$ \\
\hline Year FE & $\mathrm{x}$ & $\mathrm{x}$ & $\mathrm{x}$ & $\mathrm{x}$ \\
\hline Covariates & $\mathrm{x}$ & $\mathrm{x}$ & $\mathrm{x}$ & $\mathrm{x}$ \\
\hline Age at Marriage FE & $\mathrm{x}$ & $\mathrm{x}$ & $\mathrm{x}$ & $\mathrm{x}$ \\
\hline Age at 1st birth FE & $\mathrm{x}$ & $\mathrm{x}$ & $\mathrm{x}$ & $\mathrm{x}$ \\
\hline State Trends & $\mathrm{x}$ & $\mathrm{x}$ & $\mathrm{x}$ & $\mathrm{x}$ \\
\hline
\end{tabular}

NOTES: This table reports the DD coefficients from specification (2). The most conservative cluster-robust standard errors are in brackets. Other variables as defined in Table V. *** $1 \%, * * 5 \%, * 10 \%$. 
Table VIII: Effect of Devirupak on Child Composition, by Woman's Age

\begin{tabular}{|c|c|c|c|c|}
\hline \multirow[t]{2}{*}{ Woman's age in years: } & $\leqslant \mathbf{2 0}$ & $21-25$ & 26-30 & $30-44$ \\
\hline & \multicolumn{4}{|c|}{ Coefficients of Hry * Post } \\
\hline$\downarrow$ Dependent Variables & (1) & $(2)$ & $(3)$ & $(4)$ \\
\hline Only one boy $=1$ & $\begin{array}{c}0.0052 \\
{[0.0071]}\end{array}$ & $\begin{array}{c}0.0102^{* *} \\
{[0.0037]}\end{array}$ & $\begin{array}{l}-0.0030 \\
{[0.0028]}\end{array}$ & $\begin{array}{c}-0.0016 \\
{[0.0012]}\end{array}$ \\
\hline Only one girl $=1$ & $\begin{array}{l}-0.0075 \\
{[0.0067]}\end{array}$ & $\begin{array}{l}-0.0010 \\
{[0.0034]}\end{array}$ & $\begin{array}{c}0.0024 \\
{[0.0016]}\end{array}$ & $\begin{array}{c}0.0043^{* *} \\
{[0.0004]}\end{array}$ \\
\hline Only two girls $=1$ & $\begin{array}{c}-0.0048^{*} \\
{[0.0022]}\end{array}$ & $\begin{array}{c}0.0016 \\
{[0.0024]}\end{array}$ & $\begin{array}{c}-0.0080^{* *} \\
{[0.0019]}\end{array}$ & $\begin{array}{l}-0.0005 \\
{[0.0005]}\end{array}$ \\
\hline No Children $=1$ & $\begin{array}{l}0.0396^{*} \\
{[0.0156]}\end{array}$ & $\begin{array}{c}0.0022 \\
{[0.0062]}\end{array}$ & $\begin{array}{l}-0.0010 \\
{[0.0017]}\end{array}$ & $\begin{array}{c}-0.0016^{*} \\
{[0.0008]}\end{array}$ \\
\hline Other Compositions $=1$ & $\begin{array}{c}-0.0326^{* *} \\
{[0.0076]}\end{array}$ & $\begin{array}{l}-0.0130 \\
0.0080]\end{array}$ & $\begin{array}{c}0.0096+ \\
{[0.0045]}\end{array}$ & $\begin{array}{l}-0.0006 \\
{[0.0011]}\end{array}$ \\
\hline \# Girls & $\begin{array}{c}-0.0404^{* *} \\
{[0.0129]}\end{array}$ & $\begin{array}{c}-0.0187^{*} \\
{[0.0077]}\end{array}$ & $\begin{array}{c}0.0226 \\
{[0.0165]}\end{array}$ & $\begin{array}{c}0.0221 \\
{[0.0175]}\end{array}$ \\
\hline \# Boys & $\begin{array}{c}-0.0437^{* *} \\
{[0.0142]}\end{array}$ & $\begin{array}{c}0.0040 \\
{[0.0120]}\end{array}$ & $\begin{array}{l}0.0410^{*} \\
{[0.0165]}\end{array}$ & $\begin{array}{l}-0.0040 \\
{[0.0080]}\end{array}$ \\
\hline \# Children & $\begin{array}{c}-0.0841^{* *} \\
{[0.0252]}\end{array}$ & $\begin{array}{l}-0.0147 \\
{[0.0165]}\end{array}$ & $\begin{array}{l}0.0636^{*} \\
{[0.0274]}\end{array}$ & $\begin{array}{c}0.0181 \\
{[0.0218]} \\
\end{array}$ \\
\hline $\mathrm{N}$ & 909,095 & $1,085,109$ & 836,377 & 892,862 \\
\hline State FE & $x$ & $\mathrm{x}$ & $\mathrm{x}$ & $\mathrm{x}$ \\
\hline Year FE & $\mathrm{x}$ & $\mathrm{x}$ & $\mathrm{x}$ & $\mathrm{x}$ \\
\hline Covariates & $\mathrm{x}$ & $\mathrm{x}$ & $\mathrm{x}$ & $\mathrm{x}$ \\
\hline Age FE & $\mathrm{x}$ & $\mathrm{x}$ & $\mathrm{x}$ & $\mathrm{x}$ \\
\hline State Trends & $\mathrm{x}$ & $\mathrm{x}$ & $\mathrm{x}$ & $\mathrm{x}$ \\
\hline
\end{tabular}

NOTES: This table reports the DD coefficients from specification (2). The most conservative cluster-robust standard errors are in brackets. Other variables as defined in Table V. ${ }^{*} * 1 \%, * 5 \%,+10 \%$. 
Table X: Effect of Devirupak, by Ideal Proportion of Sons Reported at Survey

\begin{tabular}{lcc}
\hline & \multicolumn{2}{c}{ Ideal Proportion of Sons } \\
\cline { 2 - 3 }$\downarrow$ Dependent Variables & $\leqslant 0.5$ & $>0.5$ \\
\hline Only one boy $=1$ & -0.0013 & $0.0225^{* *}$ \\
& {$[0.0033]$} & {$[0.0080]$} \\
Only one girl $=1$ & $-0.0108^{* *}$ & 0.0058 \\
& {$[0.0040]$} & {$[0.0082]$} \\
Only two Girls $=1$ & $-0.0066^{* *}$ & -0.0034 \\
& {$[0.0020]$} & {$[0.0037]$} \\
No children $=1$ & $0.0235^{* *}$ & $-0.0189^{* *}$ \\
& {$[0.0053]$} & {$[0.0051]$} \\
Other compositions $=1$ & -0.0049 & -0.0060 \\
& {$[0.0044]$} & {$[0.0101]$} \\
\hline N & 433,356 & 252,817 \\
\hline State FE & $\mathrm{x}$ & $\mathrm{x}$ \\
Year FE & $\mathrm{x}$ & $\mathrm{x}$ \\
Covariates & $\mathrm{x}$ & $\mathrm{x}$ \\
Age FE & $\mathrm{x}$ & $\mathrm{x}$ \\
State Trends & $\mathrm{x}$ & $\mathrm{x}$ \\
\hline
\end{tabular}

NOTES: This table reports the DD coefficients from specification (2). Each cell corresponds to a separate regression. Sample is restricted to NFHS-2,3. Ideal proportion of sons $=\frac{\text { ideal boys }+\left(0.5 * \text { ideal }_{\text {either }}\right)}{\text { ideal }_{\text {kids }}}$ if $i$ deal $_{\text {kids }}>0$, where $i_{\text {deal }}$ boys is the ideal number of boys, $i_{\text {deal }}$ either is the ideal number of children of either sex, and $i_{d e a l} k_{k i d s}$ is the ideal number of total children, as reported by a woman. The most conservative cluster-robust standard errors are in brackets. Other variables as defined in Table V. $* * 1 \%, * 5 \%,+10 \%$. 
Table XI: Effect of Devirupak on Sterilization and the Number of Fertile Years

\begin{tabular}{lccccc}
\hline & & \multicolumn{4}{c}{ Sterilized $=1$} \\
\cline { 3 - 6 } & \# Fertile Years & All & NFHS only & DLHS only & YOS $>1994$ \\
& $(1)$ & $(2)$ & $(3)$ & $(4)$ & $(5)$ \\
\hline Hry ${ }^{*}$ Post ${ }^{*}$ One Boy & $-0.0603+$ & $0.0302^{* *}$ & 0.0127 & $0.0398^{* *}$ & $0.0131^{*}$ \\
& {$[0.0348]$} & {$[0.0035]$} & {$[0.0090]$} & {$[0.0094]$} & {$[0.0056]$} \\
Hry*Post ${ }^{*}$ One Girl & $-0.0890^{*}$ & $0.0290^{* *}$ & $0.0307^{*}$ & $0.0419^{* *}$ & $0.0193^{* *}$ \\
& {$[0.0333]$} & {$[0.0051]$} & {$[0.0114]$} & {$[0.0126]$} & {$[0.0051]$} \\
Hry*Post ${ }^{*}$ Two Girls & $-0.1998^{* *}$ & $0.0203^{* *}$ & $0.0206^{*}$ & $0.0310^{* *}$ & 0.0049 \\
& {$[0.0355]$} & {$[0.0030]$} & {$[0.0097]$} & {$[0.0064]$} & {$[0.0041]$} \\
\hline $\mathrm{N}$ & 247,669 & 247,669 & 74,021 & 173,648 & 221,192 \\
\hline
\end{tabular}

NOTES: This table reports the coefficients from a version of specification (1) estimated using repeated cross-sections of women. The number of fertile years is equal to the marital duration until survey for unsterilized women, and equal to the marital duration until sterilization for sterilized women. YOS stands for the year of survey. Each column corresponds to a separate regression. All regressions control for state trends, group trends, covariates, and fixed effects for state $\mathrm{x}$ group, age $\mathrm{x}$ group, YOS, and marital duration. The most conservative cluster-robust standard errors are in brackets. Post $=1$ if year of survey $>2002$, and zero otherwise. Other variables as defined in Table V. ${ }^{* *} 1 \%,{ }^{*} 5 \%,+10 \%$. 
Table XII: Differences in Characteristics of Couples Who Stop After One Child and Those Who Do Not

\begin{tabular}{|c|c|c|c|c|}
\hline \multirow{2}{*}{$\begin{array}{l}\text { Dependent Variable } \\
\text { Woman is - }\end{array}$} & \multicolumn{2}{|c|}{ 1st child is a girl } & \multicolumn{2}{|c|}{ 1st child is a boy } \\
\hline & Hry $*$ Post $*$ Stop & Hry $*$ Post & Hry $*$ Post $*$ Stop & Hry $*$ Post \\
\hline Poor, Rural, SC, Hindu & $\begin{array}{c}0.0252^{* *} \\
{[0.0038]}\end{array}$ & $\begin{array}{l}-0.0077 \\
{[0.0069]}\end{array}$ & $\begin{array}{c}0.0194 * * \\
{[0.0066]}\end{array}$ & $\begin{array}{l}-0.0100 \\
{[0.0093]}\end{array}$ \\
\hline Land-owning, Rural, High-caste, Hindu & $\begin{array}{r}-0.0163+ \\
{[0.0087]}\end{array}$ & $\begin{array}{c}0.0128 \\
{[0.0151]}\end{array}$ & $\begin{array}{c}-0.0220^{*} \\
{[0.0110]}\end{array}$ & $\begin{array}{c}0.0268 \\
{[0.0194]}\end{array}$ \\
\hline Muslim & $\begin{array}{l}0.0154^{*} \\
{[0.0039]}\end{array}$ & $\begin{array}{c}-0.0175^{*} \\
{[0.0046]}\end{array}$ & $\begin{array}{c}0.0207^{* *} \\
{[0.0038]}\end{array}$ & $\begin{array}{c}-0.0115^{*} \\
{[0.0054]}\end{array}$ \\
\hline Poor SC & $\begin{array}{l}0.0160^{*} \\
{[0.0025]}\end{array}$ & $\begin{array}{c}0.0021 \\
{[0.0045]}\end{array}$ & $\begin{array}{c}0.0044 \\
{[0.0046]}\end{array}$ & $\begin{array}{c}0.0040 \\
{[0.0043]}\end{array}$ \\
\hline Rich SC & $\begin{array}{c}-0.0237^{*} \\
{[0.0061]}\end{array}$ & $\begin{array}{c}0.0005 \\
{[0.0051]}\end{array}$ & $\begin{array}{c}-0.0128^{* *} \\
{[0.0048]}\end{array}$ & $\begin{array}{c}0.0160^{* *} \\
{[0.0049]}\end{array}$ \\
\hline Poor OBC & $\begin{array}{c}0.0137^{* *} \\
{[0.0030]}\end{array}$ & $\begin{array}{c}-0.0145^{*} \\
{[0.0057]}\end{array}$ & $\begin{array}{c}0.0157^{* * *} \\
{[0.0044]}\end{array}$ & $\begin{array}{l}-0.0140 \\
{[0.0091]}\end{array}$ \\
\hline $\mathrm{N}$ & \multicolumn{2}{|c|}{285,261} & \multicolumn{2}{|l|}{328,890} \\
\hline
\end{tabular}

NOTES: This table reports the DD and DDD coefficients from a version of specification (2). The most conservative clusterrobust standard errors are in brackets. The main effect of Stop is included, but not reported. Other variables as defined in Table V. $* * 1 \%, * 5 \%,+10 \%$. 


\section{Figures}

Figure VI: Equilibrium in the absence of PSDT and incentives

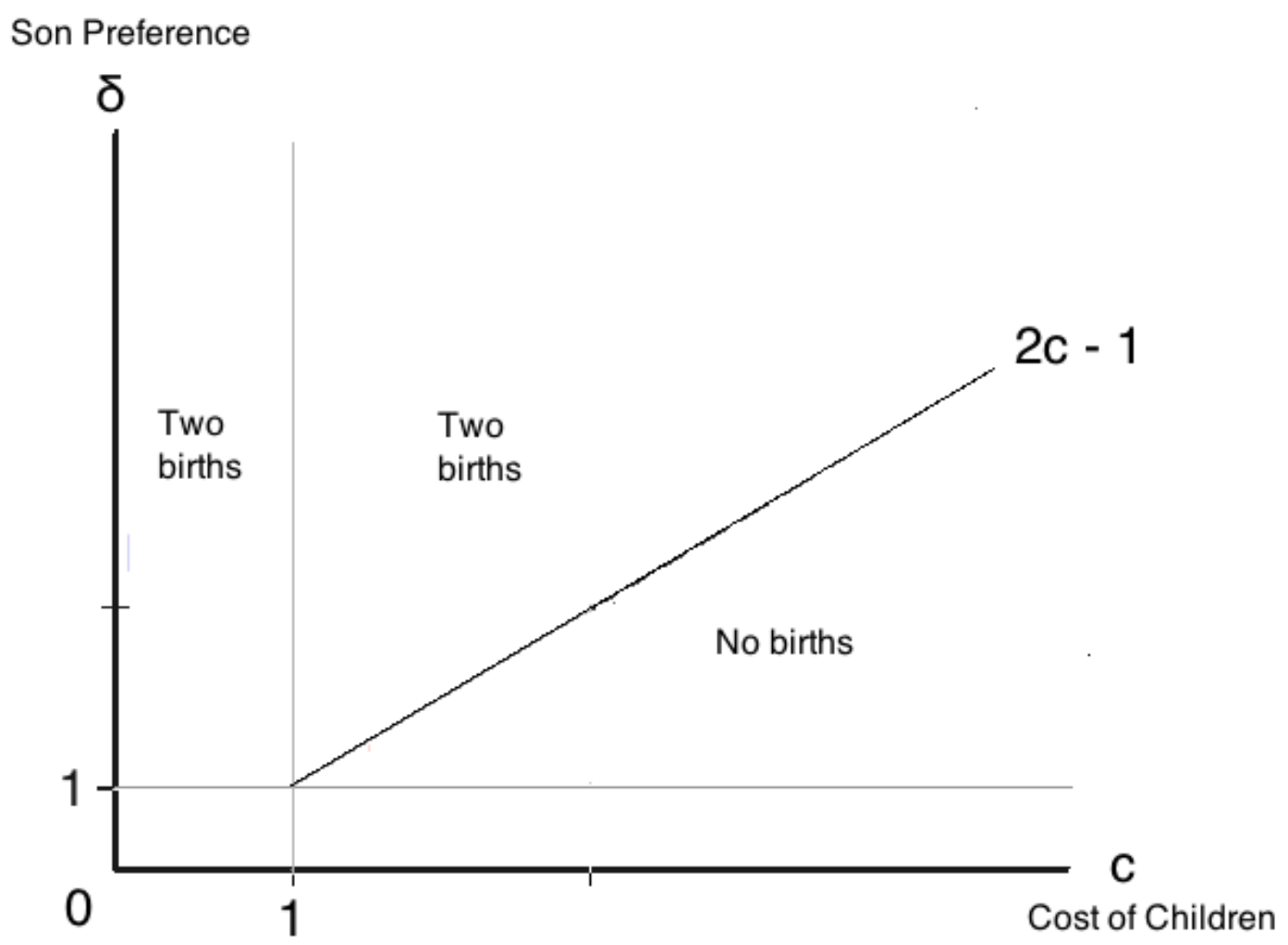


Figure VII: Equilibrium with PSDT and without incentives

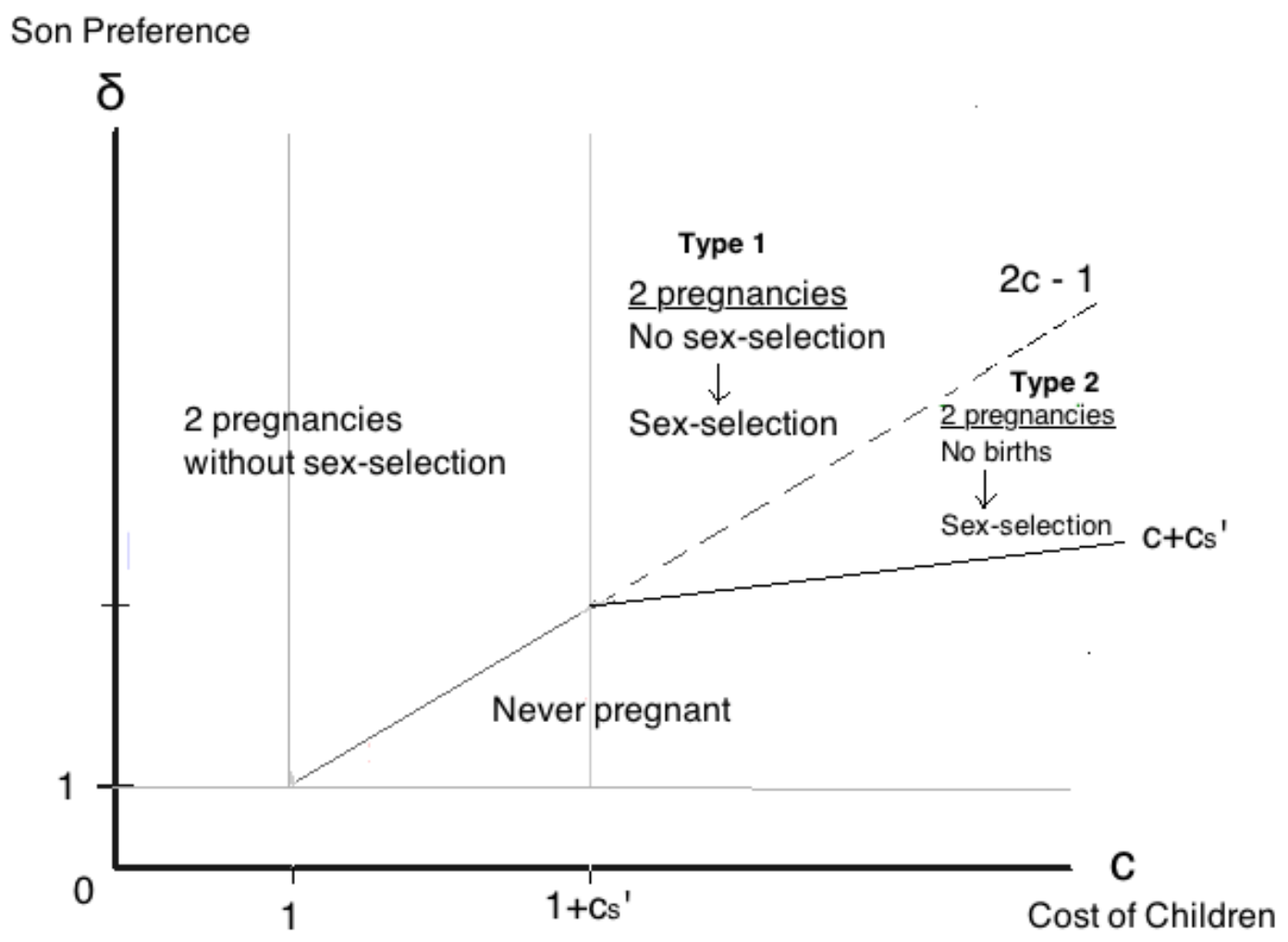


Figure VIII: Timing of Survey Rounds

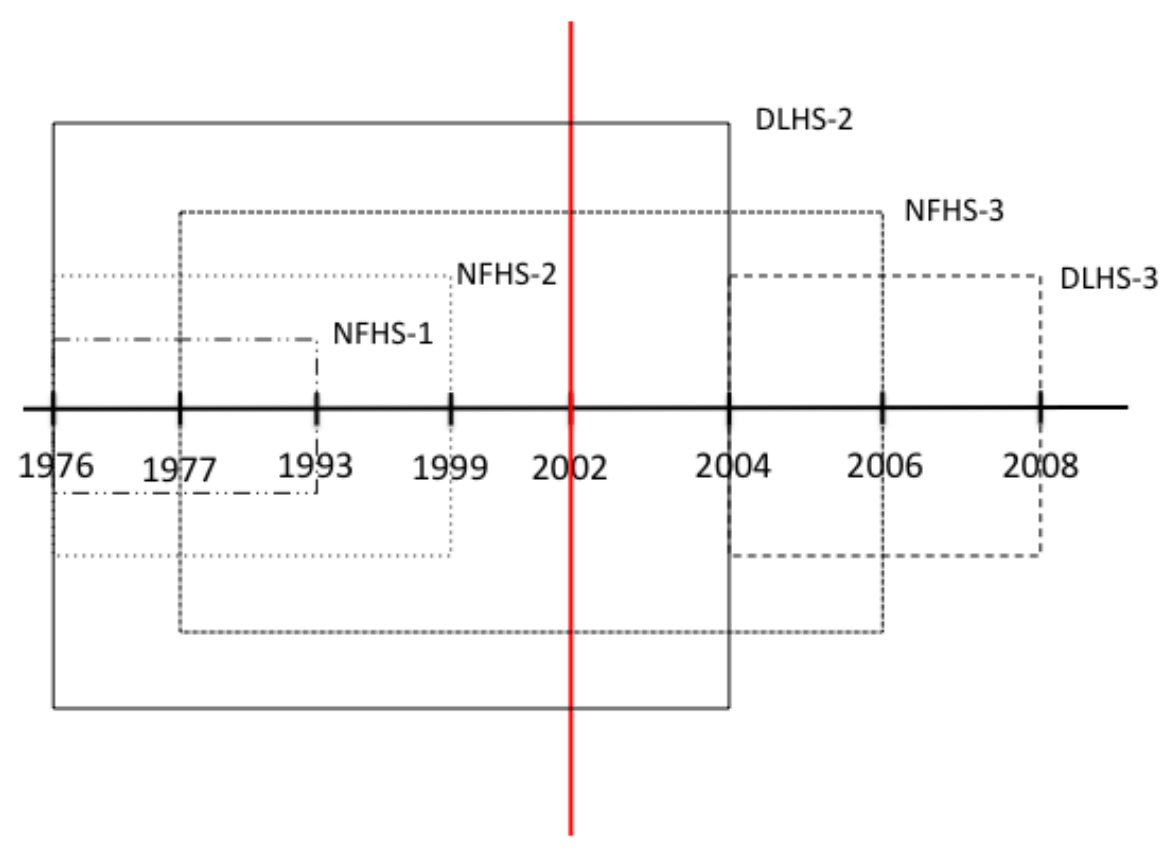




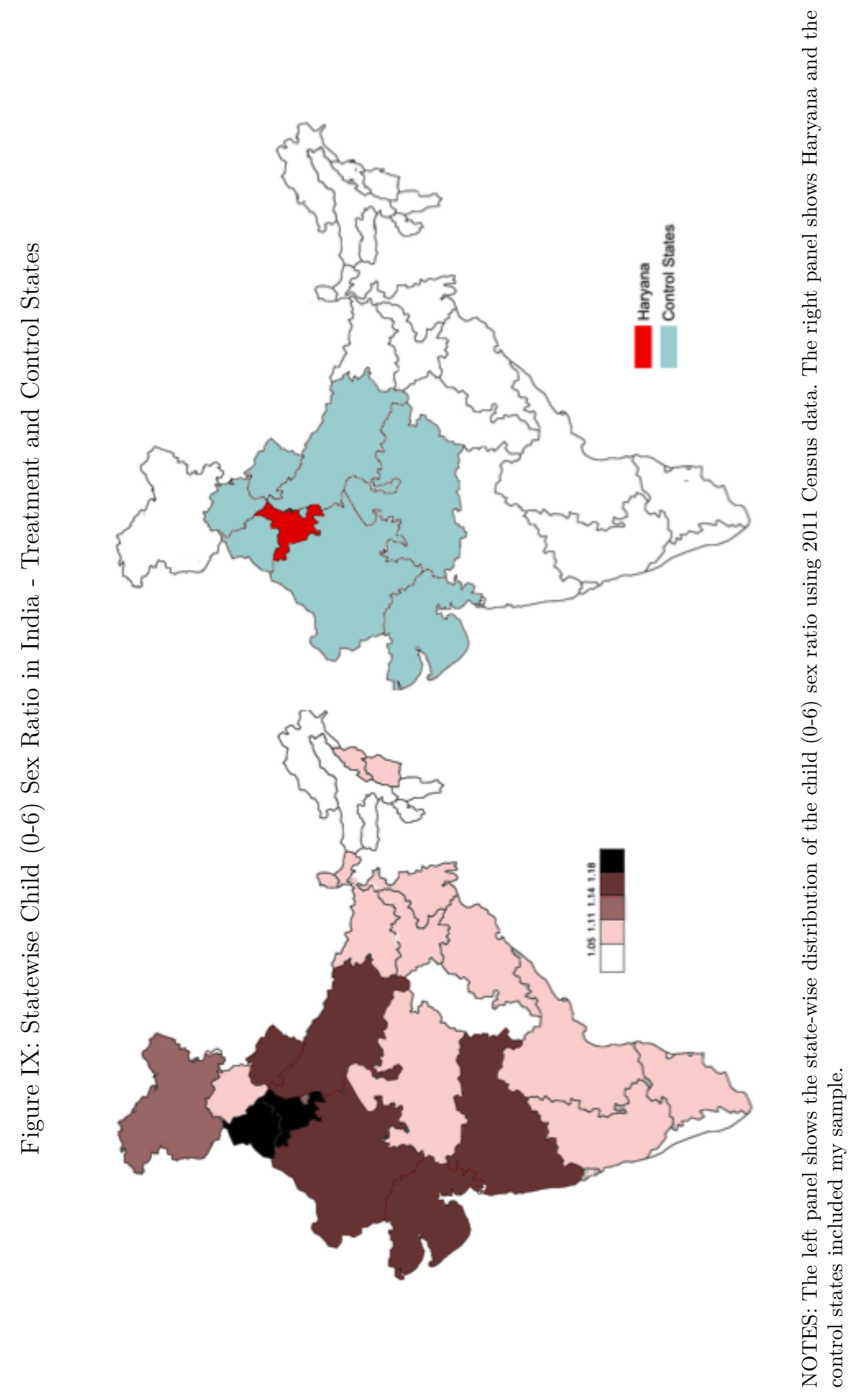


Figure X: Child (0-6) Sex Ratio in Haryana and Control States

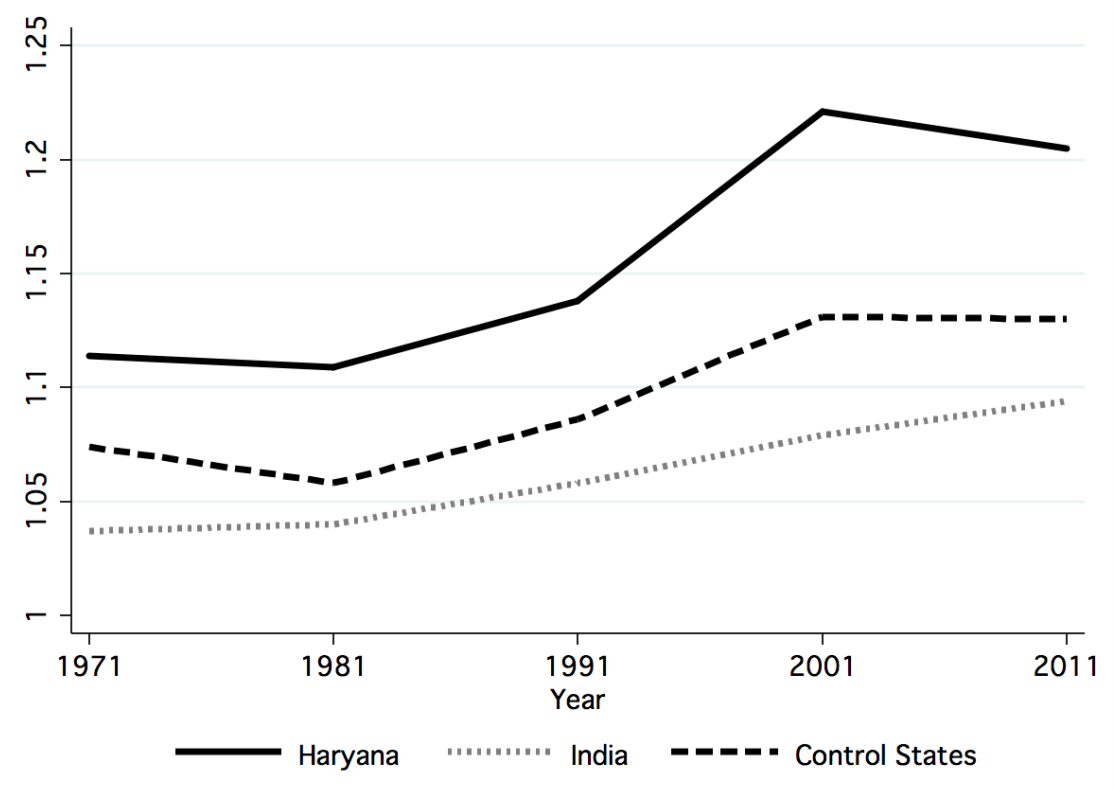

NOTES: For control states, a simple average of state sex ratios has been plotted. Source: Census of India. 
Figure XI: Differential Trends in Child Composition, Haryana vs Non-Haryana, before and after 2002
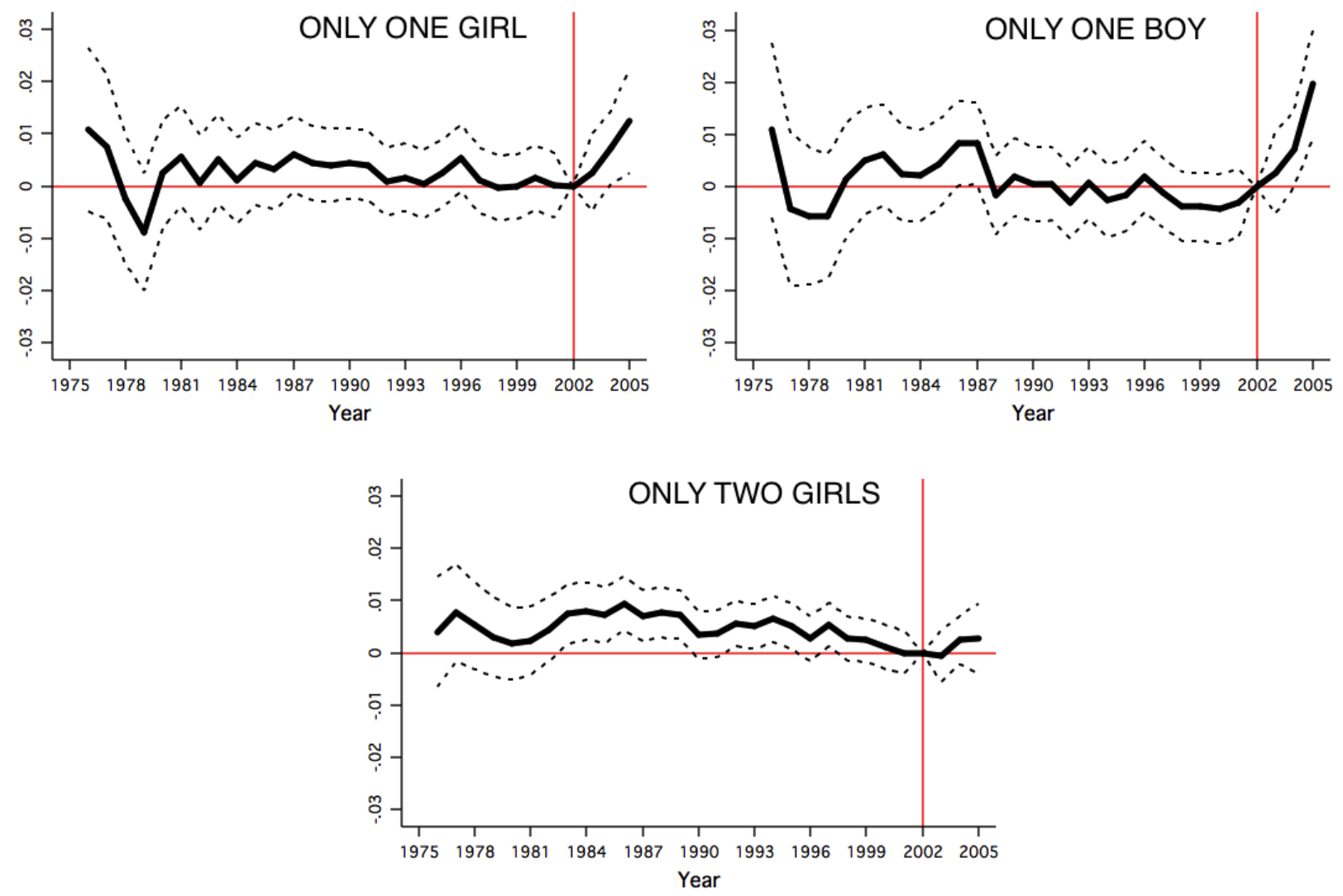

NOTES: This figure plots the $\beta_{k}$ coefficients from the following regression, with 2002 as the omitted year:

$Y_{\text {isat }}=\sum_{k=1976}^{2005} \beta_{k}$ Hry $_{s} * 1\left[\right.$ Year $\left._{t}=k\right]+X_{i}^{\prime} \delta+\gamma_{s}+\omega_{a}+\theta_{t}+\epsilon_{\text {isat }}$. Dashed lines are the 95 percent confidence intervals. 
Figure XII: Differential Trends in Child Composition, Haryana vs Non-Haryana, before and after 2002

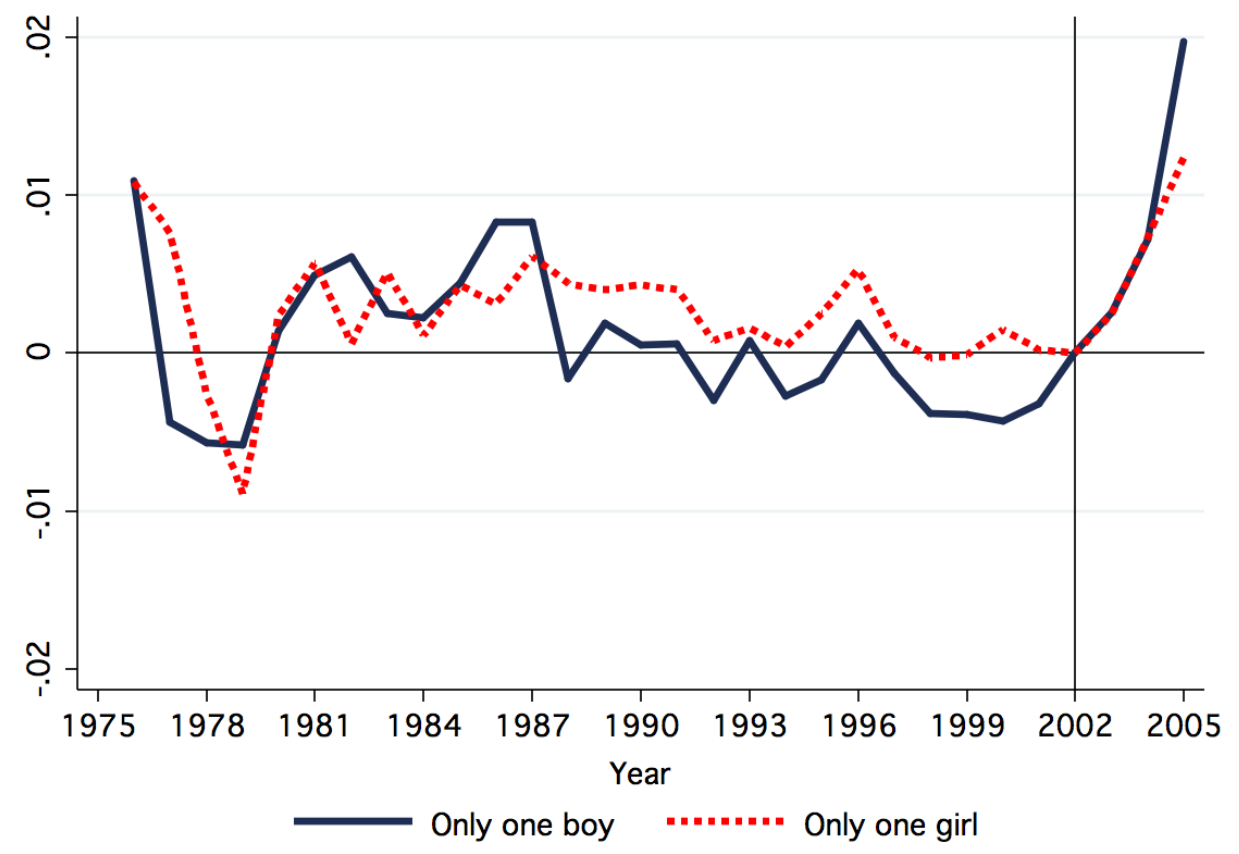

NOTES: Same as Figure XI. 
Figure XIII: Months between First and Second Birth if First Child is a Boy

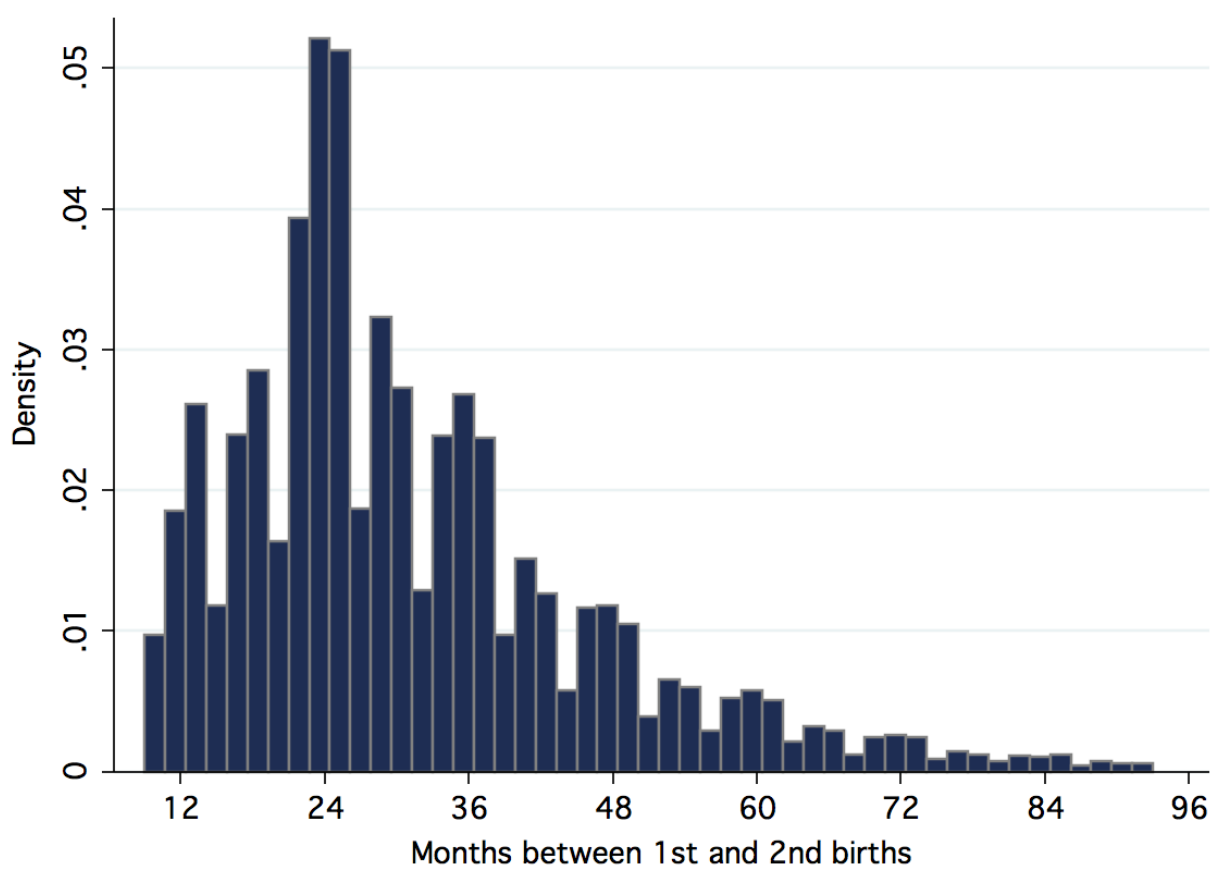

NOTES: This figure plots the distribution of the interval (in months) between a woman's first two births if the first child is a boy and is alive at the time of the second birth. 


\section{E Additional Tables and Figures}

Table XIII: Robustness Check: Control States Excluded (DD)

\begin{tabular}{|c|c|c|c|c|c|c|c|c|}
\hline \multirow[b]{2}{*}{ Dependent Variables $\downarrow$} & \multicolumn{7}{|c|}{ Control State Excluded } & \multirow[b]{2}{*}{$\begin{array}{l}\text { All } \\
(8)\end{array}$} \\
\hline & $\begin{array}{l}\mathrm{HP} \\
(1)\end{array}$ & $\begin{array}{l}\text { MP } \\
(2)\end{array}$ & $\begin{array}{l}\text { UP } \\
(3)\end{array}$ & $\begin{array}{c}\text { Punjab } \\
(4)\end{array}$ & $\begin{array}{c}\text { Rajasthan } \\
\text { (5) }\end{array}$ & $\begin{array}{l}\text { Delhi } \\
(6)\end{array}$ & $\begin{array}{c}\text { Gujarat } \\
(7)\end{array}$ & \\
\hline Only one boy $=1$ & $\begin{array}{c}0.0084^{* *} \\
{[0.004]}\end{array}$ & $\begin{array}{c}0.0089^{* *} \\
{[0.004]}\end{array}$ & $\begin{array}{l}0.0054 \\
{[0.004]}\end{array}$ & $\begin{array}{c}0.0090^{* *} \\
{[0.004]}\end{array}$ & $\begin{array}{c}0.0077^{*} \\
{[0.004]}\end{array}$ & $\begin{array}{c}0.0084^{* *} \\
{[0.004]}\end{array}$ & $\begin{array}{c}0.0084^{* *} \\
{[0.004]}\end{array}$ & $\begin{array}{c}0.0081^{* *} \\
{[0.0038]}\end{array}$ \\
\hline Only one girl $=1$ & $\begin{array}{c}-0.0008 \\
{[0.003]}\end{array}$ & $\begin{array}{l}0.0002 \\
{[0.004]}\end{array}$ & $\begin{array}{c}-0.0029 \\
{[0.004]}\end{array}$ & $\begin{array}{c}-0.0008 \\
{[0.003]}\end{array}$ & $\begin{array}{c}-0.0008 \\
{[0.003]}\end{array}$ & $\begin{array}{c}-0.0006 \\
{[0.003]}\end{array}$ & $\begin{array}{c}-0.0008 \\
{[0.003]}\end{array}$ & $\begin{array}{l}-0.0009 \\
{[0.0034]}\end{array}$ \\
\hline Only two girls $=1$ & $\begin{array}{l}0.0008 \\
{[0.002]}\end{array}$ & $\begin{array}{l}0.0012 \\
{[0.002]}\end{array}$ & $\begin{array}{c}-0.0002 \\
{[0.002]}\end{array}$ & $\begin{array}{l}0.0008 \\
{[0.002]}\end{array}$ & $\begin{array}{l}0.0005 \\
{[0.002]}\end{array}$ & $\begin{array}{l}0.0009 \\
{[0.002]}\end{array}$ & $\begin{array}{c}0.001 \\
{[0.002]}\end{array}$ & $\begin{array}{c}0.0007 \\
{[0.0017]}\end{array}$ \\
\hline No children $=1$ & $\begin{array}{c}-0.0081 \\
{[0.010]}\end{array}$ & $\begin{array}{c}-0.0115 \\
{[0.010]}\end{array}$ & $\begin{array}{l}0.0017 \\
{[0.010]}\end{array}$ & $\begin{array}{r}-0.0075 \\
{[0.010]}\end{array}$ & $\begin{array}{c}-0.0059 \\
{[0.011]}\end{array}$ & $\begin{array}{c}-0.0084 \\
{[0.010]}\end{array}$ & $\begin{array}{c}-0.0082 \\
{[0.010]}\end{array}$ & $\begin{array}{c}-0.0071 \\
{[0.0101]}\end{array}$ \\
\hline Other compositions $=1$ & $\begin{array}{c}-0.0002 \\
{[0.006]}\end{array}$ & $\begin{array}{l}0.0011 \\
{[0.006]}\end{array}$ & $\begin{array}{r}-0.0041 \\
{[0.006]}\end{array}$ & $\begin{array}{c}-0.0016 \\
{[0.006]}\end{array}$ & $\begin{array}{c}-0.0016 \\
{[0.006]}\end{array}$ & $\begin{array}{c}-0.0003 \\
{[0.006]}\end{array}$ & $\begin{array}{c}-0.0005 \\
{[0.006]}\end{array}$ & $\begin{array}{l}-0.0009 \\
{[0.0060]}\end{array}$ \\
\hline \# Girls & $\begin{array}{c}-0.0375^{* *} \\
{[0.016]}\end{array}$ & $\begin{array}{c}-0.0409^{* * *} \\
{[0.016]}\end{array}$ & $\begin{array}{c}-0.0417^{* * *} \\
{[0.013]}\end{array}$ & $\begin{array}{c}-0.0403^{* *} \\
{[0.016]}\end{array}$ & $\begin{array}{c}-0.0391^{* *} \\
{[0.015]}\end{array}$ & $\begin{array}{c}-0.0393^{* *} \\
{[0.016]}\end{array}$ & $\begin{array}{c}-0.0370^{* *} \\
{[0.015]}\end{array}$ & $\begin{array}{c}-0.0392^{* *} \\
{[0.0153]}\end{array}$ \\
\hline \# Boys & $\begin{array}{l}-0.015 \\
{[0.015]}\end{array}$ & $\begin{array}{l}-0.0195 \\
{[0.016]}\end{array}$ & $\begin{array}{c}-0.0208 \\
{[0.014]}\end{array}$ & $\begin{array}{l}-0.018 \\
{[0.016]}\end{array}$ & $\begin{array}{l}-0.019 \\
{[0.015]}\end{array}$ & $\begin{array}{l}-0.0177 \\
{[0.015]}\end{array}$ & $\begin{array}{c}-0.0144 \\
{[0.015]}\end{array}$ & $\begin{array}{l}-0.0176 \\
{[0.0152]}\end{array}$ \\
\hline \# Children & $\begin{array}{c}-0.0525^{*} \\
{[0.031]}\end{array}$ & $\begin{array}{c}-0.0603^{*} \\
{[0.031]}\end{array}$ & $\begin{array}{c}-0.0625^{* *} \\
{[0.027]}\end{array}$ & $\begin{array}{c}-0.0583^{*} \\
{[0.031]}\end{array}$ & $\begin{array}{c}-0.0581^{*} \\
{[0.030]}\end{array}$ & $\begin{array}{c}-0.0570^{*} \\
{[0.031]}\end{array}$ & $\begin{array}{c}-0.0514^{*} \\
{[0.030]}\end{array}$ & $\begin{array}{r}-0.0568^{*} \\
{[0.0303]}\end{array}$ \\
\hline $\mathrm{N}$ & $3,541,365$ & $2,923,437$ & $2,589,858$ & $3,455,069$ & $3,207,381$ & $3,567,661$ & $3,368,726$ & $3,726,289$ \\
\hline
\end{tabular}

NOTES: This table reports the DD coefficients from specification $\left(2^{\prime}\right)$ when control states are excluded one at a time. Each cell corresponds to a separate regression. The most conservative cluster-robust standard errors are in brackets. Other variables as defined in Table V. ${ }^{* * *} 1 \%,{ }^{* *} 5 \%,{ }^{*} 10 \%$. 


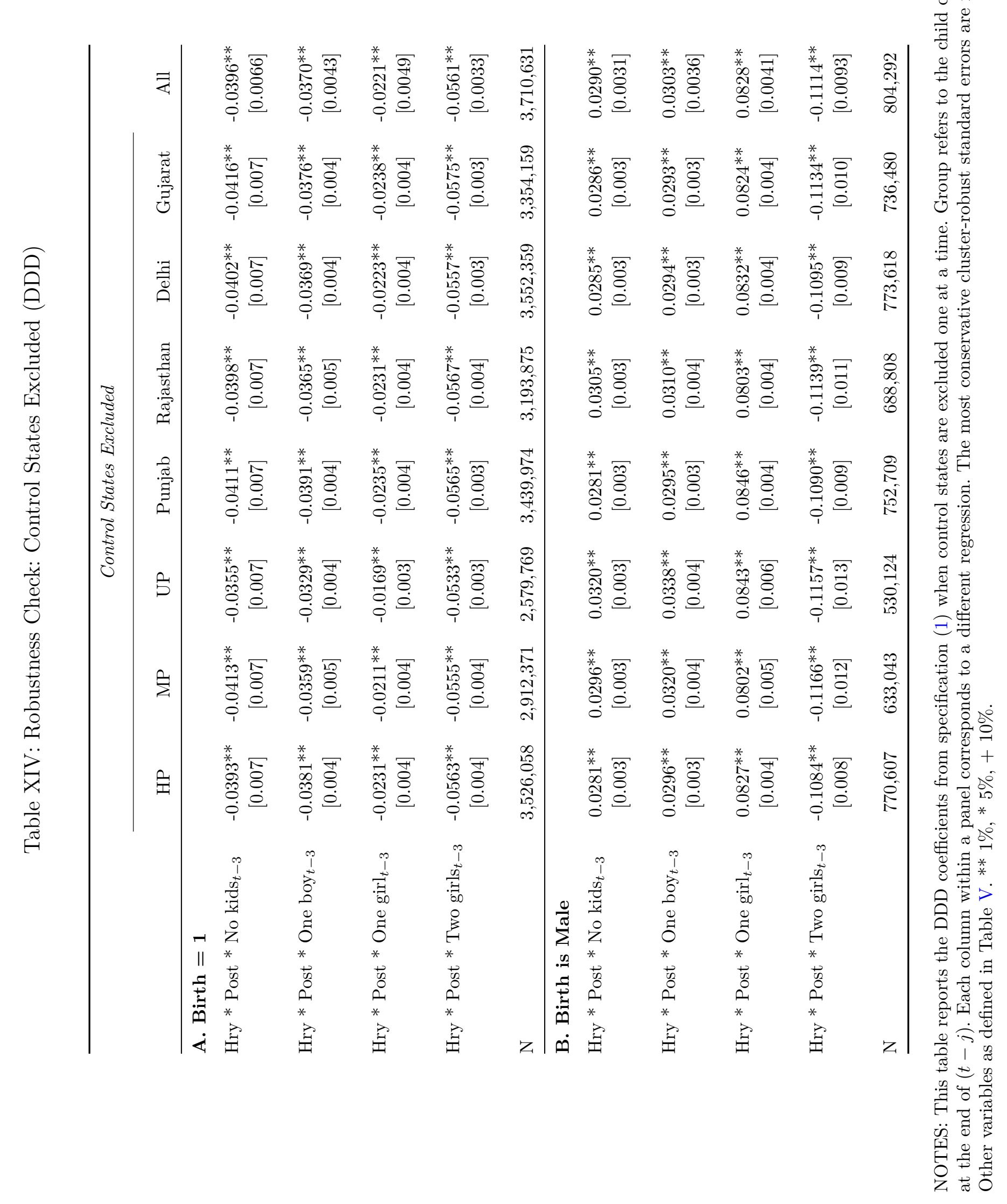




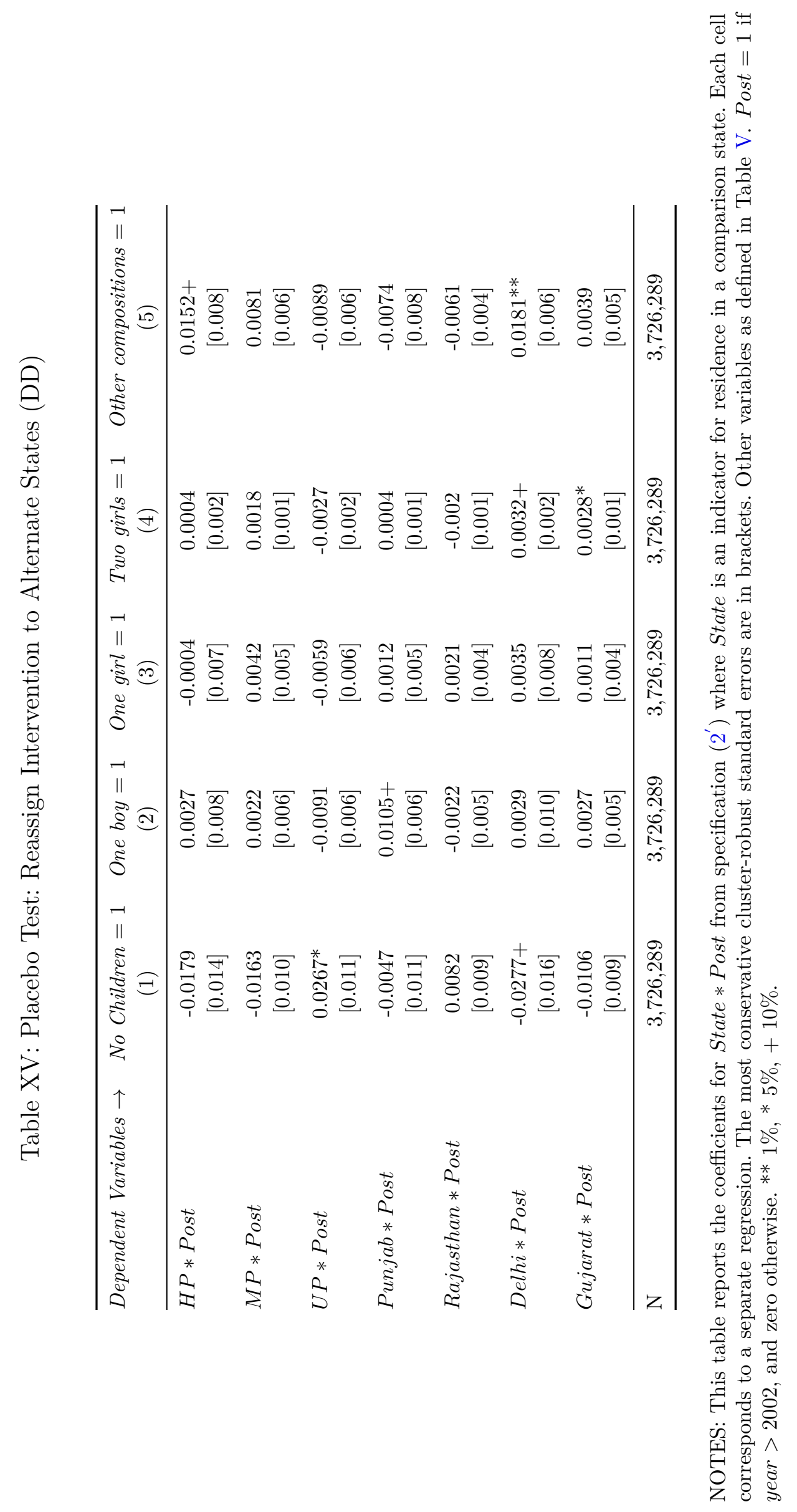




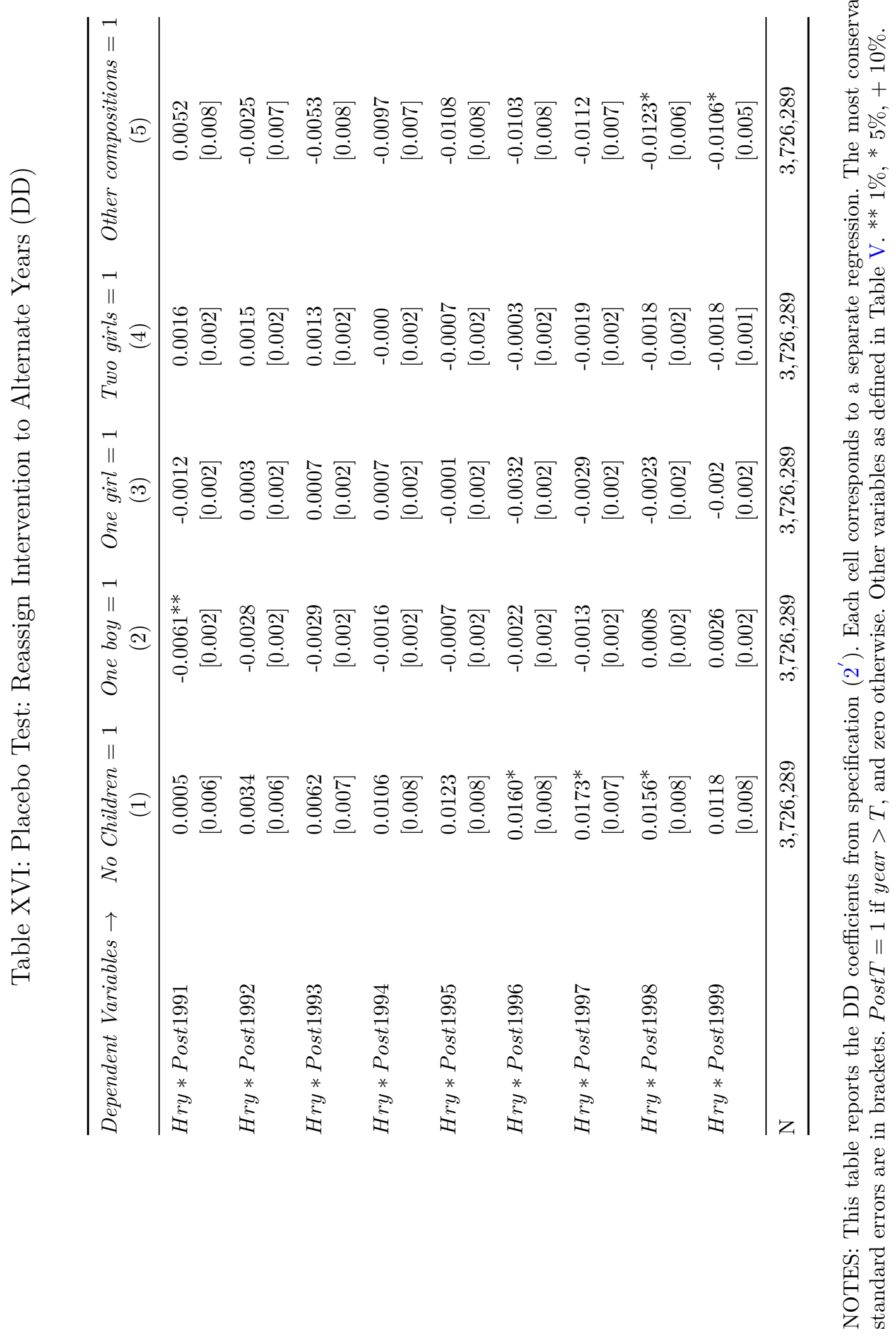


Table XVII: Effect of Devirupak Using Alternate Sub-samples of Data (DD)

\begin{tabular}{lccc}
\hline Dependent Variables $\downarrow$ & $\begin{array}{c}\text { NFHS only } \\
(1)\end{array}$ & $\begin{array}{c}\text { DLHS only } \\
(2)\end{array}$ & $\begin{array}{c}\text { Year }>\mathbf{1 9 9 5} \\
(3)\end{array}$ \\
\hline No Children $=1$ & 0.0009 & -0.0106 & $-0.0170^{* *}$ \\
& {$[0.0131]$} & {$[0.0108]$} & {$[0.0062]$} \\
One boy $=1$ & $0.0169^{* *}$ & $0.0059^{*}$ & $0.0072^{* *}$ \\
& {$[0.0064]$} & {$[0.0023]$} & {$[0.0013]$} \\
One girl $=1$ & 0.0001 & -0.0010 & 0.0004 \\
& {$[0.0065]$} & {$[0.0038]$} & {$[0.0046]$} \\
Two girls $=1$ & $-0.0051^{*}$ & 0.0025 & 0.0025 \\
& {$[0.0024]$} & {$[0.0018]$} & {$[0.0015]$} \\
Other compositions $=1$ & $-0.0128+$ & 0.0032 & 0.0069 \\
& {$[0.0064]$} & {$[0.0065]$} & {$[0.0042]$} \\
\hline $\mathrm{N}$ & $1,059,937$ & $2,666,352$ & $1,898,671$ \\
\hline
\end{tabular}

NOTES: This table reports the DD coefficients from specification $\left(2^{\prime}\right)$. Each cell corresponds to a separate regression. Post $=1$ if year of survey $>2003$, and zero otherwise. Other variables as defined in Table V. ${ }^{* *} 1 \%, * 5 \%,+10 \%$. 
Table XVIII: Effect of Devirupak Using Different Cut-off Dates

\begin{tabular}{lcccccccc}
\hline Dependent Variables $\rightarrow$ & $\begin{array}{c}\text { No children } \\
(1)\end{array}$ & $\begin{array}{c}\text { One Boy } \\
(2)\end{array}$ & $\begin{array}{c}\text { One Girl } \\
(3)\end{array}$ & $\begin{array}{c}\text { Two Girls } \\
(4)\end{array}$ & $\begin{array}{c}\text { Rest } \\
(5)\end{array}$ & $\begin{array}{c}\text { \# Children } \\
(6)\end{array}$ & $\begin{array}{c}\text { \# Girls } \\
(7)\end{array}$ & $\begin{array}{c}\text { \# Boys } \\
(8)\end{array}$ \\
\hline Hry * Post $*$ Transition & -0.0055 & $0.0077^{* *}$ & -0.0012 & 0.00002 & -0.001 & $-0.0659^{* *}$ & $-0.0442^{* * *}$ & -0.0218 \\
& {$[0.0102]$} & {$[0.0039]$} & {$[0.0038]$} & {$[0.0016]$} & {$[0.0056]$} & {$[0.0290]$} & {$[0.0148]$} & {$[0.0144]$} \\
& & & & & & & & \\
Hry * Post & -0.0084 & $0.0085^{* *}$ & -0.0006 & 0.0013 & -0.0009 & -0.0487 & $-0.0349^{* *}$ & -0.0138 \\
& {$[0.0116]$} & {$[0.0042]$} & {$[0.0037]$} & {$[0.0018]$} & {$[0.0068]$} & {$[0.0328]$} & {$[0.0162]$} & {$[0.0169]$} \\
\hline $\mathrm{N}$ & $3,726,289$ & $3,726,289$ & $3,726,289$ & $3,726,289$ & $3,726,289$ & $3,726,289$ & $3,726,289$ & $3,726,289$ \\
\hline
\end{tabular}

NOTES: This table reports the coefficients for a version of specification $\left(2^{\prime}\right)$. Each column corresponds to a separate regression. Transition indicates the year 2003. Post $=1$ if year of survey $>2003$, and zero otherwise. Other variables as defined in Table V. ${ }^{* * *} 1 \%,{ }^{* *} 5 \%, * 10 \%$.

Table XIX: State Weights in Synthetic-Haryana

\begin{tabular}{lrrr}
\hline & \multicolumn{3}{c}{ Weight for outcome variable } \\
\cline { 2 - 4 } State & One boy only & One girl only & Two girls only \\
\hline Andhra Pradesh & 0 & 0 & 0 \\
Assam & 0 & 0 & 0 \\
Bihar & 0 & 0 & 0 \\
Delhi & 0 & 0.070 & 0.011 \\
Gujarat & 0 & 0 & 0 \\
Himachal Pradesh & 0.081 & 0.057 & 0 \\
Jammu \& Kashmir & 0 & 0 & 0 \\
Karnataka & 0 & 0 & 0 \\
Kerala & 0 & 0 & 0 \\
Maharashtra & 0 & 0 & 0 \\
Madhya Pradesh & 0 & 0 & 0 \\
Orissa & 0 & 0 & 0 \\
Punjab & 0.106 & 0.231 & 0.510 \\
Rajasthan & 0 & 0.636 & 0.197 \\
Tamil Nadu & 0.016 & 0 & 0 \\
Uttar Pradesh & 0.798 & 0.006 & 0.282 \\
West Bengal & 0 & 0 & 0 \\
\hline
\end{tabular}


Figure XIV: Trends in Child Composition, Haryana vs Synthetic-Haryana, before and after 2002

ONLY ONE BOY

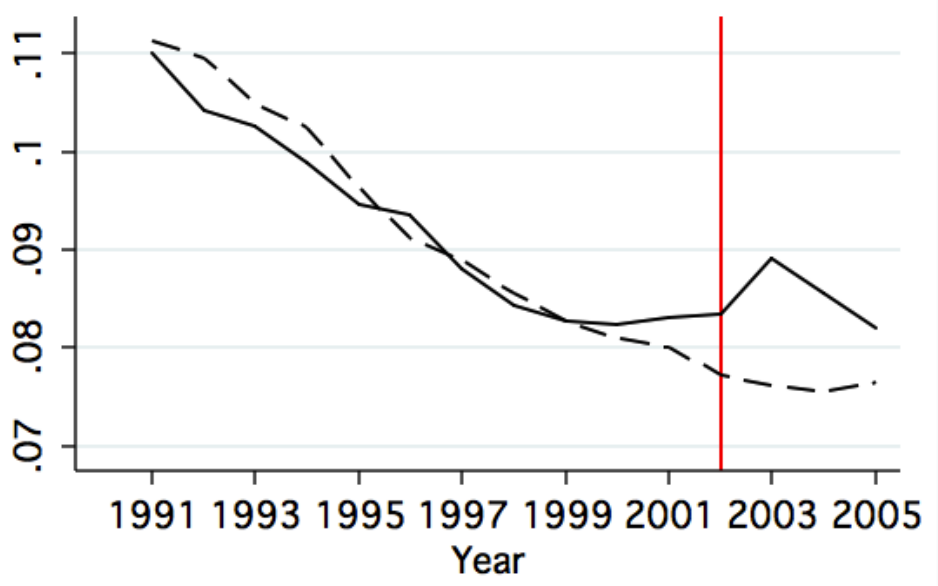

ONLY ONE GIRL

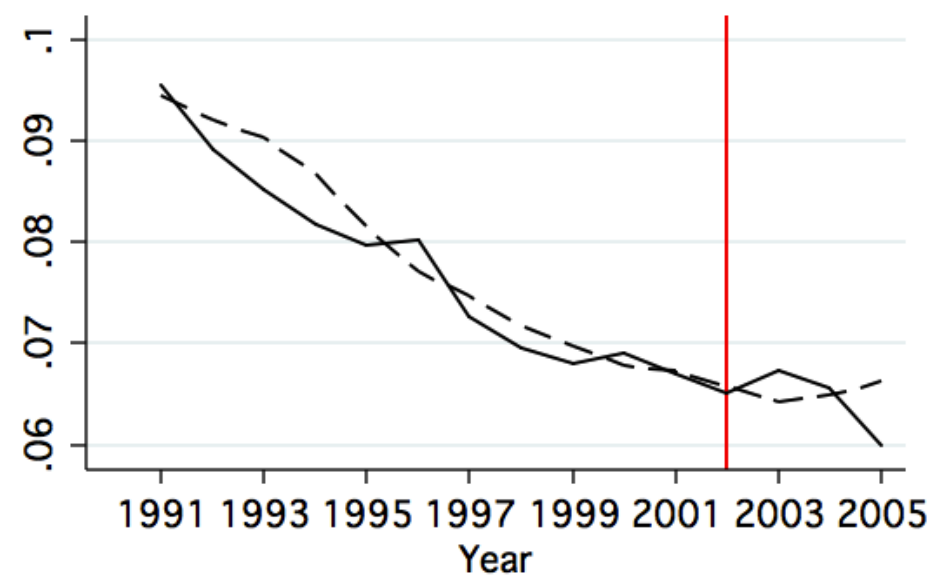

ONLY TWO GIRLS

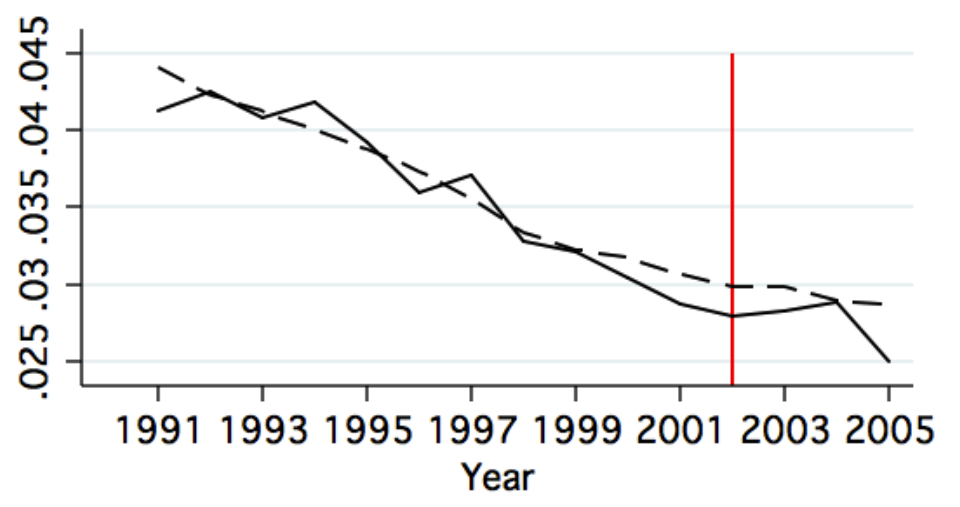

Haryana - - - Synthetic Haryana

NOTES: This figure displays the likelihood of various child compositions in Haryana and its synthetic counterpart during the period 1991-2005. The outcome variables are the share of women who report having only one boy, only one girl, and only two girls in any state-year. The predictor variables are average years of schooling, age, and age at marriage for women, along with the proportion of women who reside in an urban area, are Hindu, Muslim, Christian, SC, ST, and who belong to lowand high-SLI households. The corresponding weights assigned to each state in the donor pool are reported in Table XIX. 